ORNL/TM-2014/367

National Weatherization Assistance Program Impact Evaluation: Impact of Exhaust-Only Ventilation on Radon and Indoor Humidity - A Field Investigation

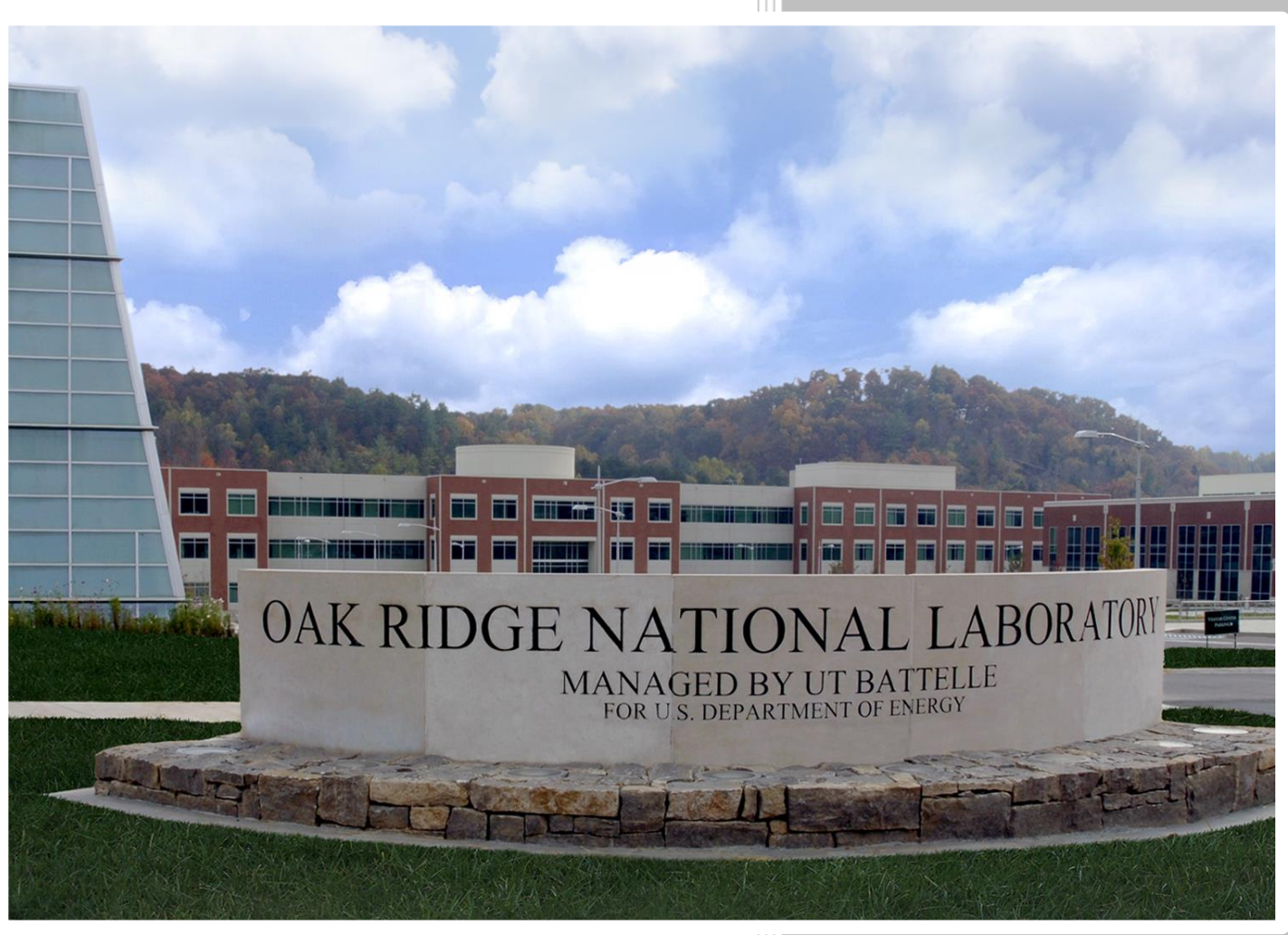

Scott Pigg

September 2014 


\section{DOCUMENT AVAILABILITY}

Reports produced after January 1, 1996, are generally available free via US Department of Energy (DOE) SciTech Connect.

Website http://www.osti.gov/scitech/

Reports produced before January 1, 1996, may be purchased by members of the public from the following source:

National Technical Information Service

5285 Port Royal Road

Springfield, VA 22161

Telephone 703-605-6000 (1-800-553-6847)

TDD 703-487-4639

Fax 703-605-6900

E-mail info@ntis.gov

Website http://www.ntis.gov/help/ordermethods.aspx

Reports are available to DOE employees, DOE contractors, Energy Technology Data Exchange representatives, and International Nuclear Information System representatives from the following source:

Office of Scientific and Technical Information

PO Box 62

Oak Ridge, TN 37831

Telephone 865-576-8401

Fax 865-576-5728

E-mail reports@osti.gov

Website http://www.osti.gov/contact.html

This report was prepared as an account of work sponsored by an agency of the United States Government. Neither the United States Government nor any agency thereof, nor any of their employees, makes any warranty, express or implied, or assumes any legal liability or responsibility for the accuracy, completeness, or usefulness of any information, apparatus, product, or process disclosed, or represents that its use would not infringe privately owned rights. Reference herein to any specific commercial product, process, or service by trade name, trademark, manufacturer, or otherwise, does not necessarily constitute or imply its endorsement, recommendation, or favoring by the United States Government or any agency thereof. The views and opinions of authors expressed herein do not necessarily state or reflect those of the United States Government or any agency thereof.

ORNL Principal Investigator

Dr. Bruce Tonn

Evaluation Team Task Manager

Scott Pigg 
Environmental Sciences Division

\title{
NATIONAL WEATHERIZATION ASSISTANCE PROGRAM IMPACT EVALUATION: IMPACT OF EXHAUST-ONLY VENTILATION ON INDOOR RADON AND HUMIDITY - A FIELD INVESTIGATION
}

\author{
Scott Pigg \\ Energy Center of Wisconsin
}

September 2014

\author{
Prepared by \\ OAK RIDGE NATIONAL LABORATORY \\ Oak Ridge, Tennessee 37831-6283 \\ managed by \\ UT-BATTELLE, LLC \\ for the \\ US DEPARTMENT OF ENERGY \\ under contract DE-AC05-00OR22725
}





\section{CONTENTS}

LIST OF FIGURES
LIST OF TABLES
ACRONYMS AND ABBREVIATIONS
ACKNOWLEDGEMENTS
EXECUTIVE SUMMARY
1.





\section{LIST OF FIGURES}

Figure

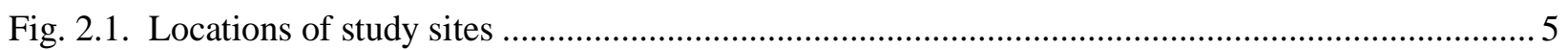

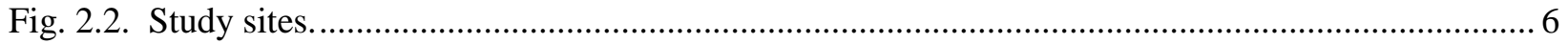

Fig. 2.3. Measured versus ASHRAE-62.2 required continuous flow.................................................... 10

Fig. 3.1. Overview of ventilation fan operation and measured radon level by site................................ 13

Fig. 3.2. Radon level by bins of outdoor temperature......................................................................... 14

Fig. 3.3. Relative change in radon level associated with fan operation.............................................. 16

Fig. 3.4. Radon and fan-operation time series for Site 18 (high impact)............................................ 17

Fig. 3.5. Fan operation and radon time series for Site 16 (low impact) ............................................. 17

Fig. 3.6. Relative impact on radon versus estimated relative fan contribution to overall ventilation......... 19

Fig. 3.7. Relative impact of fan on radon versus outdoor temperature .................................................. 20

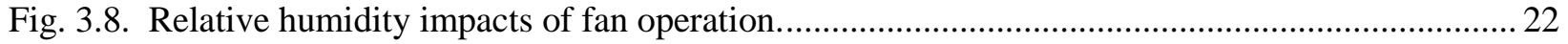





\section{LIST OF TABLES}

Table

Page

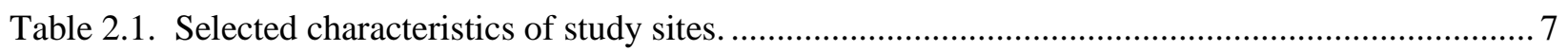

Table 2.2. Ventilation characteristics.......................................................................... 9

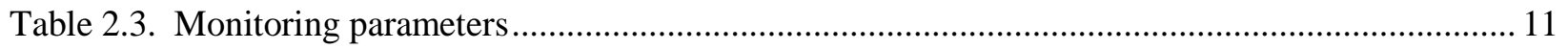

Table 3.1. Radon level with and without ventilation system operation................................................ 15

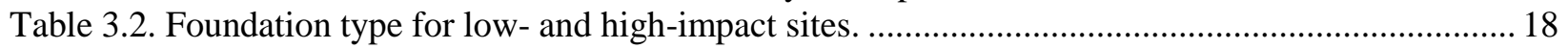

Table 3.3. Indoor temperature and humidity (at 32F outdoor temperature). ......................................... 22 



\section{ACRONYMS AND ABBREVIATIONS}

ASHRAE American Society of Heating, Refrigerating and Air Conditioning Engineers

ASOS

Automated Surface Observing System

AWOS

Automated Weather Observing System

CFM50 Cubic Feet per Minute @ 50 pascals

CFR

Code of Federal Regulations

DOE Department of Energy

IAQ Indoor Air Quality

ORNL

pCi/L

WAP

Oak Ridge National Laboratory

Picocuries per liter

WPN

Weatherization Assistance Program

Weatherization Program Notice 



\section{ACKNOWLEDGEMENTS}

The work presented in this report was funded by the U.S. Department of Energy's (DOE) Office of Weatherization and Intergovernmental Programs (OWIP).

WAP Evaluation Team members who contributed to this project include:

Ben Auchter, Energy Center of Wisconsin

Michael Blasnik, Blasnik and Associates

David Carroll, APPRISE

Dan Cautley, Energy Center of Wisconsin

Paul Francisco of the University of Illinois

Melanie Lord, Energy Center of Wisconsin

Alex McEwan, APPRISE

Nick Sayen, Energy Center of Wisconsin

Adrian Scott, Wisconsin Energy Conservation Corporation

Russ Shaber, APPRISE

Anita Sprenger, Energy Center of Wisconsin

We also gratefully acknowledge the cooperation of the 18 participating households involved in the study, as well as the assistance of the local weatherization agency staff who helped with arrangements for installation of ventilation equipment in the homes. 



\section{EXECUTIVE SUMMARY}

The study described here sought to assess the impact of exhaust-only ventilation on indoor radon and humidity in single-family homes that had been treated by the Weatherization Assistance Program (WAP). The study involved 18 homes in Colorado, Iowa, Minnesota and Ohio that had already been involved in a prior indoor-air-quality study, and had been shown to have moderately elevated radon levels.

For the study, exhaust-only ventilation that was compliant with American Society of Heating, Refrigerating and Air Conditioning Engineers (ASHRAE) Standard 62.2-2010, "Ventilation, and Acceptable Indoor Air Quality in Low-Rise Residential Buildings," was installed in each home to provide continuous background ventilation. The impact of the ventilation on radon and humidity was assessed with an experimental protocol that involved using a timer in each home to disable the installed ventilation on alternate weeks, thus allowing an examination of the difference in radon and humidity levels with and without the ventilation operating. Radon levels were monitored continuously on the lowest occupied level of the home, and humidity was tracked at the main thermostat. Monitoring was installed at the sites between late December 2012 and early March 2013, and continued into June 2013. One site was later dropped due to insufficient data from fan operating periods.

Key results are as follows:

\section{Radon}

- Radon levels declined or remained about the same for all homes in the study when the ventilation was operated. On average, the installed ventilation reduced radon levels by $12 \pm 7$ percent.

- No homes experienced any practically-significant increase in radon with operation of the ventilation - though statistical uncertainty for individual sites does not preclude that possibility. This suggests that in most cases, the dilution effect of exhaust-only ventilation outweighs any tendency to increase the radon entry rate by depressurizing foundation spaces.

- Six homes showed a larger (and more regular) decline in radon with operation of the ventilation than the other sites. These included all three sites where the exhaust ventilation was located in a basement, as well as the single site with slab-on-grade construction.

- Sites with higher ventilation flow rates relative to their estimated seasonal natural ventilation rate also tended to show a larger impact from the ventilation.

\section{Humidity}

- On average, relative humidity was reduced by a statistically significant $1.7 \pm 1.2$ percentage points by the ventilation. All but one site experienced a decline in relative humidity associated with operation of the ventilation.

- No relationship was observed between the ventilation's impact on relative humidity and general humidity level in the home. 



\section{INTRODUCTION}

\subsection{NATIONAL WEATHERIZATION ASSISTANCE PROGRAM EVALUATION OVERVIEW}

The U.S. Department of Energy's (DOE) Weatherization Assistance Program (WAP) was created by Congress in 1976 under Title IV of the Energy Conservation and Production Act. The purpose and scope of the Program as currently stated in the Code of Federal Regulations (CFR) 10CRF 440.1 is "to increase the energy efficiency of dwellings owned or occupied by low-income persons, reduce their total residential energy expenditures, and improve their health and safety, especially low-income persons who are particularly vulnerable such as the elderly, persons with disabilities, families with children, high residential energy users, and households with high energy burden." (Code of Federal Regulations, 2011)

At the request of DOE, Oak Ridge National Laboratory (ORNL) developed a comprehensive plan for a national evaluation of WAP that was published in 2007. DOE furnished funding to ORNL in 2009 for a national evaluation for Program Years 2007 and 2008, with a particular emphasis on PY 2008. ORNL subcontracted evaluation research to APPRISE Incorporated and its partners (the Energy Center of Wisconsin, Michael Blasnik and Associates, and Dalhoff Associates LLC). The Scope of Work (SOW) for the evaluation includes the following components.

- Impact Assessment - Characterization of the weatherization network and the households that are income-eligible for WAP, measurement and monetization of the energy and nonenergy impacts of the program, and assessment of the factors associated with higher levels of energy savings, cost savings, and cost-effectiveness.

- Process Assessment - Direct observation of how the weatherization network delivers services and assessment of how service delivery compares to national standards and documentation of how weatherization staff and clients perceive service delivery.

- $\quad$ Special Technical Studies - Examination of the performance of the program with respect to technical issues such as air sealing, duct sealing, furnace efficiency, and refrigerators.

- Synthesis Study - Synthesis of the findings from this evaluation into a comprehensive assessment of the success of the program in meeting its goals and identification of key areas for program enhancement.

This field study falls under the Special Technical Studies component of the larger evaluation effort.

\subsection{BACKGROUND}

When it comes to providing ventilation for buildings, there is a fundamental tension between the desire to save energy and the desire for good indoor air quality. The former desire calls for sealing buildings as tightly as possible and minimizing the exchange of air that must then be conditioned for comfort. The latter seeks to ventilate buildings as much as possible to rid them of indoor pollutants.

In recognition of this tension, in early 2011, DOE issued Weatherization Program Notice 11-6, which provided guidance for program grantees on health and safety issues related to the program. Among other things, WPN 11-6 directed grantees to meet guidelines set forth in the American Society of Heating, Refrigerating and Air Conditioning Engineer's (ASHRAE) Standard 62.2, "Ventilation and Acceptable Indoor Air Quality in Low-Rise Residential Buildings," (ASHRAE 2010, 2013) which spells out requirements for local intermittent and continuous background mechanical ventilation in homes. Grantees were given until 2012 to begin implementing the standard in the program. 
Nearly concurrently with WPN 11-6, the National WAP Evaluation effort undertook a large randomized control trial of the impact of the program on selected indoor air quality (IAQ) parameters in single-family homes (Pigg et al., forthcoming). That study found that small—but statistically significant —increases in indoor radon and humidity levels were associated with weatherization.

However, the timing of the IAQ study was such that it preceded widespread implementation of the ASHRAE 62.2 in the program. This left open the question of how these parameters are affected in program homes that receive mechanical ventilation under the 62.2 standard. The study described here sought to shed light on this question by retroactively installing 62.2-compliant ventilation in a sample of weatherized homes that were included in original IAQ field study, and observing the impact on these parameters.

It should be noted that a new (2013) version of the ASHRAE 62.2 standard was released partway through implementation of the study described here, which used the prior version of the standard (2010) as the basis for the mechanical ventilation installed in the study. The new version eliminates a default infiltration credit that existed in prior versions, but allows for full credit for natural infiltration estimated based on a blower door test, which most WAP homes receive. The impact of the new version on the incidence and required flow rates for 62.2-compliant ventilation under the program is unknown, but is thought to be minor (Francisco, 2013).

Due to budget and time constraints, the study described here was limited to the installation of exhaustonly ventilation in heating-dominated climates. The ASHRAE 62.2 standard is agnostic as to the manner in which continuous mechanical ventilation is provided (exhaust-only, supply-only and balanced are the three options), but it is thought that the majority of ventilation systems installed by the program in heating climates are of the exhaust-only type, primarily due to cost. Note however, that this type of ventilation is generally considered to be inappropriate in hot-humid climates, where the potential for mold growth from pulling moist air through building cavities is high, and balanced or supply-only ventilation is the preferred approach.

\subsection{RADON AND EXHAUST-ONLY VENTILATION}

Radon in homes has been extensively studied since the early 1980s. A full treatment of this topic is beyond the scope of this report, but a brief overview may be helpful for setting the stage for the results that follow.

Radon (Element 86, Rn) is the heaviest known substance that remains a gas under normal conditions. It is also radioactive, and this it is this aspect that drives concern about radon in homes.

In most cases, indoor radon originates in soil gas that infiltrates through foundation cracks or dirt floors in crawlspaces or basements. The concentration of radon in soil gas varies considerably over even short distances and can vary over time.

Soil gas enters a home through foundation cracks and other openings whenever the air pressure on the inside of the foundation is less than the pressure on the outside. Such depressurization can arise from several mechanisms:

1. stack effect that occurs whenever the outdoor temperature is less than the indoor temperature;

2. wind effects;

3. mechanical depressurization from exhaust fans or appliances like clothes dryers in the home; and, 
4. changes in barometric pressure, which can take longer to manifest below ground.

Radon is removed from homes through natural or mechanical ventilation. ${ }^{1}$ Somewhat paradoxically, most the same forces that drive radon entry into homes (specifically, the first three of the four above) also drive ventilation and its removal from homes. The net effect of these forces on radon concentration depends on home-specific factors, such as the location of above- and below-grade air leakage pathways, as well as characteristics of the driving forces at any point in time. Needless to say, the combination of changes in source strength and the interplay of the forces that drive radon entry and removal make radon concentration in homes highly idiosyncratic from home to home and dynamic over time. Nonetheless, efforts have been made to model these forces (e.g., Sherman, 1992).

Specifically with regard to exhaust-only ventilation, the addition of such ventilation simultaneously increases the ventilation rate of the home (which acts to reduce radon levels) and further depressurizes foundation spaces where radon typically enters the home (which acts to increase radon levels). The net impact on indoor radon concentration from installing this type of ventilation is thus not clear. The primary goal of the study described here was to gather empirical data to address this question.

\footnotetext{
${ }^{1}$ Technically speaking, radon, which has a half-life of 3.8 days, is also eliminated from homes by natural decay into its daughter products. But since it is the radiation effects of the longer-lived daughter products that create the concern about radon in the home, it is the removal of radon prior to its decay that is of interest here.
} 



\section{METHODOLOGY}

\subsection{RECRUITMENT AND CHARACTERISTICS OF STUDY HOMES}

Homes for the current study were selected from among households in heating-dominated climates that had participated in the earlier WAP Evaluation IAQ study. Specifically, the current study targeted homes with a seven-day, closed home radon test results from the prior study at or above $4 \mathrm{pCi} / \mathrm{L}$. Because homes from the prior study with measured radon above $8 \mathrm{pCi} / \mathrm{L}$ had already received radon remediation under a separate effort, this restricted the current study to homes with moderately elevated radon test results in the range of 4 to $8 \mathrm{pCi} / \mathrm{L}$.

The current study was also restricted to homes for which ASHRAE Standard 62.2-2010 called for the addition of mechanical ventilation after taking the infiltration credit based on the measured postweatherization air leakage for the home and accounting for the presence or absence of local exhaust ventilation in kitchens and bathrooms.

A total of 18 households were recruited for the study in four states: Minnesota, Iowa, Colorado and Ohio (Fig. 2.1). The sample comprises a variety of site-built home types (Fig. 2.2), with a mix of crawlspace and basement foundations, along with one home of slab-on-grade construction (Table 2.1). All of the crawlspaces were either exposed dirt or dirt with an unsealed ground covering. None of the basements in the study sample had dirt floors.

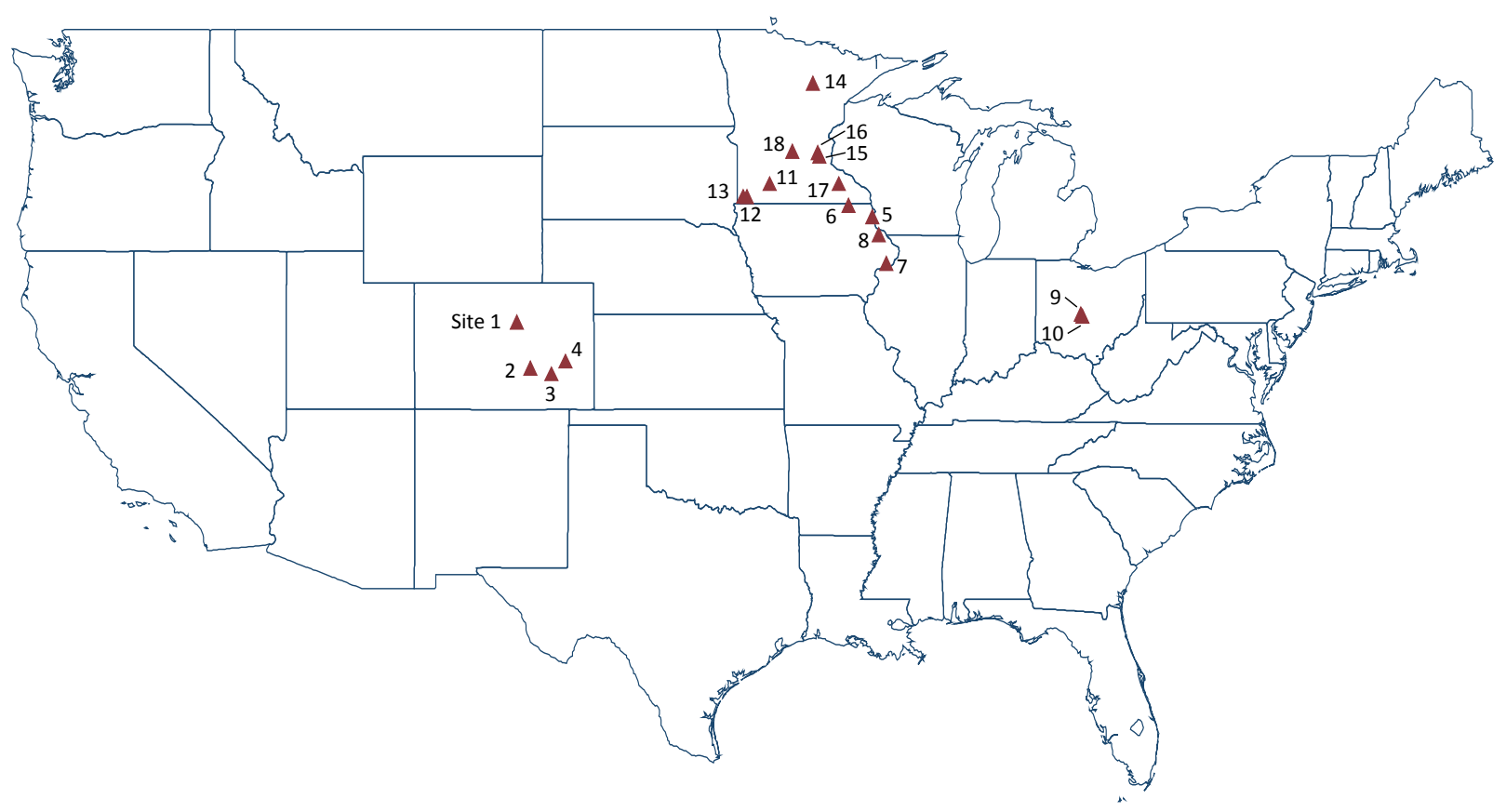

Fig. 2.1. Locations of study sites 
Site 1

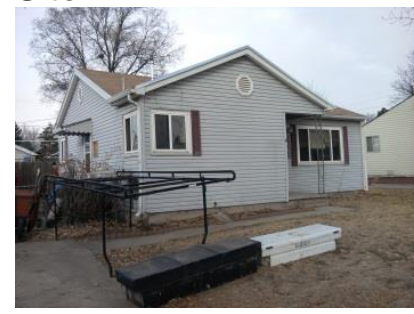

Site 4

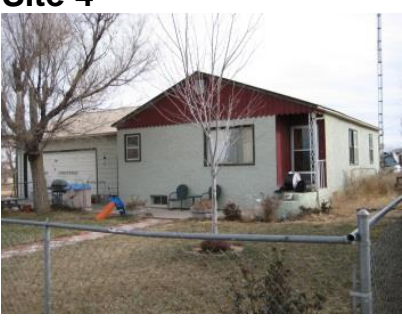

Site 7

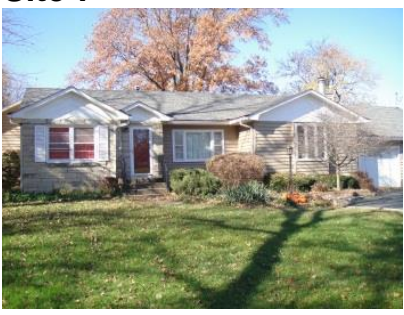

Site 10

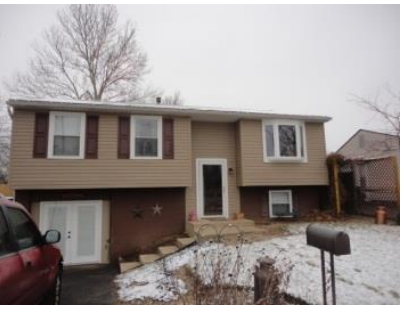

Site 13

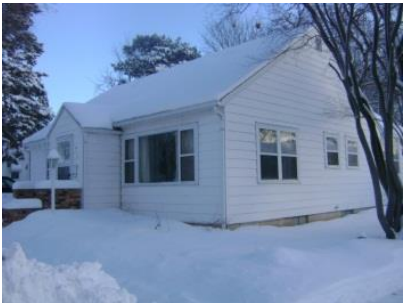

Site 16

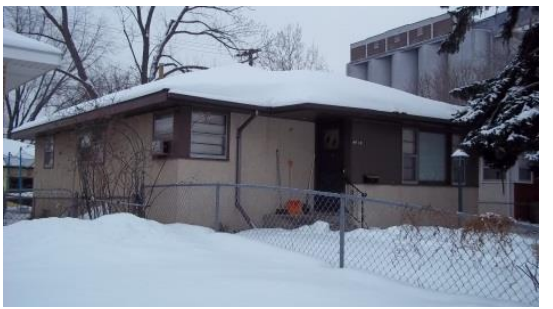

Site 2

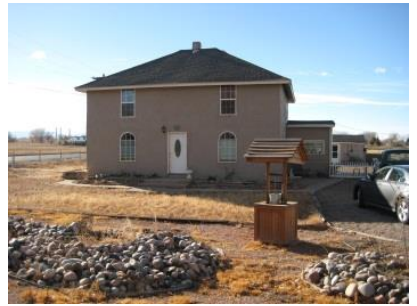

Site 5

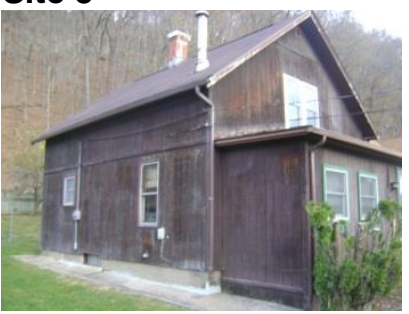

Site 8

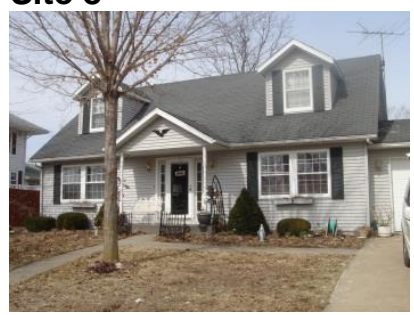

Site 11

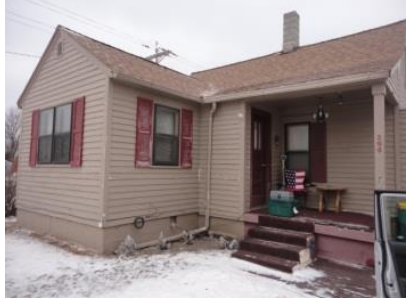

Site 14

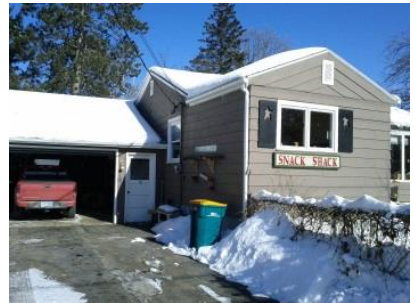

Site 17

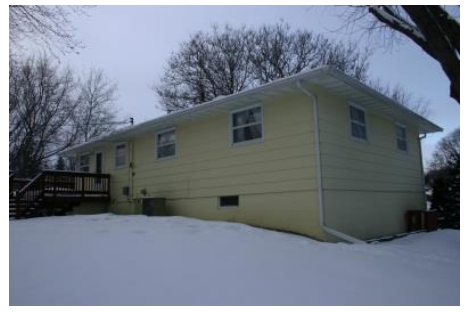

Site 3

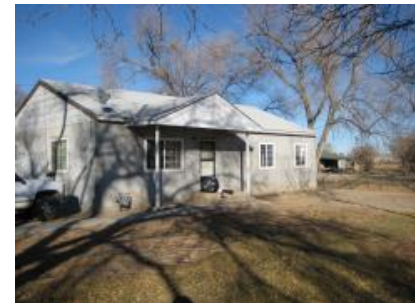

Site 6

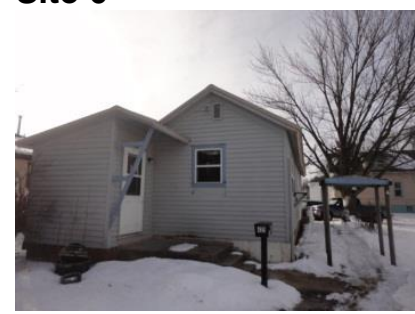

Site 9

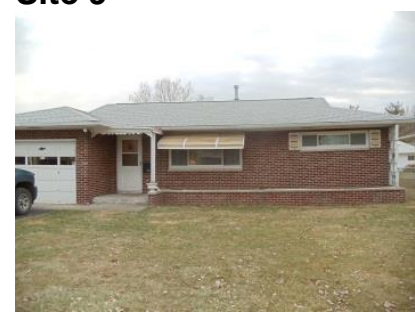

Site 12
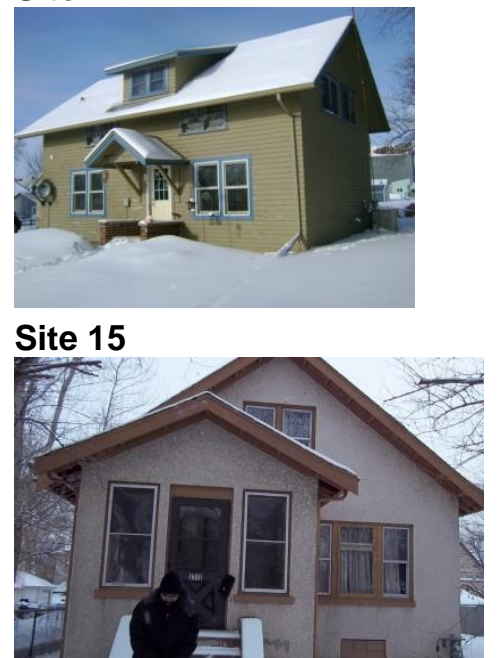

Site 18

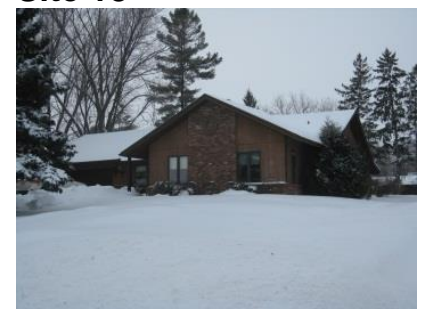

Fig. 2.2. Study sites. 
Table 2.1. Selected characteristics of study sites.

\begin{tabular}{|ccccccc|}
\hline Site & Foundation type & $\begin{array}{c}\text { Lowest } \\
\text { occupied } \\
\text { level }\end{array}$ & Stories & $\begin{array}{c}\text { Above- } \\
\text { grade } \\
\text { square } \\
\text { footage } \\
\text { f t }^{2} \text { ) }\end{array}$ & $\begin{array}{c}\text { Above- } \\
\text { grade } \\
\text { volume } \\
\text { (ft }^{\mathbf{3}} \text { ) }\end{array}$ & $\begin{array}{c}\text { Air leakage } \\
\text { (cfm50) }\end{array}$ \\
\hline 1 & crawlspace & first floor & 1 & 830 & 6,600 & 1,185 \\
2 & crawlspace/basement & first floor & 2 & 2,570 & 22,130 & 3,599 \\
3 & crawlspace & first floor & 1 & 1,380 & 11,040 & 1,397 \\
4 & basement & basement & 1 & 1,070 & 8,580 & 1,927 \\
5 & crawlspace/basement & first floor & 1.5 & 1,140 & 10,300 & 1,515 \\
6 & basement & basement & 1 & 800 & 7,200 & 1,529 \\
7 & crawlspace/basement & basement & 1 & 630 & 4,380 & 2,519 \\
8 & basement & first floor & 1.5 & 1,560 & 12,480 & 1,364 \\
9 & crawlspace & first floor & 1 & 1,150 & 9,450 & 1,495 \\
10 & basement & basement & split-level & 940 & 7,490 & 1,448 \\
11 & crawlspace/basement & first floor & 1.5 & 980 & 6,830 & 968 \\
12 & basement & first floor & 1.5 & 1,410 & 11,130 & 1,491 \\
13 & crawlspace/basement & basement & 1 & 1,360 & 10,880 & 2,475 \\
14 & basement & basement & 1 & 1,000 & 8,000 & 1,710 \\
15 & crawlspace/basement & basement & 1.5 & 2,480 & 16,120 & 2,015 \\
16 & basement & basement & 1 & 880 & 7,000 & 1,415 \\
17 & basement & basement & 1 & 1,340 & 10,750 & 1,516 \\
18 & slab on grade & first floor & 1 & 960 & 7,460 & 1,540 \\
\hline
\end{tabular}

\subsection{INSTALLED VENTILATION EQUIPMENT}

While several homes in the study had received bath fans and other ventilation work, none had received continuous mechanical ventilation as part of their weatherization work (which took place in early 2011 before DOE's requirement that the WAP program adhere to ASHRAE 62.2 had been fully implemented). The project team therefore arranged for installation of exhaust fans and fan controls in the homes to meet the ASHRAE 62.2-2010 specifications. The team generally sought to locate the fans in the lowest bathroom in the home, but the presence of existing exhaust fans and the desires of the homeowner regarding location of the new fan also played a role. Only one site received a fan that was not located in a bathroom: the exhaust fan for this site (Site 14) was located between floor joists in the basement.

All but two of the sites received either an 80-cfm or 110-cfm Panasonic Whisper Ceiling fan (Models FV08VQ5 and FV-11VQ5) with an Airetrak Advantage (Model TTi-ATRAKAV) fan controller. The Airetrak fan controller can be adjusted for both fan speed and duty cycle to achieve a target continuous ventilation rate. The speed adjustment alone was generally sufficient to achieve the target ASHRAE 62.2 continuous ventilation rate, and the controller was set to operate the fan continuously for these sites. One site (Site 3) was set to operate the fan for 55 minutes out of each hour.

In addition to the continuous background ventilation setting, the Airetrak controllers-which are mounted in the same place that a traditional fan on/off switch would be located - have an override button that can be pressed to boost the fan speed to its highest possible setting for a specified period of time. The 
controllers for the study were set for a 20-minute boost period, after which the fan returned to its background-ventilation level. Note that while the overall on/off status of the fan was tracked for the study, the operating mode was not.

Two sites had a slightly different ventilation package. One (Site 1) received a Panasonic Whisper Green fan that was incompatible with the Airetrak controller. The background ventilation flow for this model of fan is set by adjusting a flow setting on the fan itself. The fan model that was installed also had built-in motion-sensor control for boost mode, rather than the timed manual boost capability at the other sites. The motion sensor proved to be somewhat over sensitive at this site, in that it was reported by the occupant to be frequently triggered by household dogs walking by the bathroom where the fan was located. Late in the monitoring period, tape was used to partially shield the motion sensor to reduce this effect. The other site that received a non-standard ventilation package (Site 4) had an existing Fantech inline bath fan: this was paired with a new Airetrak controller, and configured for continuous ventilation.

Fan flow for each site was measured (with an Energy Conservatory exhaust-fan flow meter and calibrated DG-700 digital manometer), and then adjusted to conform with ASHRAE 62.2 requirements for ventilation, which are partly based on occupancy and partly on square footage. The calculated continuous flow included any applicable infiltration credit based on prior post-weatherization blower door test results, and accounted for local exhaust deficits from lack of verified local exhaust flow in kitchens and other bathrooms. The former can reduce (or even eliminate) the required continuous flow, depending on the measured air leakage of the home. The latter adjusts the continuous flow upwards by a prescribed amount to make up for lack of local exhaust.

Table 2.2 provides more information about the installed ventilation and other ventilation devices in the homes, and Fig. 2.3 compares the measured continuous flow for the installed ventilation with the calculated ASHRAE 62.2 requirement. Note that it was not always possible to measure fan flow (especially for kitchen fans) due to an inability to adequately mount the flow meter for an accurate measurement. Also, pre- and post-study measurements of continuous fan flow did not always agree. In most cases, the two were within 20 percent, but for five sites (Sites 7, 13, 14, 17 and 18) the two measurements differed by 30 to 60 percent. The site with largest discrepancy (Site 14) was deemed to have an error in the post-study measurement. For the remaining sites, the average of the pre- and poststudy measurements is reported here.

\subsection{EXPERIMENTAL APPROACH AND MONITORING}

The experimental approach used for the study was to cycle the installed ventilation for each site on and off on alternate weeks, in order to observe how radon and humidity levels varied with ventilation operation. This was accomplished by installing a programmable timer to interrupt power to the exhaust fan on alternate weeks. Note that the Airetrak fan controller remained powered during fan-off weeks: only power to the fan itself was interrupted for the purposes of the study. However, during the fan-off periods, the fan was completely disabled: it did not operate in either background continuous ventilation or boost mode.

Each home received three visits from a study technician. The first visit involved measuring fan flow and adjusting the fan controller settings to achieve the desired ASHRAE 62.2 mechanical ventilation rate, installing monitoring equipment and enabling the timer used to periodically disable the fan. The second visit occurred midway through the monitoring period; its purpose was to download data from the radon monitor and fan-status logger to ensure proper operation of the radon monitor and operation and tracking of the timer that controlled fan operation. The final visit occurred at the end of the study period, at which time fan flow was re-measured, and all monitoring equipment was removed from the home. 
Table 2.2. Ventilation characteristics.

\begin{tabular}{|c|c|c|cc|l|}
\hline \multirow{2}{*}{ Site } & \multicolumn{4}{|c|}{ Installed ASHRAE 62.2 ventilation } & \multicolumn{1}{|c|}{$\begin{array}{c}\text { Other intermittent } \\
\text { ventilation present } \\
\text { (cfm, if known) }\end{array}$} \\
\hline 1 & Location & $\begin{array}{c}\text { Boost- } \\
\text { mode } \\
\text { cfm }\end{array}$ & $\begin{array}{c}\text { Continuous-mode cfm } \\
\text { required } \\
\text { measured }\end{array}$ & \multicolumn{1}{|c|}{ per 62.2 } & \multicolumn{1}{|c|}{ Kitchen } \\
2 & 1st floor bathroom & 76 & 35 & 33 & None \\
3 & 1st floor bathroom & 61 & 28 & 31 & None \\
4 & 1st floor bathroom & 42 & 39 & 44 & Kitchen (37) \\
5 & 1st floor bathroom & 41 & 41 & 49 & None \\
6 & 2nd floor bathroom & 69 & 32 & 31 & None \\
7 & 1st floor bathroom & 38 & 29 & 30 & Kitchen; 1st floor bath (62); addl 1st \\
8 & Basement bathroom & 24 & 23 & 18 & floor bath (61) \\
9 & 1st floor bathroom & 47 & 49 & 64 & Kitchen; 2nd floor bath (39) \\
10 & 1st floor bathroom & 79 & 20 & 12 & Kitchen (145) \\
11 & 1st floor bathroom & 43 & 41 & 56 & Basement bath (32) \\
12 & 1st floor bathroom & 56 & 27 & 29 & Kitchen \\
13 & 1st floor bathroom & 62 & 32 & 29 & Kitchen \\
14 & 1st floor bathroom & 54 & 10 & 8 & Kitchen (83) \\
15 & Basement ceiling & 81 & 52 & 64 & Kitchen \\
16 & 1st floor bathroom & 77 & 77 & 84 & Kitchen \\
17 & 1st floor bathroom & 55 & 21 & 22 & Kitchen(118) \\
18 & Basement bathroom & 60 & 60 & 61 & Kitchen; 1st floor bath (62) \\
\hline
\end{tabular}




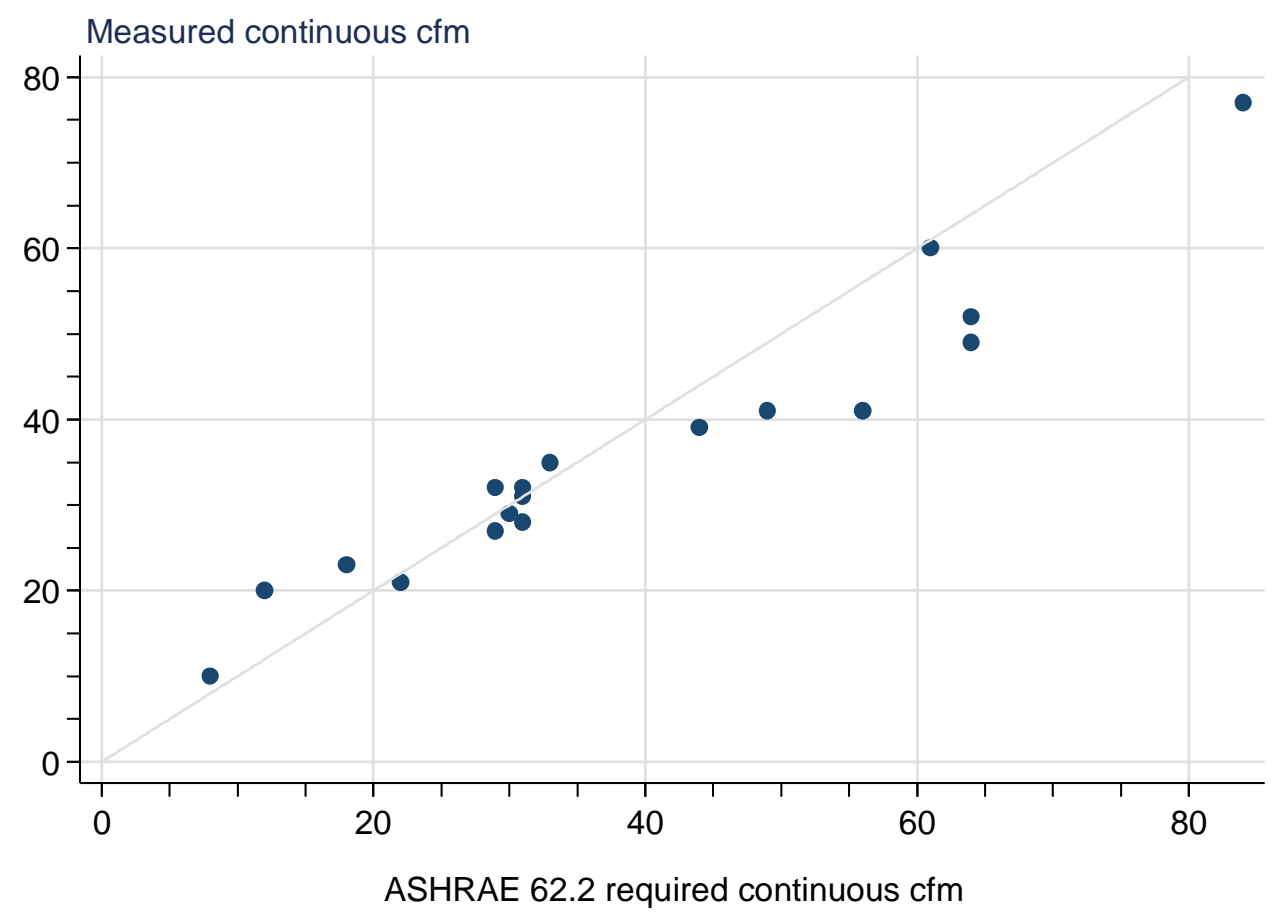

Fig. 2.3. Measured versus ASHRAE-62.2 required continuous flow.

The initial visits occurred between late December 2012 and early March 2013. Final visits occurred in June 2013

The primary parameters of interest for the study were indoor radon concentration and indoor humidity. Radon was monitored on the lowest occupied level of the home with a continuous radon monitor, configured for 4-hour or 8-hour recording of radon levels (Table 2.3). Humidity and temperature were monitored at the primary thermostat. In addition to these primary parameters, the on/off status of the installed exhaust fan and the furnace air handler were monitored. Data from these data loggers were then merged with local airport weather data for analysis. 
Table 2.3. Monitoring parameters

\begin{tabular}{|c|c|c|}
\hline Parameter & Data collected & Equipment/Source \\
\hline Radon level & $\begin{array}{l}\text { Time-stamped integrated average } \\
\text { radon concentration at four-hour } \\
\text { ( } 3 \text { sites) or eight-hour (15-sites) } \\
\text { intervals on lowest occupied level } \\
\text { of home. } \\
\text { Overall average radon level on } 1^{\text {st }} \\
\text { floor and in basement or } \\
\text { crawlspace over study period }\end{array}$ & $\begin{array}{l}\text { Sun Nuclear, model } 1028 \text { continuous } \\
\text { radon monitor } \\
\text { Accustar Alpha Track AT-100 radon } \\
\text { test kit }\end{array}$ \\
\hline $\begin{array}{l}\text { Indoor temperature and humidity } \\
\text { (at main thermostat) }\end{array}$ & $\begin{array}{l}\text { Time-stamped snapshot values at } \\
\text { 10-minute ( } 13 \text { sites ) or } 15 \text {-minute } \\
\text { ( } 5 \text { sites) intervals }\end{array}$ & $\begin{array}{l}\text { Onset Hobo tempRH logger (Model } \\
\text { U10-003) }\end{array}$ \\
\hline Ventilation operation & $\begin{array}{l}\text { Timestamp for each on/off state } \\
\text { change }\end{array}$ & $\begin{array}{l}\text { Onset Hobo State logger (Model U9- } \\
\text { 001) with Veris Hawkeye } 300 \\
\text { current switch on power lead to fan }\end{array}$ \\
\hline Furnace/AC air handler operation & $\begin{array}{l}\text { Timestamp for each on/off state } \\
\text { change }\end{array}$ & $\begin{array}{l}\text { Onset Hobo State logger (Model U9) } \\
\text { with Veris Hawkeye } 300 \text { current } \\
\text { switch on power lead to air handler }\end{array}$ \\
\hline $\begin{array}{cl}\text { Outdoor conditions } \\
\text { - } & \text { Temperature } \\
\text { - } & \text { Humidity } \\
\text { - } & \text { Wind speed } \\
\text { - } & \text { Sea-level pressure } \\
\text { - } & \text { Precipitation }\end{array}$ & $\begin{array}{l}\text { Hourly (or higher time-resolution) } \\
\text { values }\end{array}$ & $\begin{array}{l}\text { Nearby National Weather Service } \\
\text { ASOS or AWOS station. }{ }^{\dagger} \text { (Data } \\
\text { downloaded from } \\
\text { wunderground.com) }\end{array}$ \\
\hline
\end{tabular}





\section{RESULTS}

\subsection{RADON IMPACTS}

Figure 3.1 provides an overview of the fan operation and radon data for each site. Note that there are gaps in the radon data for Sites 13, 15 and 17: these resulted from loss of power to the radon monitor at the site. Also, Sites 2, 5 and 10 have long periods of fan-on or fan-off operation due to occupant interference with the fan-operation timer. Other fan-operation periods that deviated from the intended seven-day on/off schedule at other sites are the result of brief power outages that reset the timer in the middle of an operating period.

Overall, the sites exhibited a range of radon levels, from less than $0.9 \mathrm{pCi} / \mathrm{L}$ (Site 8 ) to $9.2 \mathrm{pCi} / \mathrm{L}$ (Site 13), with most falling in a range of three to seven $\mathrm{pCi} / \mathrm{L}$. Radon levels for some sites remained relatively constant throughout the monitoring period (ignoring for the moment any effects due to the mechanical ventilation), but changed significantly for others, sometimes abruptly so (e.g. Site 11). Such changes are not unusual for indoor radon concentration, which is affected by idiosyncratic soil-gas radon concentration, varying natural ventilation rate from wind and stack effect and other weather factors. Regression modeling (described below) was used to help control for some of these factors.

The impact of the installed ventilation on radon at each site is gauged by comparing radon levels with and without the ventilation operating. Results from two approaches are presented here. The first simply compares mean radon levels with and without the ventilation operating. The second uses a more complex regression model to try to better control for variation in weather conditions between the two operating modes. In particular, some sites show a fairly strong relationship between indoor radon level and outdoor temperature (Figure 3.2). Since outdoor temperature was not well-balanced between the fan-on and fanoff periods for some sites, the regression approach helps control for this potentially confounding effect. Appendix A describes the regression model in more detail.

Both analyses attempt to account for the fact that there is a transition period following each change in operating status for the ventilation. For the difference-in-means approach, data were dropped for the first 48 hours following each change in fan operating status. ${ }^{2}$ The regression analysis uses all data, but includes terms to capture transition effects over the first two days following changes in fan operating status.

\footnotetext{
${ }^{2}$ Analysis using longer and shorter screens suggest that the results are not highly sensitive to screens between one and four days, and two days represents a reasonable compromise between the competing desires to eliminate transition effects but also maximize the amount of data used in the analysis.
} 
Daily radon level (pCi/L)
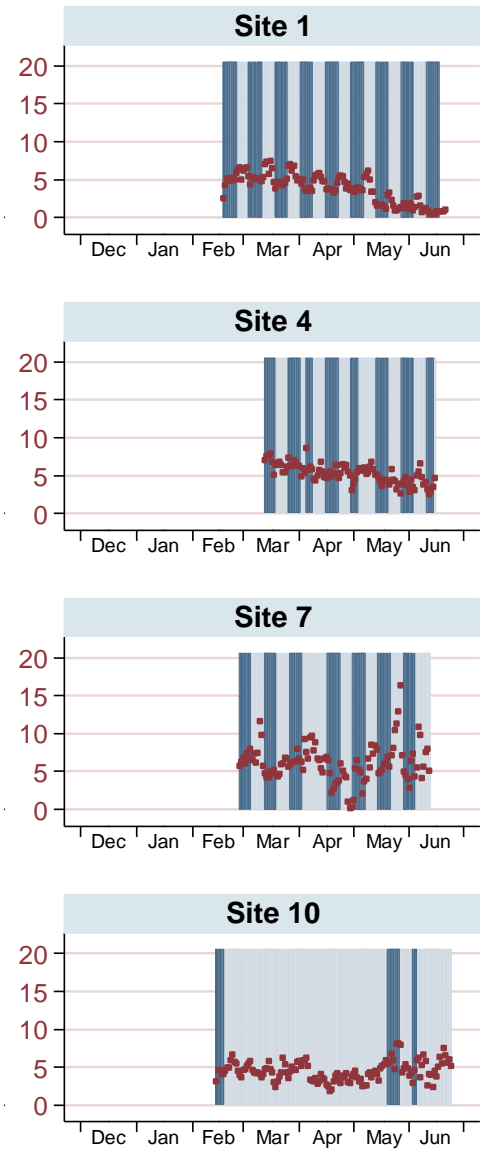

Site 13

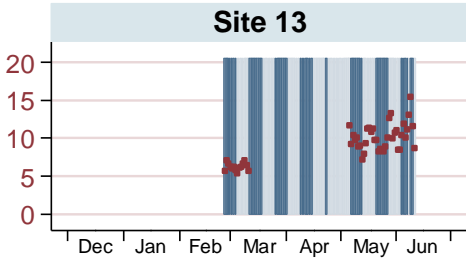

Site 16

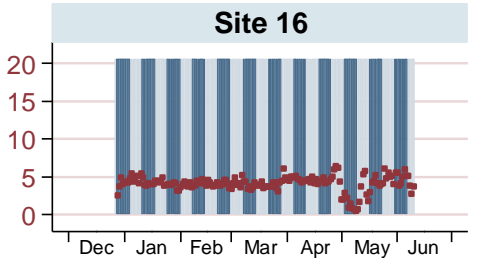

Site 2

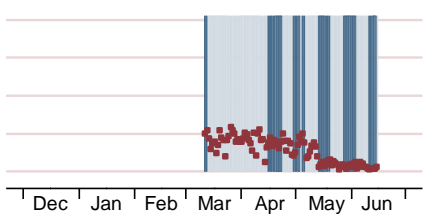

Site 5
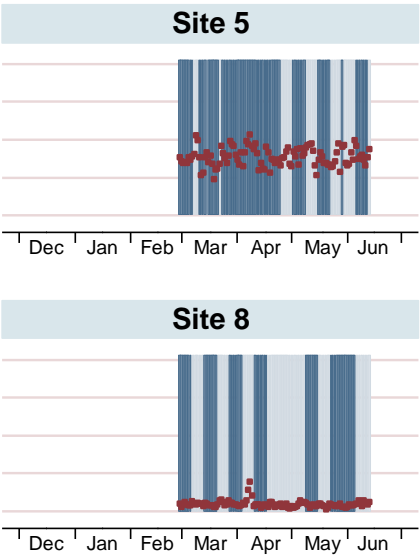

Site 11

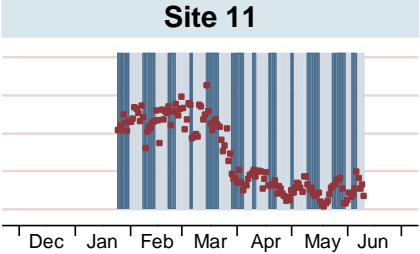

Site 14

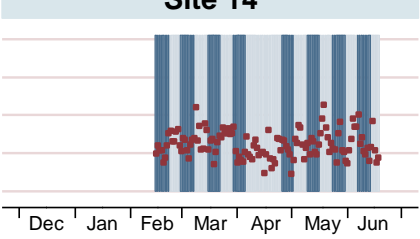

Site 17

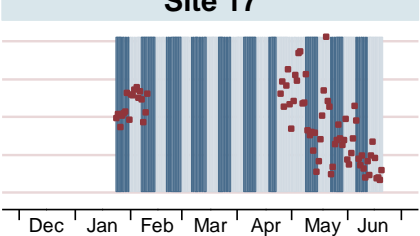

Site 3

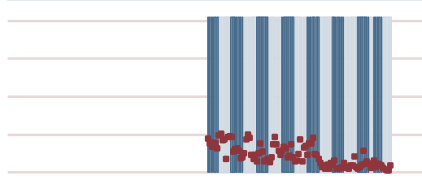

' Dec ' Jan ' Feb' Mar' Apr' May' Jun'

Site 6

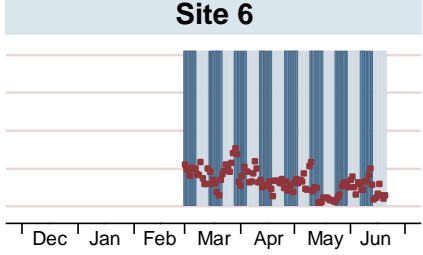

Site 9

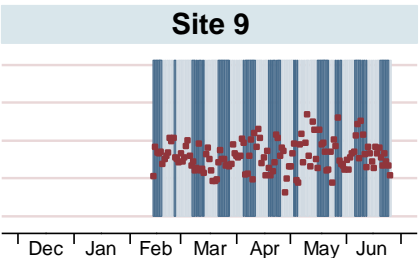

Site 12

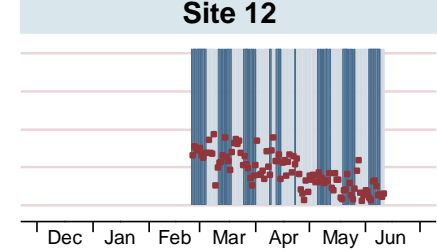

Site 15

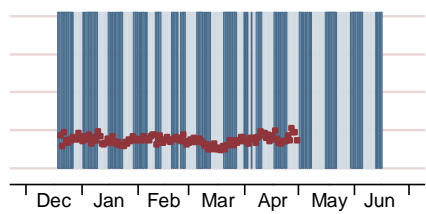

Site 18

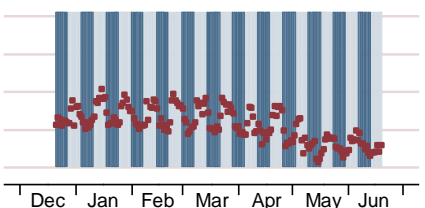

Fan off

Fan on Radon level

Fig. 3.1 Overview of ventilation fan operation and measured radon level by site. 


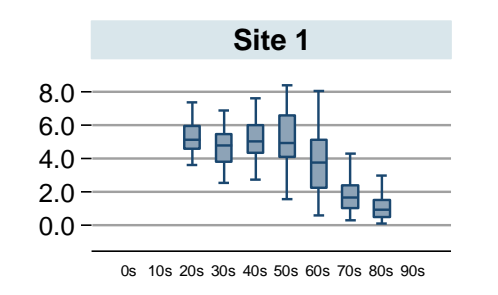

Site 4

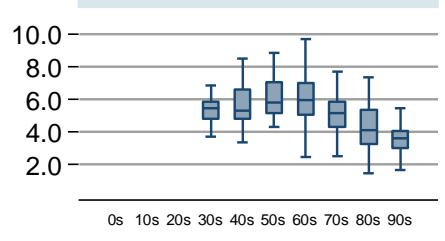

Site 7

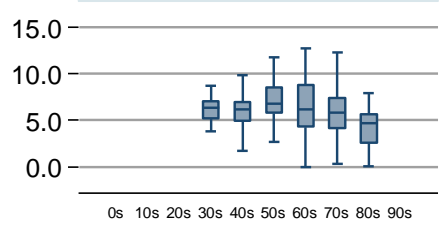

Site 10

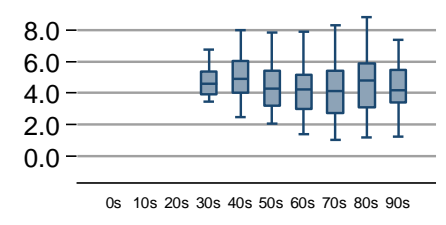

Site 13

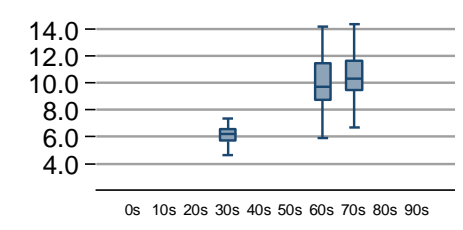

Site 16

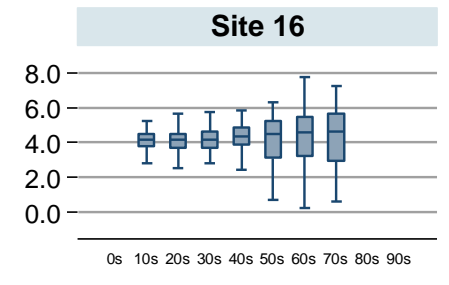

Site 2

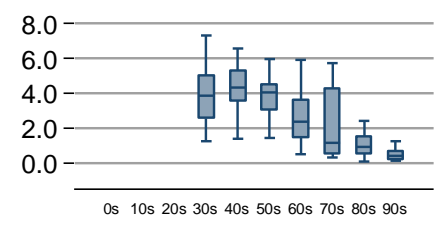

Site 5

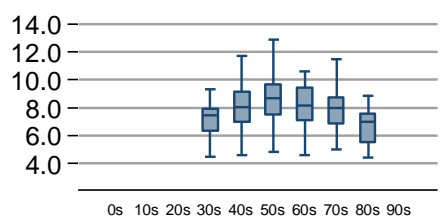

Site 8

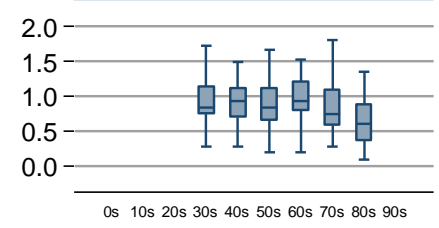

Site 11

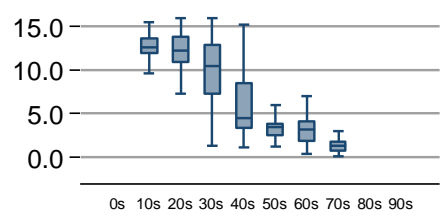

Site 14

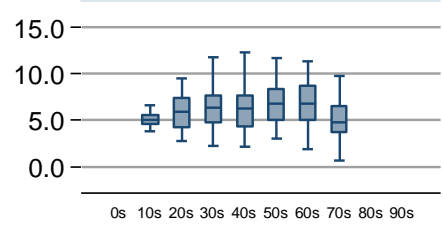

Site 17

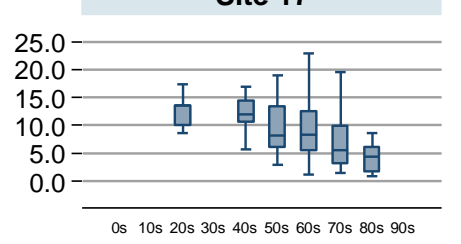

Site 3

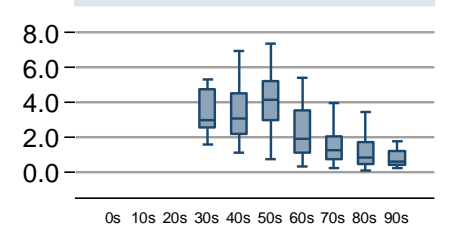

Site 6

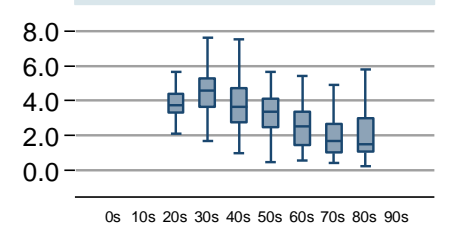

Site 9

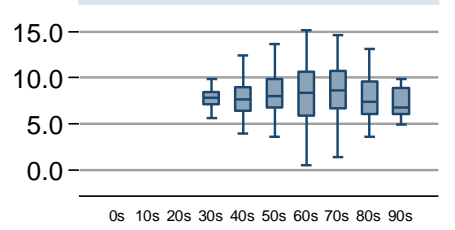

Site 12

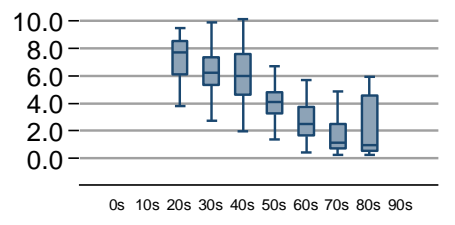

Site 15

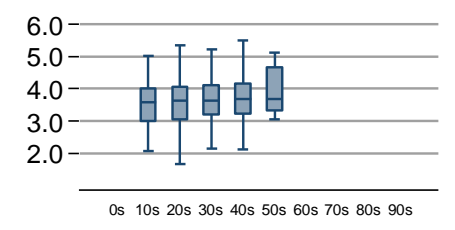

Site 18

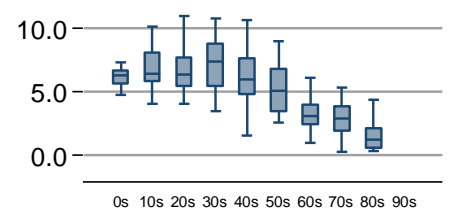

For $10 \mathrm{~F}$ bins of outdoor temperature

Box plot key:

Box shows the interquartile range (25th to 75 percentile), with horizontal line at the median

Whiskers show range of values within 1.5 IQRs of the upper and lower quartile. Outliers beyond the whiskers are not shown.

Note: box plot not shown for cases with fewer than 15 observations.

Fig. 3.2 Radon level by bins of outdoor temperature. 
Table 3.1 summarizes the results of both analyses, and Figure 3.3 graphically depicts the estimated relative impact of ventilation operation on radon levels by site. Results for Site 10 are omitted due to insufficient fan-on data.

Although the regression confidence intervals allow for a wide range of outcomes for individual sites, the pattern of point estimates across sites suggests that the ventilation generally either reduces indoor radon levels or has little or no effect. It is noteworthy that no sites show any marked increase in radon associated with operation of the ventilation.

The six sites on the left side of Figure 3.3 are notable in having a decrease in radon concentration of 15 percent or more, and for showing a regular pattern in which radon levels decline during periods of fan operation and increase during subsequent fan-off periods. This pattern is exemplified in Figure 3.4 by the time-series plot for Site 18 (similar plots for all sites can be found in Appendix B). This regular pattern strongly suggests that operation of the ventilation is indeed the causative factor behind reduced indoor radon concentrations at these sites.

Table 3.1 Radon level with and without ventilation system operation.

\begin{tabular}{|c|c|c|c|c|c|c|c|c|}
\hline \multirow[b]{3}{*}{ Site } & \multirow{2}{*}{\multicolumn{2}{|c|}{ Days of data* }} & \multirow{2}{*}{\multicolumn{2}{|c|}{$\begin{array}{l}\text { Mean radon level* } \\
(\text { pCi/L) }\end{array}$}} & \multicolumn{4}{|c|}{ Ventilation effect on radon } \\
\hline & & & & & \multicolumn{2}{|c|}{$\mathrm{pCi} / \mathrm{L}$} & \multicolumn{2}{|c|}{$\% * *$} \\
\hline & fan off & fan on & fan off & fan on & $\begin{array}{l}\text { difference } \\
\text { in means }\end{array}$ & $\begin{array}{l}\text { regression } \\
\text { estimate }\end{array}$ & $\begin{array}{l}\text { difference } \\
\text { in means }\end{array}$ & $\begin{array}{c}\text { regression } \\
\text { estimate }\end{array}$ \\
\hline 1 & 34 & 36 & 4.42 & 3.29 & -1.14 & -1.19 & $-26 \%$ & $-27 \%$ \\
\hline 2 & 23 & 18 & 2.63 & 2.42 & -0.21 & -0.10 & $-8 \%$ & $-4 \%$ \\
\hline 3 & 25 & 29 & 2.27 & 2.06 & -0.21 & -0.01 & $-9 \%$ & $-1 \%$ \\
\hline 4 & 24 & 25 & 5.31 & 5.17 & -0.15 & -0.42 & $-3 \%$ & $-8 \%$ \\
\hline 5 & 16 & 16 & 7.82 & 7.45 & -0.37 & -0.04 & $-5 \%$ & $-1 \%$ \\
\hline 6 & 32 & 32 & 3.16 & 3.08 & -0.08 & +0.05 & $-2 \%$ & $+2 \%$ \\
\hline 7 & 32 & 28 & 7.16 & 5.27 & -1.89 & -1.49 & $-26 \%$ & $-21 \%$ \\
\hline 8 & 29 & 31 & 1.18 & 0.78 & -0.40 & -0.44 & $-34 \%$ & $-37 \%$ \\
\hline 9 & 32 & 31 & 7.64 & 7.86 & +0.22 & +0.48 & $+3 \%$ & $+6 \%$ \\
\hline 10 & 20 & 8 & 4.22 & $* * *$ & $* * *$ & $* * *$ & $* * *$ & $* * *$ \\
\hline 11 & 39 & 29 & 7.64 & 6.72 & -0.92 & +0.14 & $-12 \%$ & $+2 \%$ \\
\hline 12 & 28 & 28 & 4.62 & 4.06 & -0.56 & -0.37 & $-12 \%$ & $-8 \%$ \\
\hline 13 & 12 & 12 & 9.14 & 8.42 & -0.73 & -0.87 & $-8 \%$ & $-10 \%$ \\
\hline 14 & 34 & 36 & 6.53 & 5.22 & -1.31 & -1.09 & $-20 \%$ & $-17 \%$ \\
\hline 15 & 33 & 31 & 3.73 & 3.46 & -0.26 & -0.27 & $-7 \%$ & $-7 \%$ \\
\hline 16 & 45 & 48 & 4.28 & 3.96 & -0.32 & -0.10 & $-8 \%$ & $-2 \%$ \\
\hline 17 & 28 & 16 & 10.93 & 6.97 & -3.96 & -4.12 & $-36 \%$ & $-38 \%$ \\
\hline 18 & 51 & 51 & 6.79 & 4.44 & -2.35 & -2.23 & $-35 \%$ & $-33 \%$ \\
\hline mean & 30 & 28 & 5.60 & 4.74 & -0.86 & -0.71 & $-15 \%$ & $-12 \%$ \\
\hline median & 31 & 29 & 5.31 & 4.44 & -0.40 & -0.37 & $-9 \%$ & $-8 \%$ \\
\hline
\end{tabular}

*Omits the first 48 hours following each change in fan operation status. Also omits data prior to April 9 for Site 2 and prior to April 17 for Site 5.

**Percent of mean fan-off radon level in Column 4.

***insufficient data. 


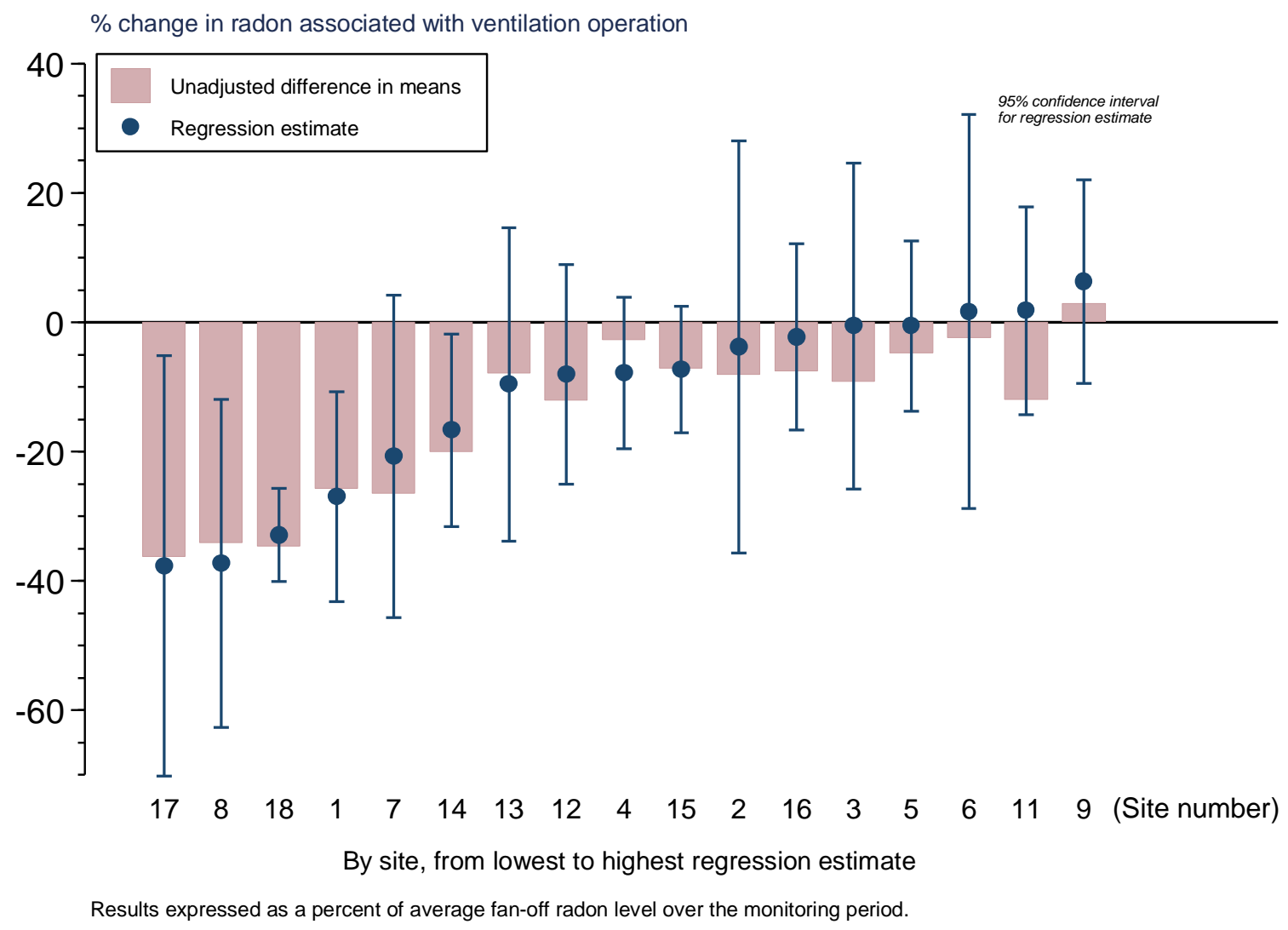

Fig. 3.3 Relative change in radon level associated with fan operation.

The impact of ventilation on radon levels is less straightforward for the other eleven sites. Fig. 3.55 shows an example of one such site (Site 16). The site exhibits several fan-off periods where the average radon level is higher than the adjacent fan-on periods - but also a number of periods where the two are nearly the same. Moreover, highly variable radon levels in May and June also muddy the picture. Though the statistics for the site indicate slightly lower radon levels during fan operation for this site, the extent to which this is due to the fan operation versus an artifact of natural variation is unclear. Other sites in this category are similarly ambiguous as to the degree to which the ventilation affects radon concentration in the home. Nonetheless, even among these low-impact sites, all of the point estimates lie either below or close to zero, suggesting that exhaust-only ventilation is unlikely to increase indoor radon levels by any significant degree.

Taken together, the regression-based results for the six high-impact and 11 low-impact sites yield a statistically-significant mean reduction of 12 percent in relative radon concentration associated with operation of the ventilation. The 95 percent confidence interval associated with this point estimate is \pm 7 percentage points, suggesting that widespread application of exhaust ventilation in similar homes will reduce indoor radon by roughly between 5 to 20 percent on average. 


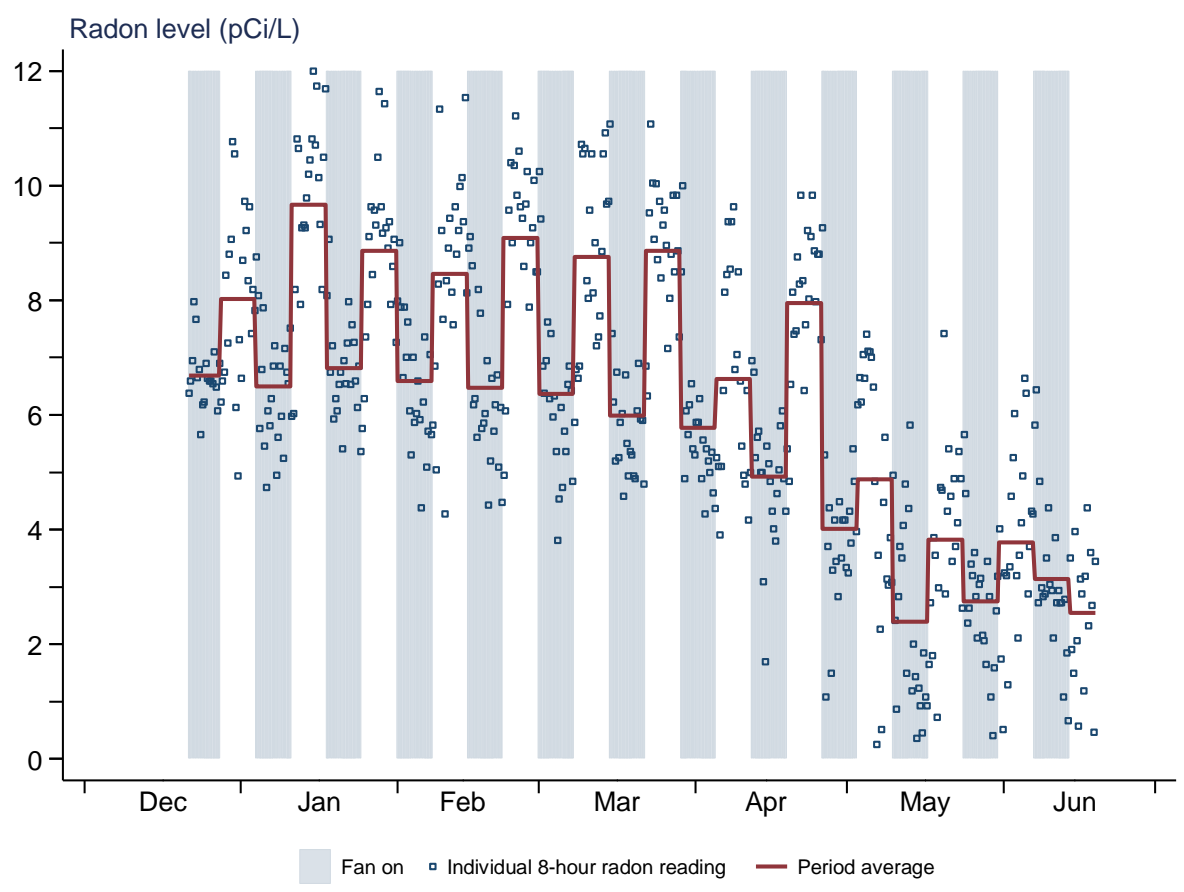

Fig. 3.4. Radon and fan-operation time series for Site 18 (high impact).

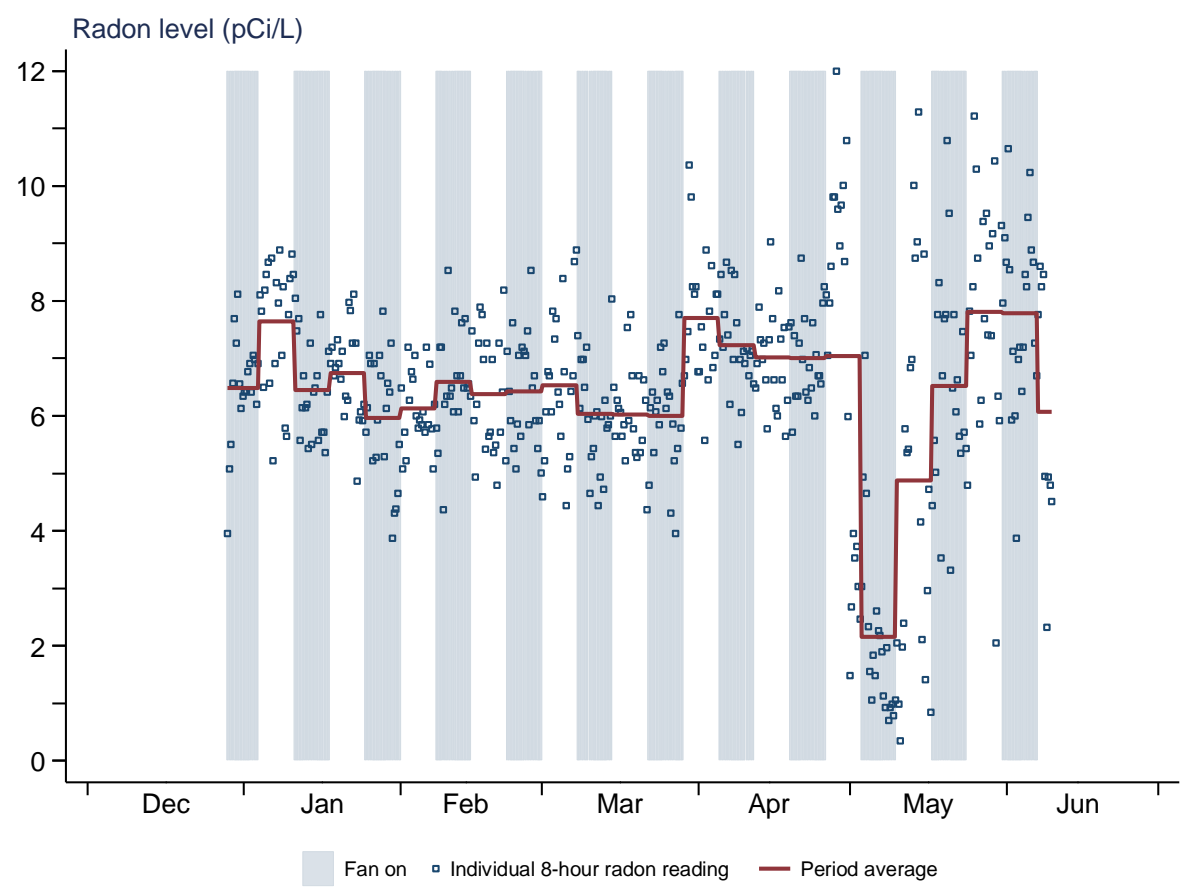

Fig. 3.5. Fan operation and radon time series for Site 16 (low impact). 
Several possible explanations were explored for why some sites showed a significant regular reduction in radon with fan operation while others did not. These included:

- foundation type

- location of the installed exhaust fan and radon monitor;

- relative contribution of the installed ventilation to overall home ventilation; and,

- outdoor temperature range over which monitoring occurred.

\section{Foundation type}

Four types of foundations are represented in the study sample: basements, crawlspaces and slab-ongrade. Some sites had mixed foundations that included both crawlspace and basement spaces. The highimpact sites were somewhat more likely to be basement homes, and somewhat less likely to be mixed basement/crawlspace homes (Table 3.2), but the differences are not statistically significant, given the small number of homes represented. The role of foundation type in the magnitude of the fan impact on radon is therefore inconclusive.

Table 3.2. Foundation type for low- and high-impact sites.

\begin{tabular}{|c|c|c|c|c|}
\hline \multirow[t]{2}{*}{ Foundation type } & \multicolumn{2}{|c|}{ Low-impact } & \multicolumn{2}{|c|}{ High-impact } \\
\hline & $\mathrm{n}$ & $\%$ & $\mathrm{n}$ & $\%$ \\
\hline Basement & 4 & $36 \%$ & 3 & $50 \%$ \\
\hline Crawlspace & 2 & $18 \%$ & 1 & $17 \%$ \\
\hline Mixed basement/crawlspace & 5 & $44 \%$ & 1 & $17 \%$ \\
\hline Slab on grade & 0 & $0 \%$ & 1 & $17 \%$ \\
\hline Total sites & 11 & $100 \%$ & 6 & $100 \%$ \\
\hline
\end{tabular}

\section{Location of fan and radon monitor}

Interestingly, the six high-impact sites included all three cases where the exhaust fan was installed in a basement (Sites 7,14 and 17). The single site in the study with a slab-on-grade foundation (Site 18) is also among the high-impact sites. This suggests that putting the fan close to radon entry points may result in a larger impact than when the fan is located, say, on a first floor bathroom above a basement.

This assessment is somewhat complicated by the location of the radon monitor itself, however. The monitors were placed on the lowest occupied level of the home, which was a basement for about half of the sites, including all three of the sites where the fan was installed in a basement. It is conceivable that a radon monitor in a basement might record a stronger response than one on a first floor, because it is closer to the typical radon point of entry. However, none of the high-impact sites included homes with a fan on a first floor and a radon monitor in the basement, and five of the low-impact sites had radon monitors in the basement. This suggests that for the sites with basement fans, it is the location of the fan and not the radon monitor that is important.

\section{Mechanical ventilation contribution to overall ventilation}

Another possible discriminant for high versus low impact on radon is the extent to which the installed mechanical ventilation affects the overall ventilation rate of the homes in the study. The sites varied their post-weatherization air leakage rates, and the ASHRAE 62.2 calculation procedure produces different values for the amount of mechanical ventilation to install depending on the size of the home, number of bedrooms, air leakage and presence or absence of local exhaust in bathrooms and kitchens. Although the 
62.2 procedure takes air leakage into account, variation in the other factors means that the installed mechanical ventilation can be expected to have a relatively larger impact on overall ventilation rates for some homes compared to others.

Actual overall ventilation rates (which vary significantly with outdoor temperature and wind) were not measured for the homes in the study. However, air leakage measurements and other information about the homes allow for estimation of the seasonal average natural ventilation rate for each site. ${ }^{3}$ These estimates can then be compared against the continuous flow provided by the mechanical ventilation to roughly gauge the relative increase in ventilation from the ventilation.

Figure 3.6 plots the regression-estimated relative impact of the mechanical ventilation on radon against the estimated relative increase in overall ventilation from it. ${ }^{4}$

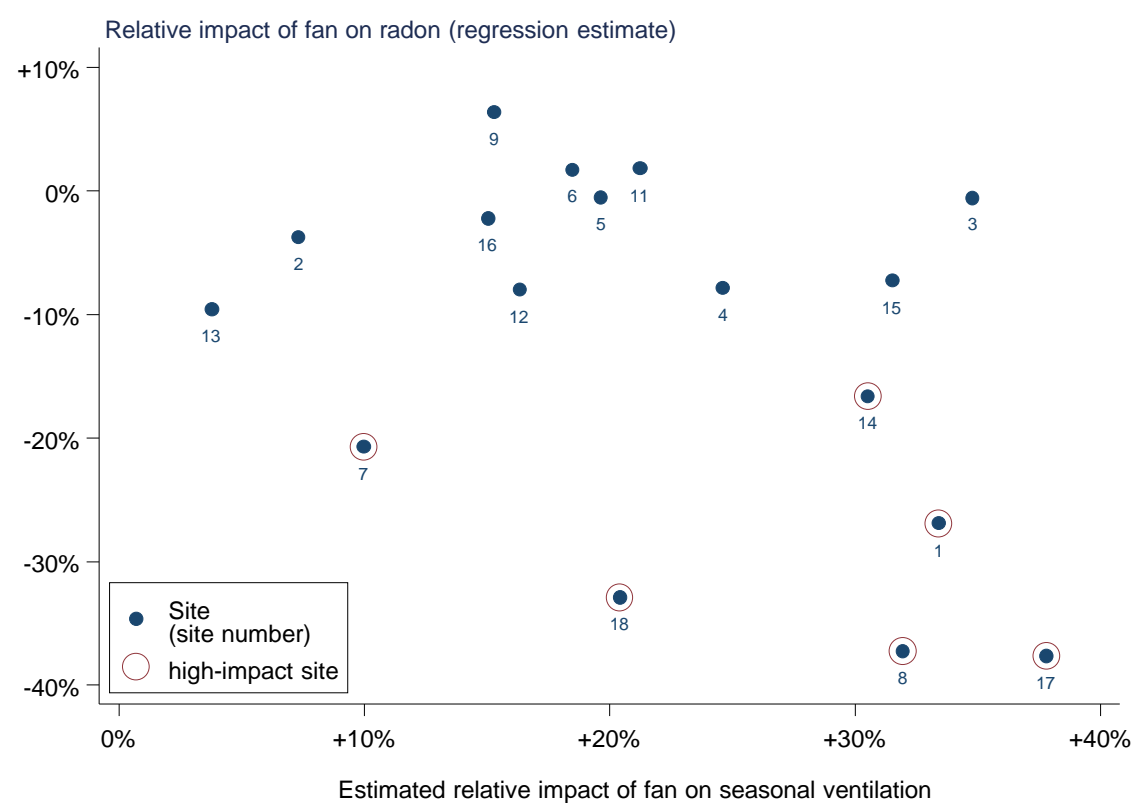

Fig. 3.6. Relative impact on radon versus estimated relative fan contribution to overall ventilation.

\footnotetext{
${ }^{3}$ Estimates used here are based on the enhanced model of natural ventilation in the ASHRAE Handbook of Fundamentals (ASHRAE 2009), and were implemented by Paul Francisco of the University of Illinois.

${ }^{4}$ The latter estimates assume that on a seasonal basis only half of the measured fan flow is incremental to natural ventilation. See Palmiter and Bond (1991).
} 
Overall, there is a statistically significant relationship between the two values in the expected direction, and the high-impact sites tend to be clustered toward the high end of estimated impact of the fan on overall ventilation rate. However, two high-impact sites (Sites 7 and 18) are on the moderate to low end of the range of estimated fan impact on overall ventilation, and at two low-impact sites (Sites 3 and 15) have high estimated fan impacts on the seasonal ventilation rate. Given that actual ventilation rates can vary considerably from estimates based on air leakage tests, results such as these would perhaps not be unexpected.

\section{Outdoor temperature during monitoring}

Temperature-induced stack effect is the dominant driving force behind natural ventilation in homes in heating climates, and this effect varies strongly with outdoor temperature: ventilation is high in cold weather when the indoor-outdoor temperature difference is highest and low when the temperature difference is small. For a ventilation system with fixed flow, this means that the relative contribution of the mechanical ventilation to overall ventilation should be small in cold weather and large in warmer weather.

Because the study sites were geographically dispersed and the monitoring periods varied, it is possible that high-impact sites are concentrated among homes that were monitored under warmer conditions. Figure 3.7 does not support this hypothesis, however: high- and low-impact sites were both monitored across a range of average outdoor temperatures, and no overall relationship between radon impact and temperature is apparent.

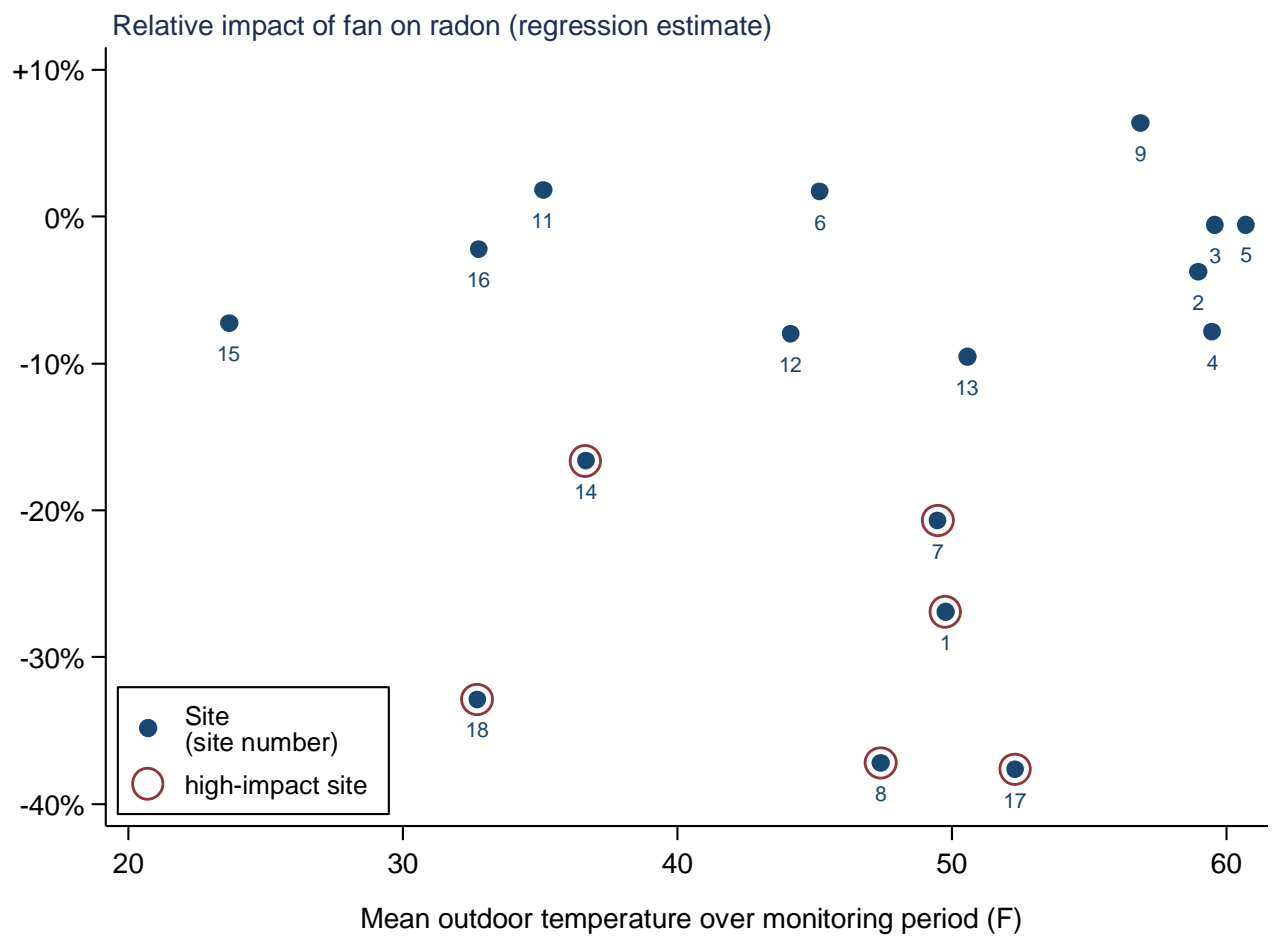

Fig. 3.7. Relative impact of fan on radon versus outdoor temperature. 


\subsection{HUMIDITY}

Indoor temperature and humidity were measured at the primary thermostat for each site. The analysis here looks at the impact of fan operation on indoor humidity under space-heating conditions, and examines both absolute humidity (the weight of water in a given weight of dry air) and relative humidity (the amount of moisture relative to the maximum that can be held in air at a given temperature)

Indoor absolute humidity is strongly affected by outdoor absolute humidity (owing to ventilation), and outdoor absolute humidity is closely related to outdoor temperature (because cold air can hold less moisture than warm air). Because of these relationships, results presented here are based on regressing daily indoor absolute humidity against outdoor absolute humidity for days with and without fan operation, and then normalizing these results to typical outdoor humidity at a 32F outdoor temperature. These results are then translated into relative humidity terms using the average indoor temperature for each site (also normalized to 32F outdoor temperature).

As with radon, transition effects are a concern. Because the time required for humidity effects to be felt may be longer than those for radon, the first three days following each fan-operation status change were omitted from the analysis. In addition, Site 10 was dropped due to insufficient fan-on data, and Site 13 was dropped due to data quality issues with the humidity data.

Results of the analysis are summarized in Table 3.3 and Figure 3.8. On average, fan operation reduced normalized indoor relative humidity by a statistically significant $1.7 \pm 1.2$ percentage points, with a range of point estimates from about -7 percentage points to +3 percentage points, with most sites showing a nominal (if not statistically significant) reduction in humidity associated with fan operation. One site showed a nominal increase in relative humidity of about 3 percentage points; this site is notable both in having the lowest average fan-off relative humidity in the sample, and for having the weakest observed relationship between indoor and outdoor humidity.

Note that there is no particular relationship between the fan's impact on indoor humidity and the general humidity level in the home. Fan operation at the site with the highest relative humidity had no discernible impact, and the largest humidity impact (Site 1) was seen at a site with moderate existing humidity levels.

The $1.7 \pm 1.2$ percent decrease in relative humidity associated with the ventilation is about the same as the average increase in humidity associated with weatherization observed in the earlier IAQ study $(1.1 \pm$ $0.6 \%)$.

The results here are generally consistent with an earlier study that employed a similar methodology for 32 Wisconsin homes (Pigg et al., 2011). Operation of ASHRAE 62.2-2007 compliant exhaust-only ventilation in those homes resulted in a decline in indoor relative humidity of two to three percentage points. It is possible that both studies somewhat under-state the full humidity impact of the mechanical ventilation owing to the fact that the fans were cycled on and off every week to two weeks: this cycling interval would not allow for drying effects at longer time scales to be observed. 
Table 3.3. Indoor temperature and humidity (at 32F outdoor temperature).

\begin{tabular}{|c|c|c|c|c|c|c|c|}
\hline \multirow[b]{2}{*}{ Site } & \multirow{2}{*}{$\begin{array}{l}\text { Mean indoor } \\
\text { temperature }(\mathrm{F})\end{array}$} & \multicolumn{3}{|c|}{ Absolute humidity (grains/lb) } & \multicolumn{3}{|c|}{ Relative humidity (\%) } \\
\hline & & Fan-off & Fan-on & Difference & Fan-off & Fan-on & Difference \\
\hline 1 & 66.3 & 40.5 & 32.0 & -8.5 & 34.7 & 27.5 & -7.2 \\
\hline 2 & 66.0 & 25.6 & 28.8 & +3.1 & 22.8 & 25.6 & +2.8 \\
\hline 3 & 69.0 & 36.5 & 32.6 & -3.9 & 29.8 & 26.7 & -3.1 \\
\hline 4 & 72.0 & 50.2 & 47.8 & -2.4 & 36.5 & 34.7 & -1.8 \\
\hline 5 & 67.8 & 34.5 & 31.1 & -3.4 & 33.5 & 30.3 & -3.3 \\
\hline 6 & 64.7 & 39.7 & 38.0 & -1.7 & 41.9 & 40.0 & -1.8 \\
\hline 7 & 61.3 & 38.3 & 38.4 & +0.1 & 46.5 & 46.6 & +0.1 \\
\hline 8 & 67.3 & 34.0 & 33.4 & -0.6 & 33.1 & 32.5 & -0.6 \\
\hline 9 & 73.0 & 37.3 & 33.9 & -3.4 & 30.2 & 27.5 & -2.7 \\
\hline 11 & 71.3 & 31.1 & 31.6 & +0.5 & 26.0 & 26.4 & +0.4 \\
\hline 12 & 69.0 & 38.7 & 35.9 & -2.8 & 34.9 & 32.4 & -2.5 \\
\hline 14 & 67.8 & 38.7 & 38.1 & -0.6 & 36.7 & 36.2 & -0.5 \\
\hline 15 & 78.1 & 36.6 & 34.2 & -2.4 & 24.9 & 23.3 & -1.6 \\
\hline 16 & 74.7 & 48.3 & 42.6 & -5.7 & 36.8 & 32.5 & -4.3 \\
\hline 17 & 69.5 & 38.3 & 36.7 & -1.6 & 34.6 & 33.2 & -1.4 \\
\hline 18 & 60.9 & 25.5 & 25.5 & +0.0 & 31.1 & 31.1 & +0.0 \\
\hline mean & 68.7 & 37.1 & 35.0 & -2.1 & 33.4 & 31.7 & -1.7 \\
\hline median & 68.4 & 37.8 & 34.1 & -2.1 & 34.1 & 31.8 & -1.7 \\
\hline
\end{tabular}
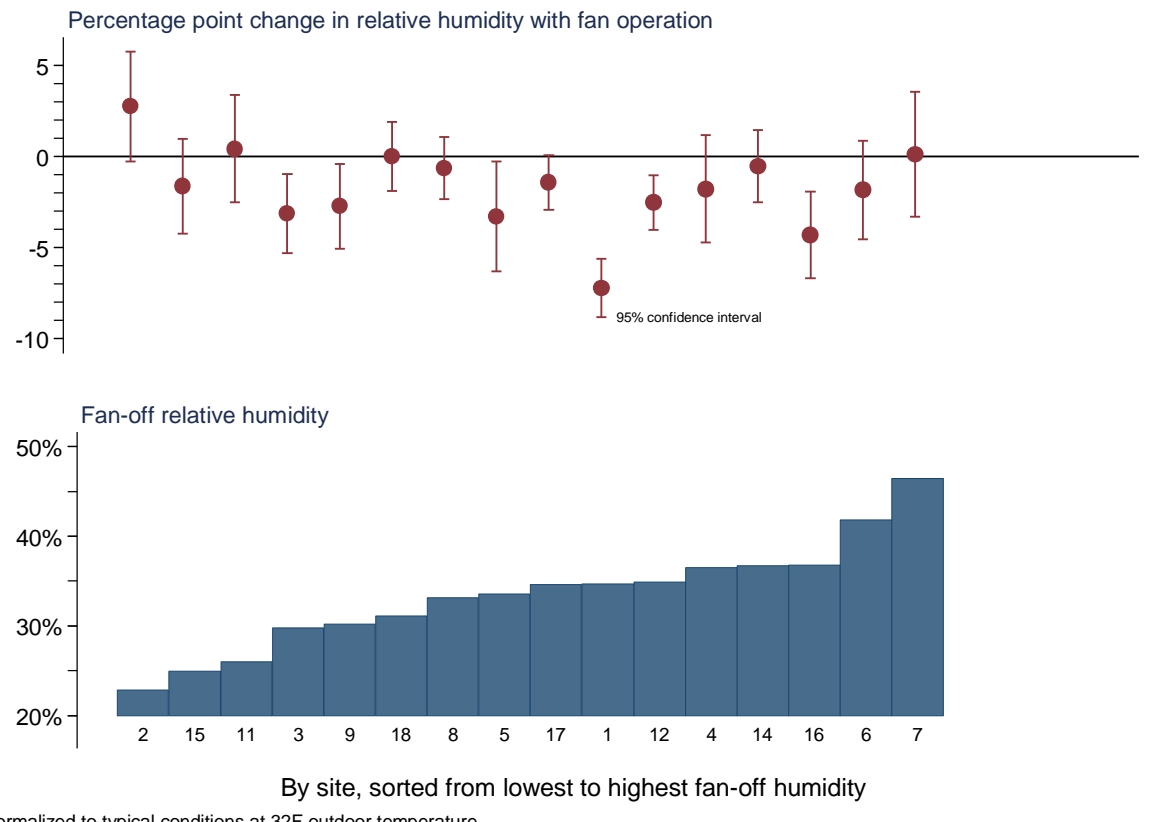

Fig. 3.8. Relative humidity impacts of fan operation. 


\section{CONCLUSIONS}

\section{Radon}

Overall, the results of this study suggest that the installation of ASHRAE-62.2 compliant exhaust-only ventilation generally reduces radon levels in single-family, site built homes with moderately elevated radon levels. Although the study sample size is small, and the impact of the ventilation on radon levels in the individual homes in the study is not precisely known, it is striking that none of the sites showed any significant increase in radon associated with operation of the exhaust fans. This suggests that in most cases, the dilution effect of fan-induced ventilation dominates over any depressurization effect that would tend to increase the rate of radon entry into the home.

The study provides some indications regarding why some homes in the study experienced a larger decline in indoor radon with operation of the ventilation than others. Locating the exhaust fan close to the source of radon entry, such as in a basement, makes intuitive sense and appears be a factor, given that all three sites with fans in a basement showed a significant reduction in radon. To the extent that this is true, there are trade-offs to be considered: if only one fan is to be installed in a home, for instance, is it preferable to locate the fan in a little-used basement space for better radon control, or in a high-traffic first-floor bathroom for humidity and odor control?

In a broader sense, the study results suggest that widespread implementation of ASHRAE 62.2 in the weatherization program will help offset the tendency of the program to increase radon levels as revealed in the prior IAQ study. However, the extent to which this offsetting occurs in an aggregate sense depends on the proportion and characteristics of homes that receive 62.2-compliant ventilation, and the degree to which program-installed ventilation acts similarly to that of the homes in the study. If locating the fan in the basement, for example, is an important factor, and fewer homes in the program receive basementlocated ventilation, then the aggregate impact of 62.2 ventilation in the program could be less than observed here.

On the other hand, because it depressurizes foundation spaces, exhaust-only ventilation is arguably least beneficial mechanical ventilation strategy from a radon-control perspective: to the extent that the program installs supply-only or balanced ventilation in homes, the aggregate impact of ASHRAE 62.2 ventilation on radon could be larger than this study would otherwise suggest.

Indoor radon - and the impact of mechanical ventilation on radon-Is a complex phenomenon, and scope and monitoring period for this study precluded more detailed investigation in a larger sample of homes. Additional field research would shed more light on how mechanical ventilation affects indoor radon, and how such ventilation can be optimized to reduce indoor radon levels.

\section{Humidity}

Operating the exhaust-only mechanical ventilation decreased heating-season indoor humidity levels for most homes in the sample, but only by a small amount for the most part. Moreover, the magnitude of the effect was not well correlated with indoor humidity levels. This suggests both that exhaust ventilation at ASHRAE 62.2 levels should not be counted on to solve issues with high indoor humidity and that the addition of ventilation may tend to exacerbate humidity issues in homes that are overly dry to begin with. Nonetheless, the results suggest that ASHRAE 62.2 ventilation has the potential to offset a tendency for weatherization to slightly increase average indoor humidity levels, as was found in the prior IAQ study. 



\section{REFERENCES}

American Society of Heating, Refrigerating and Air Conditioning Engineers (ASHRAE) 2009. 2009 ASHRAE Handbook - Fundamentals (I-P Edition), American Society of Heating, Refrigerating and AirConditioning Engineers, Inc.

American Society of Heating Refrigeration and Air-Conditioning Engineers (ASHRAE) Standard 62.22010, "Ventilation, and Acceptable Indoor Air Quality in Low-Rise Residential Buildings.”"

American Society of Heating Refrigeration and Air-Conditioning Engineers (ASHRAE) Standard 62.22013, "Ventilation, and Acceptable Indoor Air Quality in Low-Rise Residential Buildings.”"

Francisco, Paul. 2013. Personal communication, July 20, 2013.

Palmiter, L., and T. Bond. 1991. "Interaction of Mechanical Systems and Natural Infiltration." Proceedings of the AIVC 1991 Conference on Air Movement and Ventilation Control Within Buildings, 1:285-295. Coventy, Great Britain: The Air Infiltration and Ventilation Centre.

Pigg, Scott, Andy Mendyk, Robert Parkhurst, Adrian Scott, Patrick Larkin and Bob Pfeiffer. 2011. "Impacts of Mechanical Ventilation in Wisconsin Weatherization Homes-Final Report." Prepared for Wisconsin Division of Administration, Division of Energy Services, Madison, Wisconsin. Available at: http://homeenergyplus.wi.gov/docview.asp?docid=22505\&locid=25

Pigg, S., Cautley, D., Francisco, P. with Hawkins, B., and Brennan, T. 2014a. Weatherization and Indoor Environment Quality: Measured Impacts in Single-Family Homes Under the Weatherization Assistance Program. ORNL/TM-2014/170, Oak Ridge National Laboratory, Oak Ridge, Tennessee, September.

Sherman, Max. 1992. "Simplified Modeling for Infiltration and Radon Entry," In: Proceedings, Thermal Performance of the Exterior Envelopes of Buildings Conference V, Atlanta, GA: ASHRAE, LBL-31305. 



\section{APPENDIX A. REGRESSION MODELS}





\section{APPENDIX A. REGRESSION MODELS}

This appendix describes the regression model used to adjust observed differences in radon levels with and without ventilation system operation for weather factors. The model specification is:

$$
R d n_{t}=\begin{aligned}
& \beta_{0}+\beta_{1} \text { ventstatus }_{t}+\beta_{2} x_{10 t}+\beta_{3} x_{11 t}+\beta_{4} x_{12 t}+\beta_{5} x_{00 t}+\beta_{6} x_{01 t}+\beta_{7} x_{02 t}+ \\
& \beta_{8} \text { tcat }_{0 t}+\beta_{9} \text { tcat }_{10 t}+\beta_{10} \text { tcat }_{20 t}+\ldots \beta_{16} \text { tcat }_{80 t}+\beta_{17} d s p_{t}+\beta_{18} \text { wind }_{t}+u_{t}
\end{aligned}
$$

where,

$R d n_{t} \equiv$ average radon level $(\mathrm{pCi} / \mathrm{L})$ for a site during 24 -hour period $t$.

ventstatus $s_{t}$ is a binary indicator for whether the ventilation system was operating (1) or not $(0)$ during period $t$.

$x_{10 t}$ through $x_{02 t}$ are binary indicators for transition days. The first subscript denotes a transition from fan-off to fan-on (1) or fan-on to fan-off (0). The second subscript denotes the transition period: 0 is the transition day; 1 is the first full 24 -hour period following the transition; and, 2 is the second 24-hour period following the transition.

tcat $_{0 t}$ through tcat $_{80 t}$ are binary $(0 / 1)$ indicators for whether average outdoor temperature at a nearby weather station over 24-hour radon reading period $t$ is in the range of $\leq 0 \mathrm{~F}$ $\left(\right.$ tcat $\left._{0}\right), 1-10 \mathrm{~F}\left(\right.$ tcat $\left._{10}\right), 11-20 \mathrm{~F}\left(\right.$ tcat $\left._{20}\right), \ldots 80 \mathrm{~F}+\left(\right.$ tcat $\left._{80}\right)$.

$d s / p_{t}$ is the change in sea-level air pressure (in. $\mathrm{Hg}$ ) from the prior period, $t-1$.

wind $_{t}$ is the average wind speed ( $\mathrm{mph}$ ) at a nearby weather station over period $t$.

$u_{t}$ is a first-order auto-correlated error term $\equiv \rho u_{t-1}+\varepsilon_{t}$

where

$\rho$ is a fitted auto-correlation parameter

$\varepsilon_{t}$ is random, uncorrelated error

The iterative Prais-Winsten procedure (as implemented in Stata, Version 12.1) was used to estimate the value of the auto-correlation parameter $\rho$ and fit the model coefficients. The specification above was used after exploring other models that included terms precipitation, operation status of heating and cooling equipment and indoor/outdoor temperature differences as well as alternative specifications for outdoor temperature.

The primary coefficient of interest is $\beta_{1}$ which represents the mean change in radon level associated with operation of the ventilation system for Day 3 and beyond following a fanoperation status change, and controlling for the other factors in the model.

Model fits by site are shown on the following pages.

$\star \star \star$ Site $1 \star \star \star$ 


\begin{tabular}{|c|c|c|c|c|c|c|}
\hline Source | & SS & $d f$ & MS & Number of obs & $=$ & 122 \\
\hline & & & ----- & F( 15, & $=$ & 3.03 \\
\hline Model | & 23.925429 & 15 & 1.5950286 & Prob $>F$ & $=$ & 0.0005 \\
\hline Residual | & 55.8842109 & 106 & .527209537 & R-squared & $=$ & 0.2998 \\
\hline--------+ & & & ----------- & Adj R-squared & $=$ & 0.2007 \\
\hline Total | & 79.8096399 & 121 & .659583801 & Root MSE & $=$ & .72609 \\
\hline
\end{tabular}

\begin{tabular}{|c|c|c|c|c|c|c|c|}
\hline$r d n$ & । & Coef. & Std. Err. & t & $P>|t|$ & [95\% Conf. & Interval] \\
\hline ventstatus & । & -1.190833 & .3620648 & -3.29 & 0.001 & -1.908662 & -.4730045 \\
\hline x10 & । & .4405756 & .3562626 & 1.24 & 0.219 & -.2657496 & 1.146901 \\
\hline x11 & । & -.1226306 & .3185999 & -0.38 & 0.701 & -.7542859 & .5090248 \\
\hline$x 12$ & । & .0815895 & .2415497 & 0.34 & 0.736 & -.3973062 & .5604852 \\
\hline $\mathrm{x} 00$ & । & -1.190387 & .3549537 & -3.35 & 0.001 & -1.894118 & -.4866572 \\
\hline x01 & । & -.2128838 & .3227473 & -0.66 & 0.511 & -.8527617 & .4269941 \\
\hline$x 02$ & । & .1037683 & .2426593 & 0.43 & 0.670 & -.3773273 & .5848639 \\
\hline tcat & । & & & & & & \\
\hline 30 & । & -.2899861 & .2965612 & -0.98 & 0.330 & -.8779476 & .2979753 \\
\hline 40 & । & .2773621 & .3772204 & 0.74 & 0.464 & -.470514 & 1.025238 \\
\hline 50 & I & .3342165 & .4281876 & 0.78 & 0.437 & -.5147072 & 1.18314 \\
\hline 60 & । & .1378483 & .4839355 & 0.28 & 0.776 & -.8216009 & 1.097297 \\
\hline 70 & I & .1968214 & .5579926 & 0.35 & 0.725 & -.9094532 & 1.303096 \\
\hline 80 & I & .3152836 & .6244607 & 0.50 & 0.615 & -.9227704 & 1.553338 \\
\hline wind & । & -.010506 & .0190748 & -0.55 & 0.583 & -.0483237 & .0273117 \\
\hline$d s l p$ & । & -.1616719 & .3058058 & -0.53 & 0.598 & -.7679615 & .4446178 \\
\hline _cons & । & 4.228015 & 1.138432 & 3.71 & 0.000 & 1.970963 & 6.485067 \\
\hline rho & । & .9436862 & & & & & \\
\hline Durbin-Watson & & tatistic (o & iginal) & 1.204165 & & & \\
\hline urbin-Watson & & tistic & 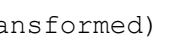 & 2.119645 & & & \\
\hline
\end{tabular}

$\star \star *$ Site 2

Source I SS df MS

$\begin{array}{ll}\text { Number of obs }= & 68 \\ F(15, \quad 52)= & 4.39\end{array}$ 


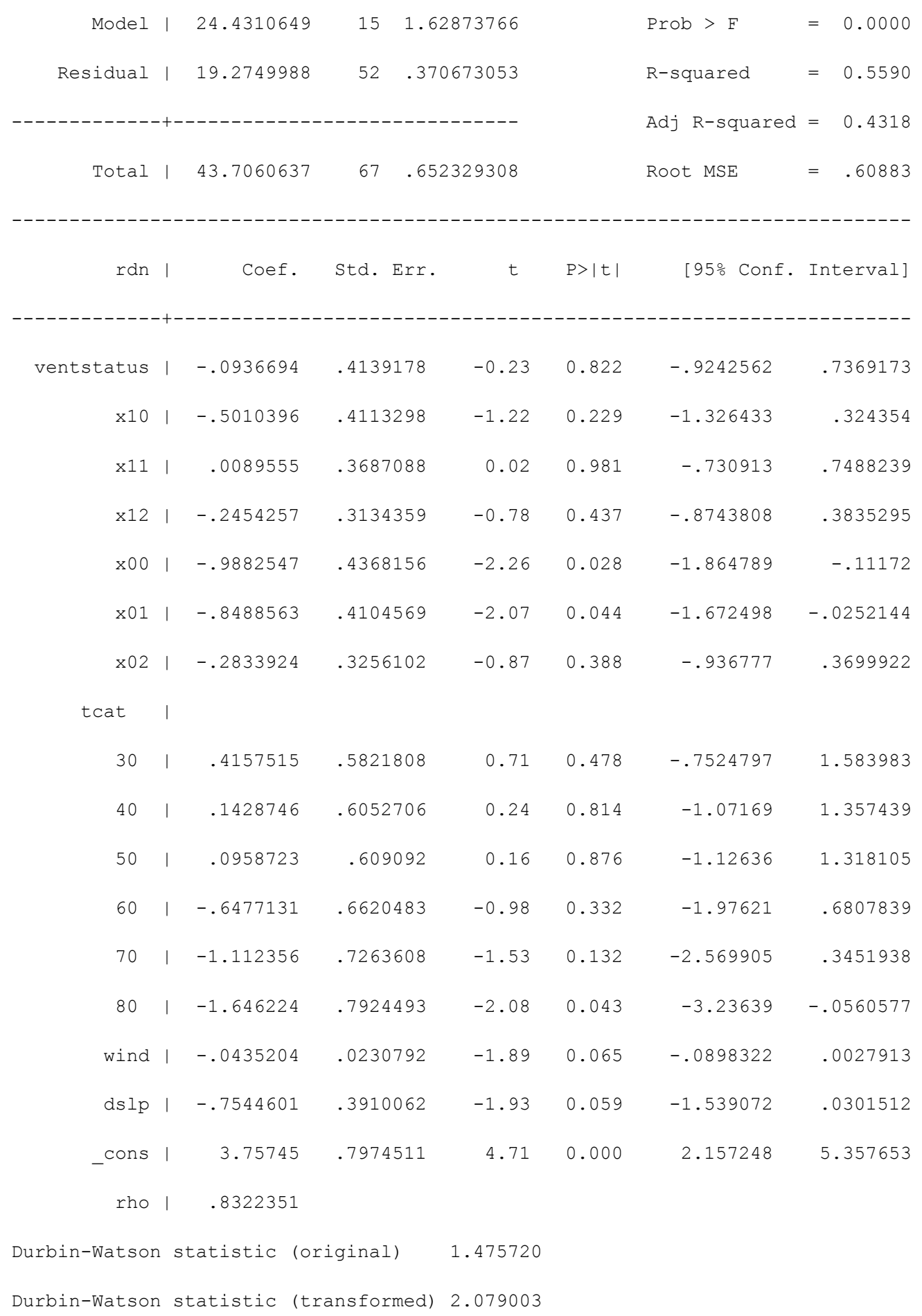


$\star \star \star$ Site $3 \star \star \star$

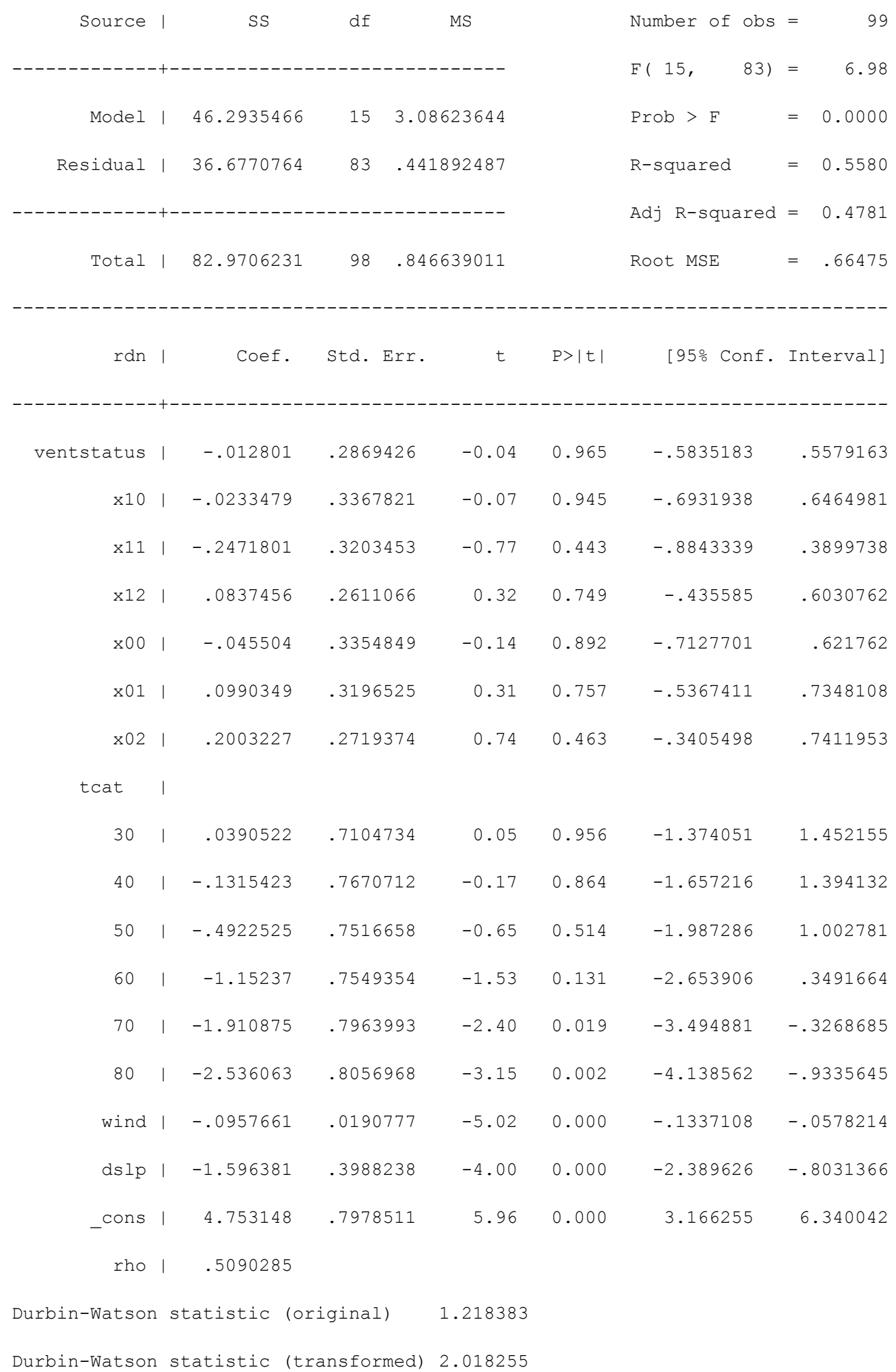




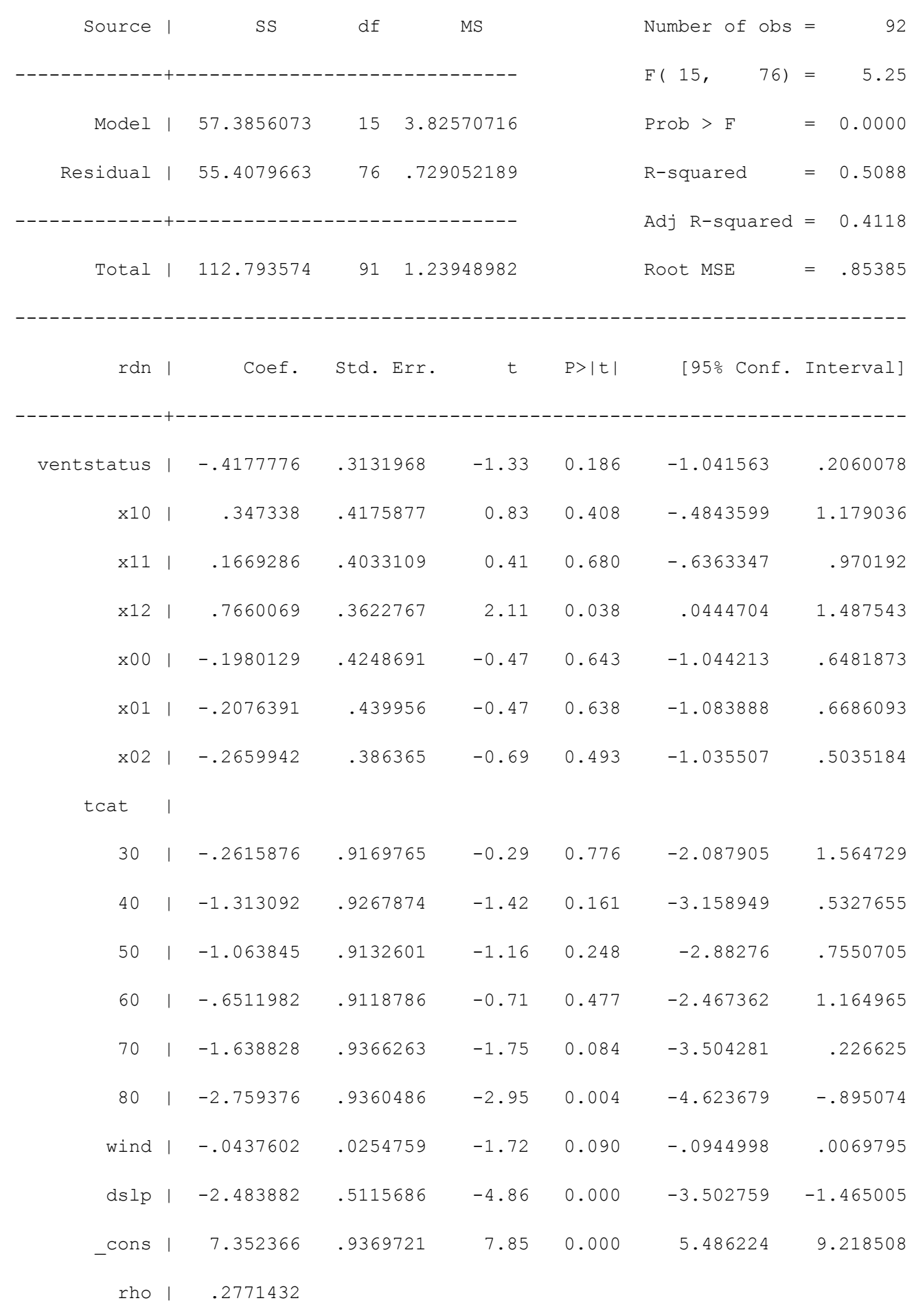

Durbin-Watson statistic (original) $\quad 1.627987$

Durbin-Watson statistic (transformed) 1.998571 
$\star \star \star$ Site $5 * \star \star$

\begin{tabular}{|c|c|c|c|c|c|c|c|c|}
\hline \multirow{2}{*}{\multicolumn{2}{|c|}{ Source }} & SS & $d f$ & & MS & & \multicolumn{2}{|c|}{ Number of obs $=$} \\
\hline & & & & & ---- & & $\mathrm{F}(13$ & 0.41 \\
\hline Model & । & 7.15261082 & 13 & \multicolumn{2}{|c|}{.550200832} & & Prob > F & $=0.9582$ \\
\hline Residual & । & 56.468278 & 42 & \multicolumn{2}{|c|}{1.34448281} & & R-squared & $=0.1124$ \\
\hline & & & & & ----- & & Adj R-squared & $=-0.1623$ \\
\hline Total & । & 63.6208888 & 55 & \multicolumn{2}{|c|}{1.15674343} & & Root MSE & $=1.1595$ \\
\hline$r d n$ & I & Coef. & Std. & Err. & t & $P>|t|$ & [95\% Conf. & Interval] \\
\hline ventstatus & । & -.0431305 & .5111 & 135 & -0.08 & 0.933 & -1.074599 & .9883383 \\
\hline x10 & । & .4872923 & .7323 & 354 & 0.67 & 0.509 & -.9906205 & 1.965205 \\
\hline x11 & । & .1895646 & .751 & 447 & 0.25 & 0.802 & -1.326917 & 1.706046 \\
\hline $\mathrm{x} 12$ & । & .8417916 & .6663 & 088 & 1.26 & 0.213 & -.5028739 & 2.186457 \\
\hline$x 00$ & । & .2772482 & .6892 & 334 & 0.40 & 0.690 & -1.113681 & 1.668178 \\
\hline $\mathrm{x} 01$ & । & -.0182951 & $.7380^{\circ}$ & 788 & -0.02 & 0.980 & -1.507798 & 1.471208 \\
\hline $\mathrm{x} 02$ & । & -.3394445 & .6467 & 318 & -0.52 & 0.602 & -1.644602 & .9657131 \\
\hline tcat & I & & & & & & & \\
\hline 50 & । & .631648 & .772 & 285 & 0.82 & 0.418 & -.9268862 & 2.190182 \\
\hline 60 & । & .5114722 & .780 & 851 & 0.66 & 0.516 & -1.064349 & 2.087293 \\
\hline 70 & । & -.0235795 & .7419 & 793 & -0.03 & 0.975 & -1.520954 & 1.473795 \\
\hline 80 & । & .0031242 & .9660 & 111 & 0.00 & 0.997 & -1.946365 & 1.952614 \\
\hline wind & 1 & -.005975 & .0478 & 008 & -0.12 & 0.901 & -.1024408 & .0904909 \\
\hline dslp & I & -1.385472 & 1.116 & 252 & -1.24 & 0.221 & -3.638159 & .867216 \\
\hline _cons & । & 7.452184 & 1.011 & 021 & 7.37 & 0.000 & 5.411861 & 9.492507 \\
\hline rho & | & .2020419 & & & & & & \\
\hline Durbin-Watson & & tatistic (or & iginal & & 1.708678 & & & \\
\hline Durbin-Watson & & atistic (t & sfo & & & & & \\
\hline
\end{tabular}


*** Site $6 * \star \star$

\begin{tabular}{|c|c|c|c|c|c|c|c|}
\hline Source & I & \multicolumn{4}{|c|}{ MS } & Number of obs & $=\quad 110$ \\
\hline & & & -------1 & ----- & & F( 16, & 4.14 \\
\hline Model & I & 62.9115721 & 3.93 & 197326 & & Prob > F & $=0.0000$ \\
\hline Residual & । & 88.2966201 & .949 & 426023 & & R-squared & $=0.4161$ \\
\hline---- & -+ & & -------- & ------ & & Adj $R$-squared $=$ & $=0.3156$ \\
\hline Total & I & 151.208192 & 109 & 723112 & & Root MSE & $=.97438$ \\
\hline rdn & I & Coef. & Std. Err. & $t$ & $P>|t|$ & [95\% Conf. & Interval] \\
\hline ventstatus & । & .0529707 & .4854064 & 0.11 & 0.913 & -.9109503 & 1.016892 \\
\hline$x 10$ & । & .9212593 & .5227945 & 1.76 & 0.081 & -.1169069 & 1.959425 \\
\hline $\mathrm{x} 11$ & । & .0657763 & .4851746 & 0.14 & 0.892 & -.8976842 & 1.029237 \\
\hline$x 12$ & । & -.2443549 & .3825073 & -0.64 & 0.525 & -1.003939 & .5152289 \\
\hline$x 00$ & I & -.7724647 & .5002436 & -1.54 & 0.126 & -1.765849 & .2209198 \\
\hline$x 01$ & । & -.5865028 & .4665988 & -1.26 & 0.212 & -1.513076 & .3400699 \\
\hline$x 02$ & । & -.4535084 & .3622724 & -1.25 & 0.214 & -1.17291 & .2658929 \\
\hline tcat & I & & & & & & \\
\hline 20 & । & 1.097161 & .8265743 & 1.33 & 0.188 & -.5442519 & 2.738574 \\
\hline 30 & I & 1.128916 & .9035827 & 1.25 & 0.215 & -.6654205 & 2.923252 \\
\hline 40 & । & 2.144705 & .9854743 & 2.18 & 0.032 & .1877484 & 4.101662 \\
\hline 50 & I & 1.580282 & 1.016593 & 1.55 & 0.123 & -.4384693 & 3.599034 \\
\hline 60 & । & .2676869 & 1.042247 & 0.26 & 0.798 & -1.80201 & 2.337384 \\
\hline 70 & । & -.5614227 & 1.051046 & -0.53 & 0.595 & -2.648593 & 1.525747 \\
\hline 80 & । & .0450603 & 1.102749 & 0.04 & 0.967 & -2.144782 & 2.234902 \\
\hline wind & । & -.0564686 & .0244296 & -2.31 & 0.023 & -.1049809 & -.0079563 \\
\hline$d s l p$ & I & -.8442835 & .481462 & -1.75 & 0.083 & -1.800372 & .1118046 \\
\hline _cons & I & 3.065683 & 1.064349 & 2.88 & 0.005 & .9520963 & 5.17927 \\
\hline rho & I & .7023169 & & & & & \\
\hline Durbin-Watson & s & tatistic (or & iginal) & 0.911449 & & & \\
\hline
\end{tabular}




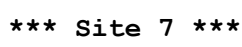

\begin{tabular}{|c|c|c|c|c|c|c|c|}
\hline \multicolumn{2}{|l|}{ Source } & SS & $d f$ & MS & & \multicolumn{2}{|c|}{ Number of obs $=$} \\
\hline & & & ---- & ---- & & F( 15, & 0.91 \\
\hline Model & । & 56.3140915 & 3.75 & 427276 & & Prob > F & $=0.5529$ \\
\hline Residual & । & 357.795153 & 4.11 & 258796 & & R-squared & $=0.1360$ \\
\hline---- & + & & & ---- & & Adj R-squared & $=-0.0130$ \\
\hline Total & । & 414.109244 & 102 & 989455 & & Root MSE & 2.028 \\
\hline$r d n$ & । & Coef. & Std. Err. & t & $P>|t|$ & [95\% Conf. & Interval] \\
\hline ventstatus & । & -1.485016 & .8983291 & -1.65 & 0.102 & -3.270543 & .30051 \\
\hline $\mathrm{x} 10$ & । & .0772333 & 1.089938 & 0.07 & 0.944 & -2.089137 & 2.243604 \\
\hline x11 & । & .2466539 & 1.024769 & 0.24 & 0.810 & -1.790185 & 2.283493 \\
\hline $\mathrm{x} 12$ & । & .2613335 & .8257862 & 0.32 & 0.752 & -1.380006 & 1.902673 \\
\hline$x 00$ & । & -.5816194 & .9500279 & -0.61 & 0.542 & -2.469903 & 1.306664 \\
\hline$x 01$ & । & -.0722488 & .9409131 & -0.08 & 0.939 & -1.942415 & 1.797918 \\
\hline $\mathrm{x} 02$ & । & .6442377 & .7928224 & 0.81 & 0.419 & -.9315827 & 2.220058 \\
\hline tcat & I & & & & & & \\
\hline 30 & I & .5248622 & 1.292371 & 0.41 & 0.686 & -2.043864 & 3.093589 \\
\hline 40 & । & .5122314 & 1.494994 & 0.34 & 0.733 & -2.459231 & 3.483693 \\
\hline 50 & । & .7652699 & 1.546164 & 0.49 & 0.622 & -2.307899 & 3.838439 \\
\hline 60 & I & .5443932 & 1.604259 & 0.34 & 0.735 & -2.644246 & 3.733032 \\
\hline 70 & । & -.375175 & 1.640545 & -0.23 & 0.820 & -3.635935 & 2.885585 \\
\hline 80 & I & -.4977372 & 1.734864 & -0.29 & 0.775 & -3.945967 & 2.950492 \\
\hline wind & । & -.0507486 & .0552689 & -0.92 & 0.361 & -.1606015 & .0591043 \\
\hline$d s l p$ & I & -.7275223 & 1.164204 & -0.62 & 0.534 & -3.041503 & 1.586458 \\
\hline _cons & । & 7.162923 & 1.75376 & 4.08 & 0.000 & 3.677136 & 10.64871 \\
\hline rho & I & .5869047 & & & & & \\
\hline Durbin-Watson & s & tatistic (or & iginal) & 0.892677 & & & \\
\hline
\end{tabular}


$\star \star \star$ Site $8 * \star \star$

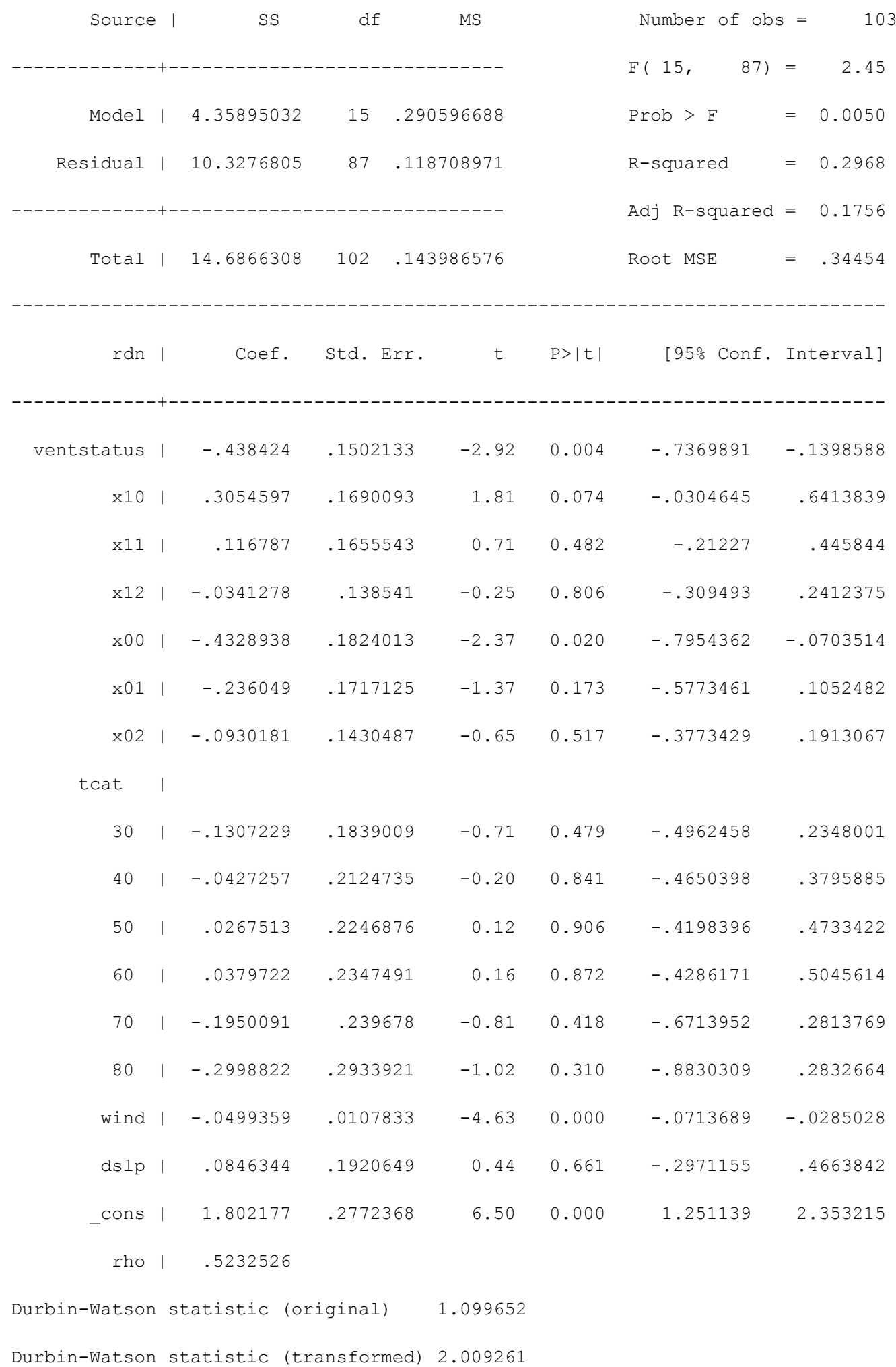


$\star \star \star$ Site $9 \star \star \star$

\begin{tabular}{|c|c|c|c|c|c|c|c|}
\hline Source & & SS & $d f$ & MS & & Number of obs & $=$ \\
\hline------------- & & ------------ & ---------1 & ------- & & $F(14, \quad 108)$ & 1.85 \\
\hline Model & | & 107.752453 & 14 & 6966038 & & Prob > F & 0.0405 \\
\hline Residual & | & 449.869306 & 108 & 6545654 & & R-squared & 0.1932 \\
\hline--------------- & + & ------------- & ---------- & ------- & & Adj R-squared & 0.0887 \\
\hline Total & | & 557.621759 & 122 & 7067016 & & Root MSE & $=2.0409$ \\
\hline rdn & | & Coef. & Std. Err. & $t$ & $P>|t|$ & [95\% Conf. & Interval] \\
\hline ventstatus & | & .4835696 & .6063086 & 0.80 & 0.427 & -.7182393 & 1.685378 \\
\hline x10 & | & -.5261888 & .7800892 & -0.67 & 0.501 & -2.072461 & 1.020083 \\
\hline x11 & | & .5227321 & .8056669 & 0.65 & 0.518 & -1.074239 & 2.119704 \\
\hline x12 & | & -.7479541 & .7472572 & -1.00 & 0.319 & -2.229147 & .7332393 \\
\hline $\mathrm{x} 00$ & | & .7772491 & .788375 & 0.99 & 0.326 & -.7854469 & 2.339945 \\
\hline x01 & | & .6413462 & .786316 & 0.82 & 0.417 & -.9172686 & 2.199961 \\
\hline $\mathrm{x} 02$ & | & 1.666883 & .7820234 & 2.13 & 0.035 & .1167767 & 3.216989 \\
\hline tcat & | & & & & & & \\
\hline 40 & | & -.0318267 & .9111117 & -0.03 & 0.972 & -1.837808 & 1.774155 \\
\hline 50 & | & .2516552 & .9475407 & 0.27 & 0.791 & -1.626535 & 2.129845 \\
\hline 60 & | & .0977703 & 1.036355 & 0.09 & 0.925 & -1.956465 & 2.152006 \\
\hline 70 & | & .6579056 & .9142214 & 0.72 & 0.473 & -1.15424 & 2.470051 \\
\hline 80 & | & -.3539508 & .936616 & -0.38 & 0.706 & -2.210486 & 1.502585 \\
\hline wind & | & -.2262339 & .0696411 & -3.25 & 0.002 & -.3642745 & -.0881932 \\
\hline $\mathrm{dslp}$ & | & -1.21101 & 1.127805 & -1.07 & 0.285 & -3.446516 & 1.024496 \\
\hline _cons & | & 9.384023 & 1.113242 & 8.43 & 0.000 & 7.177384 & 11.59066 \\
\hline rho & | & .1874386 & & & & & \\
\hline Durbin-Watson & & tatistic (or & (ginal) & 1.638812 & & & \\
\hline Durbin-Watson & & tatistic (tr & sformed) & 1.972057 & & & \\
\hline
\end{tabular}


$\star \star \star$ Site 11

\begin{tabular}{|c|c|c|c|c|c|c|c|}
\hline \multirow[t]{2}{*}{ Source } & 1 & SS & $d f$ & MS & \multicolumn{3}{|c|}{ Number of obs $=$} \\
\hline & & & & ---- & & F( 17, & 3.44 \\
\hline Model & । & 101.787404 & 5.9 & 5.98749436 & & Prob > F & $=0.0000$ \\
\hline Residual & । & 199.916128 & 115 & 1.73840112 & & R-squared & $=0.3374$ \\
\hline & & & & ----- & & Adj R-squared & $=0.2394$ \\
\hline Total & । & 301.703532 & 132 & 2.28563282 & \multicolumn{2}{|r|}{ Root MSE } & $=1.3185$ \\
\hline$r d n$ & I & Coef. & Std. Err. & t & $P>|t|$ & [95\% Conf. & Interval] \\
\hline ventstatus & I & .1370341 & .6194554 & 0.22 & 0.825 & -1.089988 & 1.364056 \\
\hline x10 & 1 & .721565 & .6019226 & 1.20 & 0.233 & -.4707278 & 1.913858 \\
\hline $\mathrm{x} 11$ & I & -.0793685 & .5339301 & -0.15 & 0.882 & -1.136981 & .9782442 \\
\hline $\mathrm{x} 12$ & 1 & -.2591398 & .4265817 & -0.61 & 0.545 & -1.104116 & .5858365 \\
\hline$x 00$ & । & -.29355 & .5447702 & -0.54 & 0.591 & -1.372635 & .7855349 \\
\hline$x 01$ & I & -.133897 & .4793793 & -0.28 & 0.781 & -1.083455 & .8156612 \\
\hline $\mathrm{x} 02$ & 1 & -.2573412 & .3728278 & -0.69 & 0.491 & -.9958412 & .4811589 \\
\hline tcat & 1 & & & & & & \\
\hline 10 & I & .9970493 & .7108173 & 1.40 & 0.163 & -.4109429 & 2.405042 \\
\hline 20 & I & .8967625 & .9086941 & 0.99 & 0.326 & -.9031855 & 2.696711 \\
\hline 30 & । & .3474427 & .9956599 & 0.35 & 0.728 & -1.624768 & 2.319653 \\
\hline 40 & I & .2702453 & 1.035556 & 0.26 & 0.795 & -1.780992 & 2.321483 \\
\hline 50 & 1 & -.0286586 & 1.170072 & -0.02 & 0.981 & -2.346347 & 2.28903 \\
\hline 60 & I & .6185027 & 1.278839 & 0.48 & 0.630 & -1.914632 & 3.151637 \\
\hline 70 & 1 & .449619 & 1.35639 & 0.33 & 0.741 & -2.237128 & 3.136366 \\
\hline 80 & 1 & .5590671 & 1.544087 & 0.36 & 0.718 & -2.499472 & 3.617606 \\
\hline wind & I & -.1185512 & .0279921 & -4.24 & 0.000 & -.1739982 & -.0631042 \\
\hline$d s l p$ & I & 1.188866 & .4879954 & 2.44 & 0.016 & .2222415 & 2.155491 \\
\hline _cons & I & 6.968142 & 2.604782 & 2.68 & 0.009 & 1.80857 & 12.12771 \\
\hline rho & | & 37899 & & & & & \\
\hline
\end{tabular}

Durbin-Watson statistic (original) 1.138243

Durbin-Watson statistic (transformed) 2.357592 
$\star \star \star$ Site 12

\begin{tabular}{|c|c|c|c|c|c|c|}
\hline Source & SS & $d f$ & MS & \multicolumn{2}{|c|}{ Number of obs $=$} & 105 \\
\hline & & & -------- & F( 15, & $=$ & 14.16 \\
\hline Model | & 309.598454 & 15 & 20.639897 & Prob > F & $=$ & 0.0000 \\
\hline Residual | & 129.727524 & 89 & 1.45761263 & R-squared & $=$ & 0.7047 \\
\hline-------+ & $1-3-2-3-1$ & $-\ldots$ & ----------- & Adj R-squared & $=$ & 0.6549 \\
\hline Total | & 439.325978 & 104 & 4.22428825 & Root MSE & $=$ & 1.2073 \\
\hline
\end{tabular}

rdn | Coef. Std. Err. t $\mathrm{P}>|\mathrm{t}| \quad$ [95\% Conf. Interval]

\begin{tabular}{|c|c|c|c|c|c|c|}
\hline ventstatus & -.3700238 & .3946104 & -0.94 & 0.351 & -1.154106 & .4140586 \\
\hline $\mathrm{x} 10$ & -.4229919 & .5194596 & -0.81 & 0.418 & -1.455147 & .6091632 \\
\hline x11 & -.0273701 & .514024 & -0.05 & 0.958 & -1.048725 & .9939846 \\
\hline $\mathrm{x} 12$ & .0313172 & .5069113 & 0.06 & 0.951 & -.9759048 & 1.038539 \\
\hline$x 00$ & -.6959352 & .5005455 & -1.39 & 0.168 & -1.690509 & .2986381 \\
\hline x01 & .5931803 & .5037459 & 1.18 & 0.242 & -.407752 & 1.594113 \\
\hline $\mathrm{x} 02$ & .8957873 & .5071699 & 1.77 & 0.081 & -.1119485 & 1.903523 \\
\hline tcat & I & & & & & \\
\hline 30 & -.4231729 & .7094728 & -0.60 & 0.552 & -1.83288 & .9865345 \\
\hline 40 & -1.259412 & .7288672 & -1.73 & 0.087 & -2.707656 & .1888316 \\
\hline 50 & -3.038483 & .7989124 & -3.80 & 0.000 & -4.625905 & -1.451062 \\
\hline 60 & -4.334887 & .7366525 & -5.88 & 0.000 & -5.7986 & -2.871174 \\
\hline 70 & -5.609515 & .7675125 & -7.31 & 0.000 & -7.134546 & -4.084485 \\
\hline 80 & -6.207991 & 1.099931 & -5.64 & 0.000 & -8.393531 & -4.022451 \\
\hline wind & -.1451795 & .0363442 & -3.99 & 0.000 & -.2173946 & -.0729643 \\
\hline dslp & -1.220193 & .6500353 & -1.88 & 0.064 & -2.511799 & .0714132 \\
\hline _cons & 8.838176 & .8034363 & 11.00 & 0.000 & 7.241765 & 10.43459 \\
\hline rho & .1846946 & & & & & \\
\hline Durbin-Watson & \multicolumn{2}{|c|}{ statistic (original) } & \multicolumn{4}{|l|}{1.658140} \\
\hline tson & statistic (t & $(t)$ & 990092 & & & \\
\hline
\end{tabular}




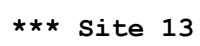

\begin{tabular}{|c|c|c|c|c|c|c|c|}
\hline \multirow[t]{2}{*}{ Source } & & SS & $d f$ & MS & \multicolumn{3}{|c|}{ Number of obs $=$} \\
\hline & & & & ----- & & F( 15, & 3.11 \\
\hline Model & । & 110.91306 & 7.3 & 420397 & & Prob > F & $=0.0043$ \\
\hline Residual & । & 68.9709395 & $2.3^{-}$ & 830826 & & R-squared & $=0.6166$ \\
\hline & & & & ----- & & Adj R-squared & $=0.4183$ \\
\hline Total & । & 179.883999 & 44 & 882727 & & Root MSE & $=1.5422$ \\
\hline$r d n$ & I & Coef. & Std. Err. & t & $P>|t|$ & [95\% Conf. & Interval] \\
\hline ventstatus & I & -.874031 & 1.082741 & -0.81 & 0.426 & -3.088485 & 1.340423 \\
\hline x10 & 1 & 1.925765 & 1.090091 & 1.77 & 0.088 & -.3037215 & 4.155252 \\
\hline x11 & । & .9191585 & 1.078731 & 0.85 & 0.401 & -1.287094 & 3.125411 \\
\hline $\mathrm{x} 12$ & 1 & -.0605064 & .9438697 & -0.06 & 0.949 & -1.990937 & 1.869924 \\
\hline $\mathrm{x} 00$ & । & .2834381 & 1.241559 & 0.23 & 0.821 & -2.255834 & 2.822711 \\
\hline $\mathrm{x} 01$ & I & .7114756 & 1.322989 & 0.54 & 0.595 & -1.994341 & 3.417292 \\
\hline $\mathrm{x} 02$ & I & -.3720996 & 1.160656 & -0.32 & 0.751 & -2.745907 & 2.001708 \\
\hline tcat & 1 & & & & & & \\
\hline 30 & I & .2406948 & 1.512067 & 0.16 & 0.875 & -2.851829 & 3.333219 \\
\hline 40 & I & .0513171 & 2.255258 & 0.02 & 0.982 & -4.561203 & 4.663837 \\
\hline 50 & । & 2.564335 & 2.222256 & 1.15 & 0.258 & -1.980689 & 7.109359 \\
\hline 60 & I & 3.954348 & 1.711261 & 2.31 & 0.028 & .4544267 & 7.454269 \\
\hline 70 & 1 & 3.428355 & 1.793364 & 1.91 & 0.066 & -.2394863 & 7.096196 \\
\hline 80 & I & 3.210023 & 2.138554 & 1.50 & 0.144 & -1.163811 & 7.583857 \\
\hline wind & 1 & -.0401177 & .0782429 & -0.51 & 0.612 & -.2001424 & .1199071 \\
\hline $\mathrm{dslp}$ & 1 & -1.09683 & 1.985612 & -0.55 & 0.585 & -5.157862 & 2.964202 \\
\hline - cons & I & 7.082497 & 1.999408 & 3.54 & 0.001 & 2.993248 & 11.17175 \\
\hline rho & I & .4183387 & & & & & \\
\hline Durbin-Watson & & tatistic (or & iginal) & 1.007184 & & & \\
\hline
\end{tabular}


$\star \star \star$ Site $14 \star \star \star$

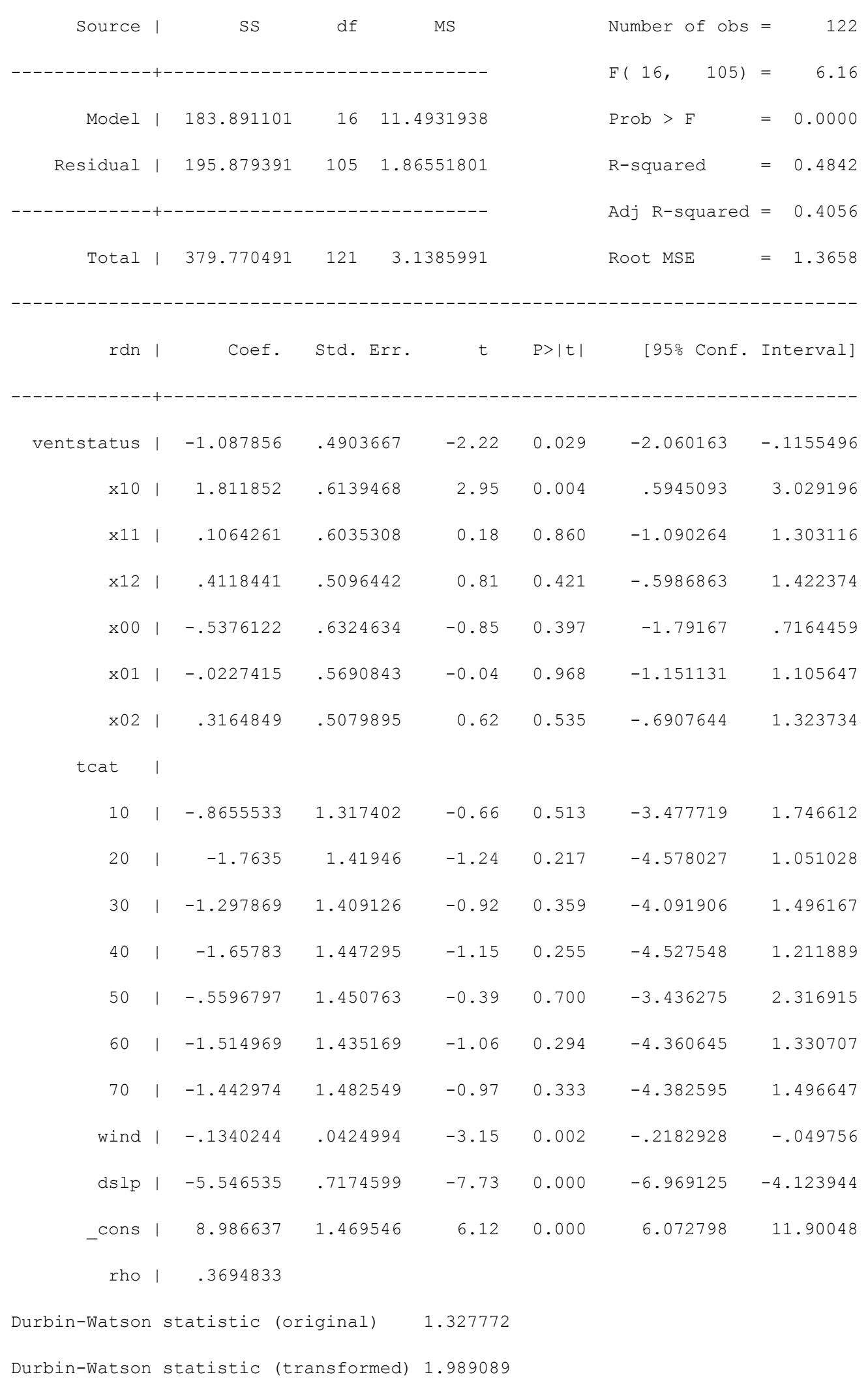


$\star \star \star$ Site 15

\begin{tabular}{|c|c|c|c|c|c|c|}
\hline Source & SS & $d f$ & MS & \multicolumn{2}{|c|}{ Number of obs $=$} & 127 \\
\hline-1 & & & --------- & $F(16$, & $=$ & 5.21 \\
\hline Model | & 18.8669966 & 16 & 1.17918729 & Prob > F & $=$ & 0.0000 \\
\hline Residual | & 24.8807997 & 110 & .226189088 & R-squared & $=$ & 0.4313 \\
\hline--1 & & & - --------- & Adj R-squared & $=$ & 0.3485 \\
\hline Total | & 43.7477963 & 126 & .347204733 & Root MSE & $=$ & .47559 \\
\hline
\end{tabular}

rdn $\mid$ Coef. Std. Err. $\quad t \quad P>|t| \quad$ [95\% Conf. Interval]

\begin{tabular}{|c|c|c|c|c|c|c|c|}
\hline ventstatus & I & -.2708626 & .1839942 & -1.47 & 0.144 & -.6354959 & .0937707 \\
\hline x10 & I & .4243495 & .1999102 & 2.12 & 0.036 & .0281744 & .8205246 \\
\hline$x 11$ & I & .3756436 & .1943563 & 1.93 & 0.056 & -.0095249 & .7608121 \\
\hline$x 12$ & I & .2048304 & .1799457 & 1.14 & 0.257 & -.1517798 & .5614406 \\
\hline$x 00$ & I & -.1933349 & .1994445 & -0.97 & 0.334 & -.5885872 & .2019174 \\
\hline$x 01$ & I & -.0913094 & .1959191 & -0.47 & 0.642 & -.479575 & .2969563 \\
\hline$x 02$ & I & -.094257 & .168603 & -0.56 & 0.577 & -.4283886 & .2398746 \\
\hline tcat & I & & & & & & \\
\hline 10 & । & -.1132027 & .256943 & -0.44 & 0.660 & -.6224035 & .395998 \\
\hline 20 & I & -.0432021 & .2843118 & -0.15 & 0.880 & -.6066414 & .5202373 \\
\hline 30 & I & -.020893 & .2902818 & -0.07 & 0.943 & -.5961634 & .5543773 \\
\hline 40 & । & .0234226 & .3017533 & 0.08 & 0.938 & -.5745815 & .6214268 \\
\hline 50 & । & .3431473 & .3620205 & 0.95 & 0.345 & -.3742922 & 1.060587 \\
\hline 60 & । & .7279952 & .5658134 & 1.29 & 0.201 & -.3933142 & 1.849305 \\
\hline 70 & । & .6442359 & .4764451 & 1.35 & 0.179 & -.2999664 & 1.588438 \\
\hline wind & I & -.0124571 & .0147154 & -0.85 & 0.399 & -.0416196 & .0167054 \\
\hline dslp & I & -.7636364 & .1850575 & -4.13 & 0.000 & -1.130377 & -.3968958 \\
\hline _cons & I & 3.872489 & .3363341 & 11.51 & 0.000 & 3.205953 & 4.539024 \\
\hline rho & I & .46665 & & & & & \\
\hline
\end{tabular}

Durbin-Watson statistic (original) 1.201595

Durbin-Watson statistic (transformed) 2.265225 
$\star \star \star$ Site $16 \star \star \star$

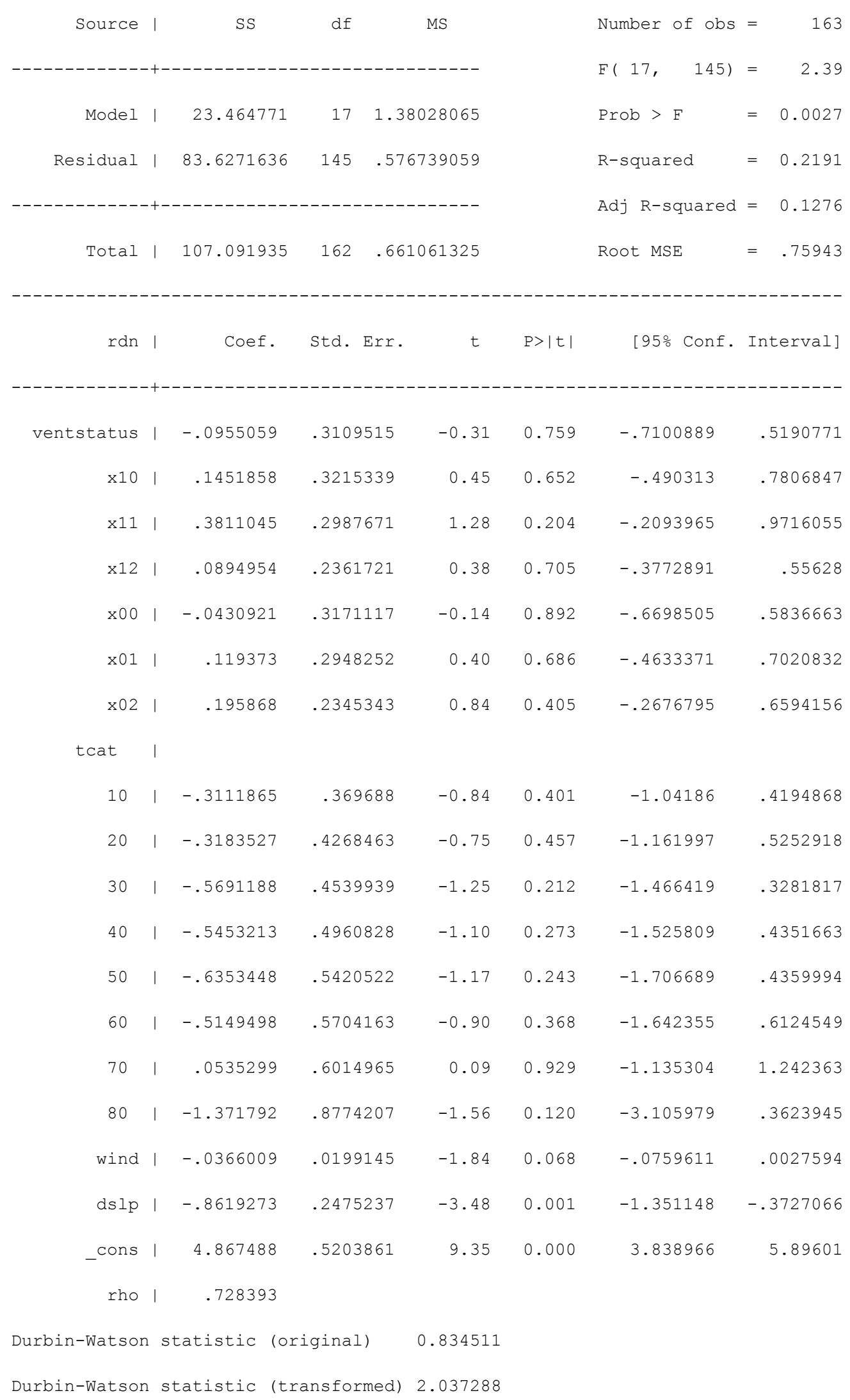


$\star \star \star$ Site 17

\begin{tabular}{|c|c|c|c|c|c|c|c|}
\hline \multicolumn{2}{|c|}{ Source } & SS & $d f$ & MS & \multicolumn{3}{|c|}{ Number of obs $=$} \\
\hline & & & & ---- & & F( 17, & 2.98 \\
\hline Model & । & 354.101468 & 20. & 20.8294981 & & Prob > F & $=0.0012$ \\
\hline Residual & । & 371.033516 & 7.0 & 7.00063237 & & R-squared & $=0.4883$ \\
\hline & + & & & ----- & & Adj R-squared & $=0.3242$ \\
\hline Total & । & 725.134983 & 10 & 10.3590712 & & Root MSE & $=2.6459$ \\
\hline$r d n$ & । & Coef. & Std. Err. & t & $P>|t|$ & [95\% Conf. & Interval] \\
\hline ventstatus & । & -4.115688 & 1.771817 & -2.32 & 0.024 & -7.669504 & -.5618721 \\
\hline x10 & । & 3.779619 & 1.950996 & 1.94 & 0.058 & -.1335839 & 7.692822 \\
\hline $\mathrm{x} 11$ & । & .6813519 & 1.905605 & 0.36 & 0.722 & -3.140808 & 4.503512 \\
\hline$x 12$ & । & -.488019 & 1.429576 & -0.34 & 0.734 & -3.355386 & 2.379348 \\
\hline$x 00$ & । & -3.578092 & 1.830559 & -1.95 & 0.056 & -7.249729 & .093544 \\
\hline$x 01$ & । & -.7252273 & 1.752795 & -0.41 & 0.681 & -4.240888 & 2.790434 \\
\hline$x 02$ & । & -1.557876 & 1.362284 & -1.14 & 0.258 & -4.290272 & 1.17452 \\
\hline tcat & I & & & & & & \\
\hline 10 & । & -.1756462 & 2.605026 & -0.07 & 0.946 & -5.400666 & 5.049374 \\
\hline 20 & । & -2.440253 & 3.633643 & -0.67 & 0.505 & -9.728418 & 4.847912 \\
\hline 30 & । & -2.364531 & 3.45424 & -0.68 & 0.497 & -9.29286 & 4.563798 \\
\hline 40 & । & -3.952279 & 3.63728 & -1.09 & 0.282 & -11.24774 & 3.34318 \\
\hline 50 & । & -2.92966 & 3.507394 & -0.84 & 0.407 & -9.964601 & 4.105281 \\
\hline 60 & । & -4.49327 & 3.554708 & -1.26 & 0.212 & -11.62311 & 2.636571 \\
\hline 70 & । & -5.438244 & 3.634429 & -1.50 & 0.141 & -12.72799 & 1.851498 \\
\hline 80 & । & -6.728075 & 3.833949 & -1.75 & 0.085 & -14.418 & .9618536 \\
\hline wind & I & .0614517 & .0971497 & 0.63 & 0.530 & -.1334059 & .2563093 \\
\hline$d s l p$ & I & -10.21603 & 2.19834 & -4.65 & 0.000 & -14.62534 & -5.806717 \\
\hline _cons & । & 14.47422 & 3.744966 & 3.86 & 0.000 & 6.962767 & 21.98567 \\
\hline rho & । & .6909045 & & & & & \\
\hline
\end{tabular}

Durbin-Watson statistic (original) 1.183874

Durbin-Watson statistic (transformed) 2.201835 
$\star \star \star$ Site 18

\begin{tabular}{|c|c|c|c|c|c|c|c|}
\hline Source & 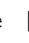 & SS & $d f$ & MS & \multicolumn{3}{|c|}{ Number of obs $=$} \\
\hline & & & & ---- & & E ( 17, & 24.60 \\
\hline Model & । & 299.528819 & 17. & 17.6193423 & & Prob > F & $=0.0000$ \\
\hline Residual & I & 115.298086 & 161 & .716137183 & & R-squared & $=0.7221$ \\
\hline & & & & ---- & & Adj R-squared & $=0.6927$ \\
\hline Total & 1 & 414.826906 & 178 & 2.33048823 & \multicolumn{2}{|r|}{ Root MSE } & $=.84625$ \\
\hline rdn & I & Coef. & Std. Err. & t & $P>|t|$ & [95\% Conf. & Interval] \\
\hline ventstatus & 1 & -2.234892 & .2489254 & -8.98 & 0.000 & -2.726472 & -1.743312 \\
\hline x10 & 1 & 1.855643 & .3106266 & 5.97 & 0.000 & 1.242215 & 2.469071 \\
\hline $\mathrm{x} 11$ & I & .203703 & .3057921 & 0.67 & 0.506 & -.4001777 & .8075837 \\
\hline $\mathrm{x} 12$ & 1 & .3515174 & .2612523 & 1.35 & 0.180 & -.1644057 & .8674405 \\
\hline$x 00$ & 1 & -2.485869 & .3011279 & -8.26 & 0.000 & -3.080539 & -1.8912 \\
\hline $\mathrm{x} 01$ & I & -.7608005 & .2952108 & -2.58 & 0.011 & -1.343785 & -.1778158 \\
\hline $\mathrm{x} 02$ & 1 & -.1286471 & .2650407 & -0.49 & 0.628 & -.6520517 & .3947575 \\
\hline tcat & I & & & & & & \\
\hline 10 & I & .0825952 & .3673263 & 0.22 & 0.822 & -.6428038 & .8079942 \\
\hline 20 & I & -.243839 & .398173 & -0.61 & 0.541 & -1.030154 & .5424763 \\
\hline 30 & I & -.1420174 & .4135021 & -0.34 & 0.732 & -.9586047 & .6745698 \\
\hline 40 & I & -.6883413 & .4452216 & -1.55 & 0.124 & -1.567568 & .1908859 \\
\hline 50 & I & -1.933531 & .4803782 & -4.03 & 0.000 & -2.882186 & -.984876 \\
\hline 60 & I & -3.184674 & .4619553 & -6.89 & 0.000 & -4.096947 & -2.272401 \\
\hline 70 & I & -4.154298 & .4656726 & -8.92 & 0.000 & -5.073912 & -3.234684 \\
\hline 80 & I & -5.309863 & .6075477 & -8.74 & 0.000 & -6.509653 & -4.110073 \\
\hline wind & I & -.0790026 & .0200825 & -3.93 & 0.000 & -.1186617 & -.0393436 \\
\hline$d s l p$ & I & -.9510474 & .3204659 & -2.97 & 0.003 & -1.583906 & -.3181888 \\
\hline _cons & I & 8.870934 & .4458688 & 19.90 & 0.000 & 7.990429 & 9.751439 \\
\hline rho & 1 & 38295 & & & & & \\
\hline
\end{tabular}

Durbin-Watson statistic (original) 1.281556

Durbin-Watson statistic (transformed) 1.984302 


$$
\text { A-21 }
$$





\section{APPENDIX B. TIME SERIES PLOTS}

Plots on the following pages show 8-hour radon and fan operation data for each site, along with the average radon level associated with each fan on/off period. Note that no screening for transition periods has been applied to the period averages here. Also note that the plots are individually scaled for radon for each site. 



\section{Site 1}

Radon level ( $\mathrm{pCi} / \mathrm{L})$

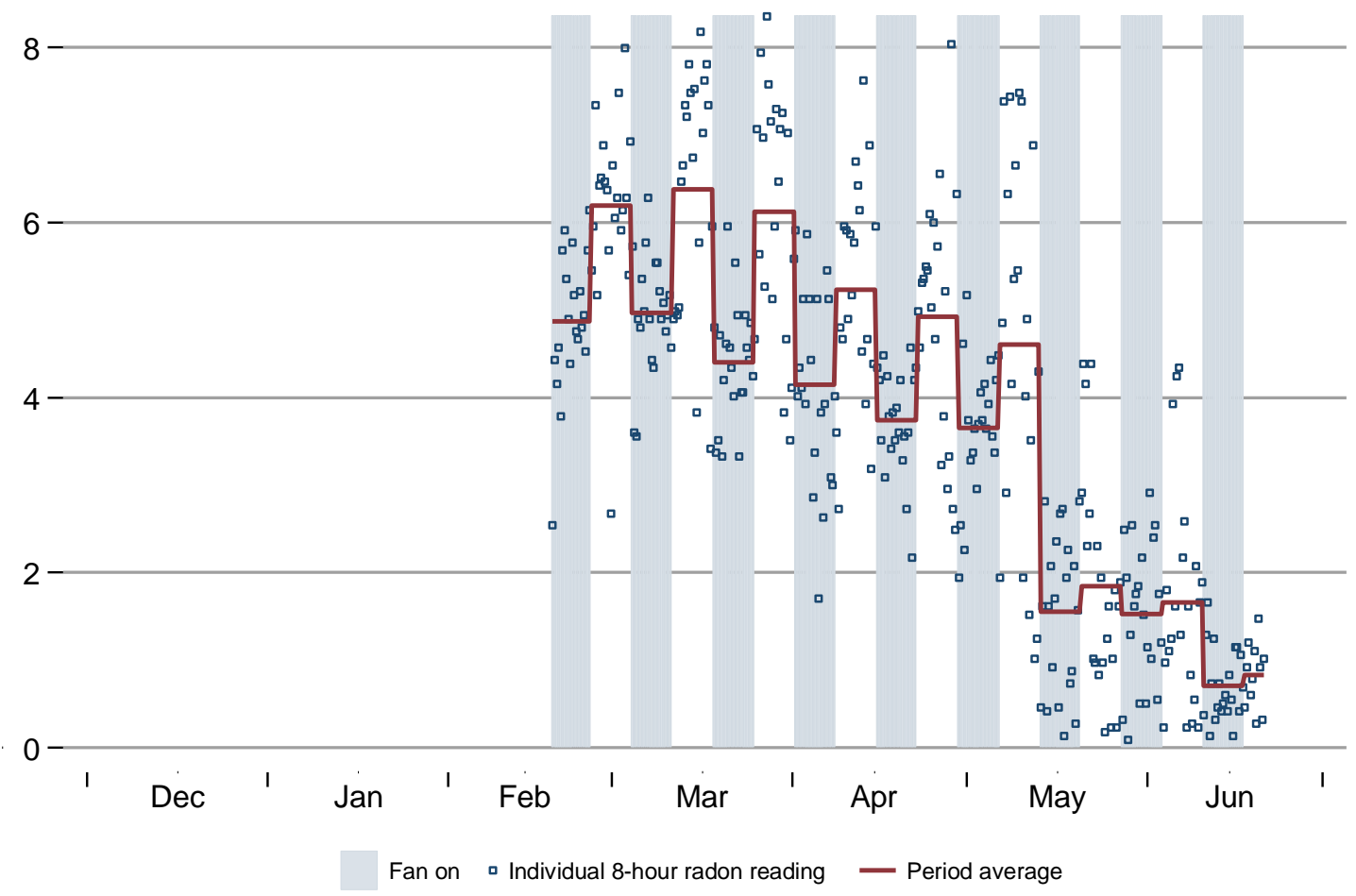

\section{Site 2}

Radon level ( $p C i / L)$

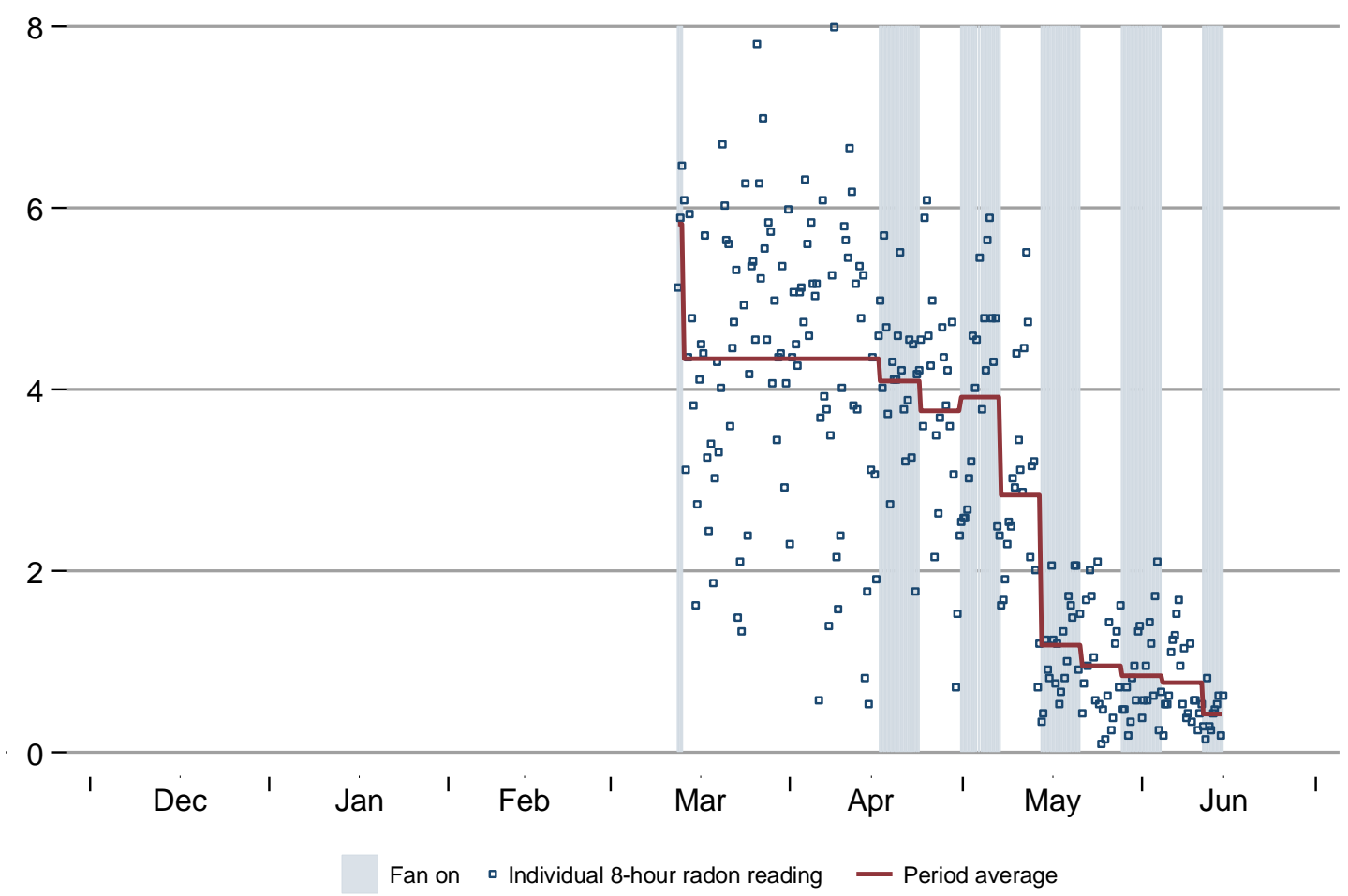




\section{Site 3}

Radon level ( $p \mathrm{Ci} / \mathrm{L}$ )

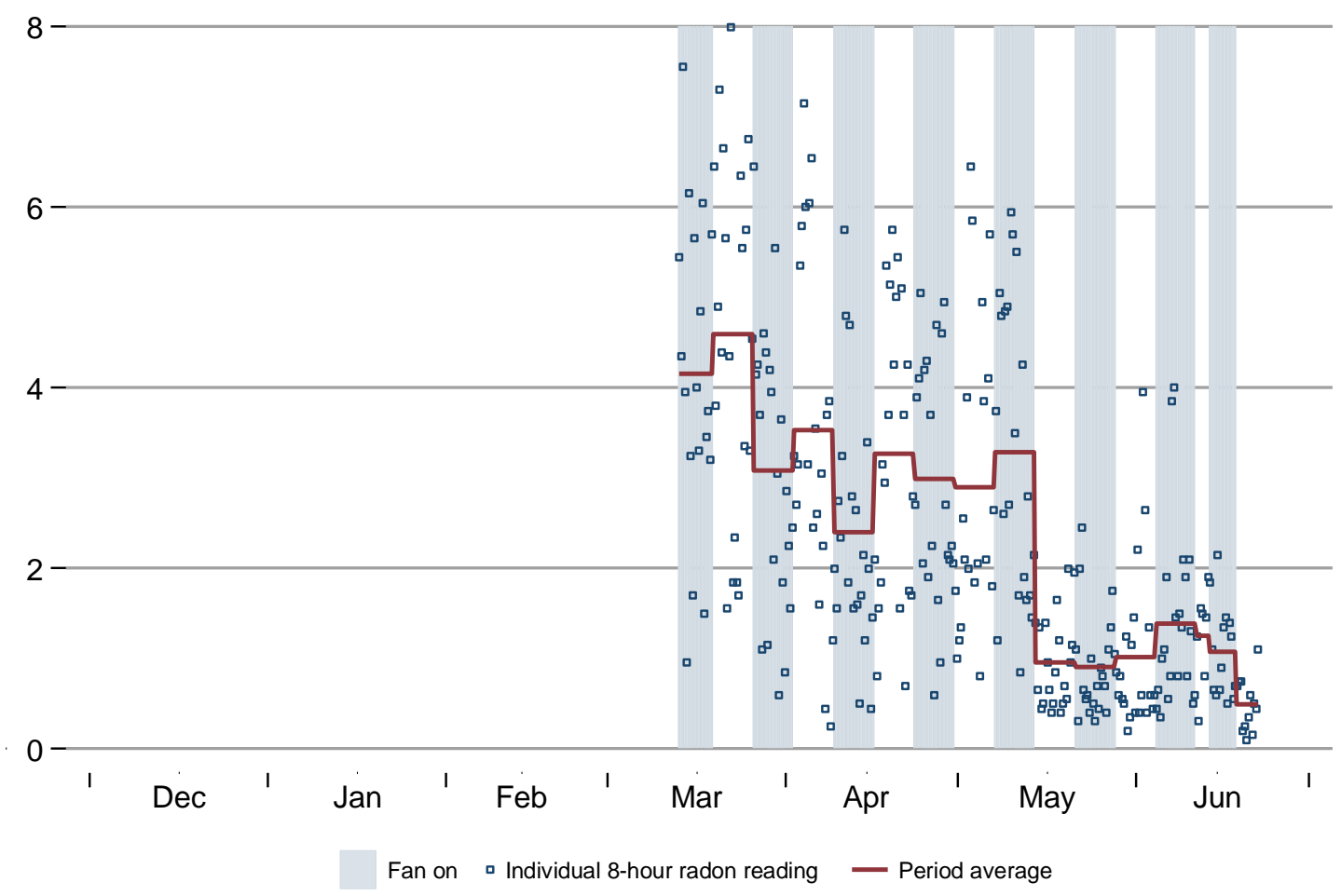

Site 4

Radon level ( $\mathrm{pCi} / \mathrm{L})$

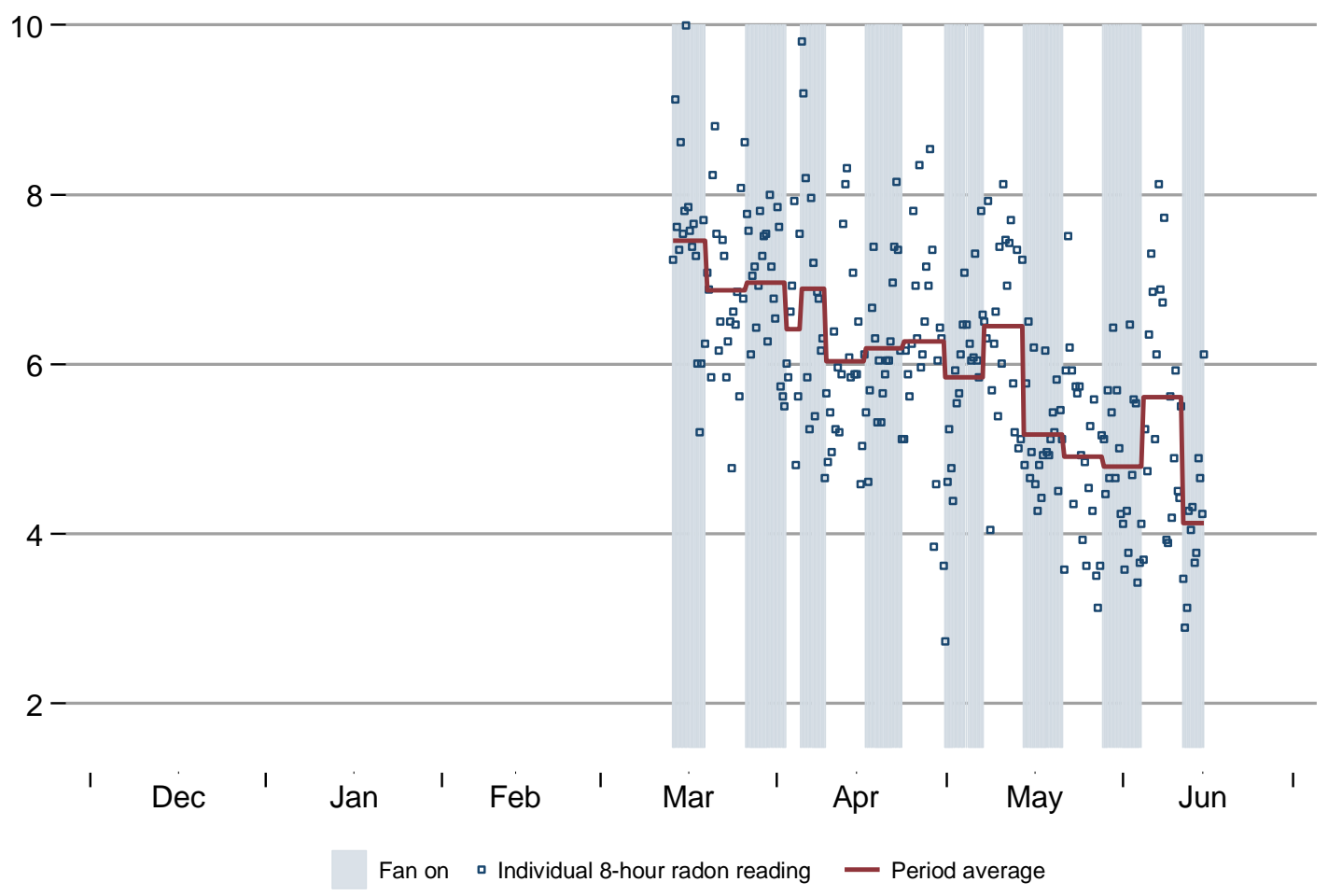




\section{Site 5}

Radon level ( $p C i / L)$

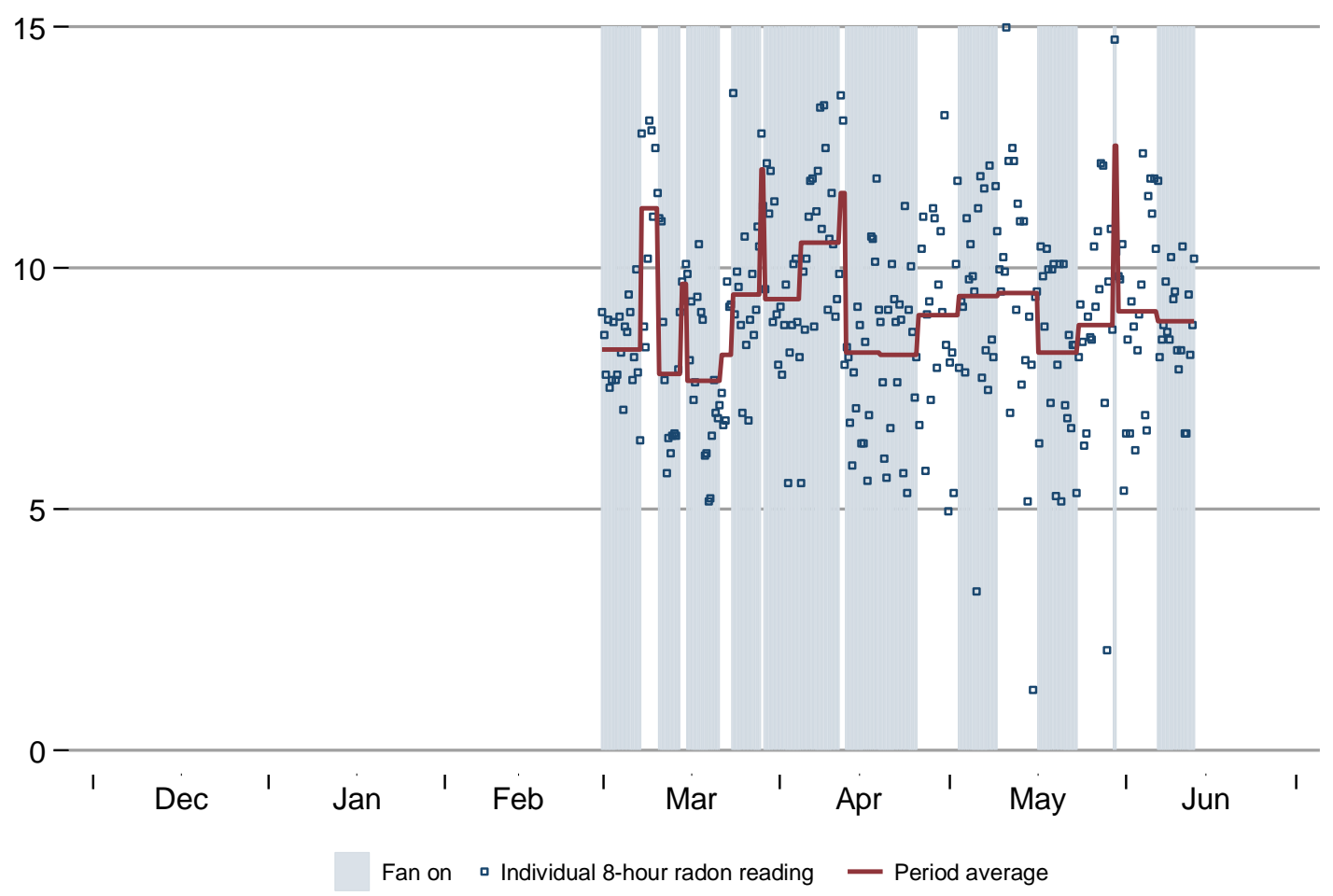

\section{Site 6}

Radon level ( $p \mathrm{Ci} / \mathrm{L})$

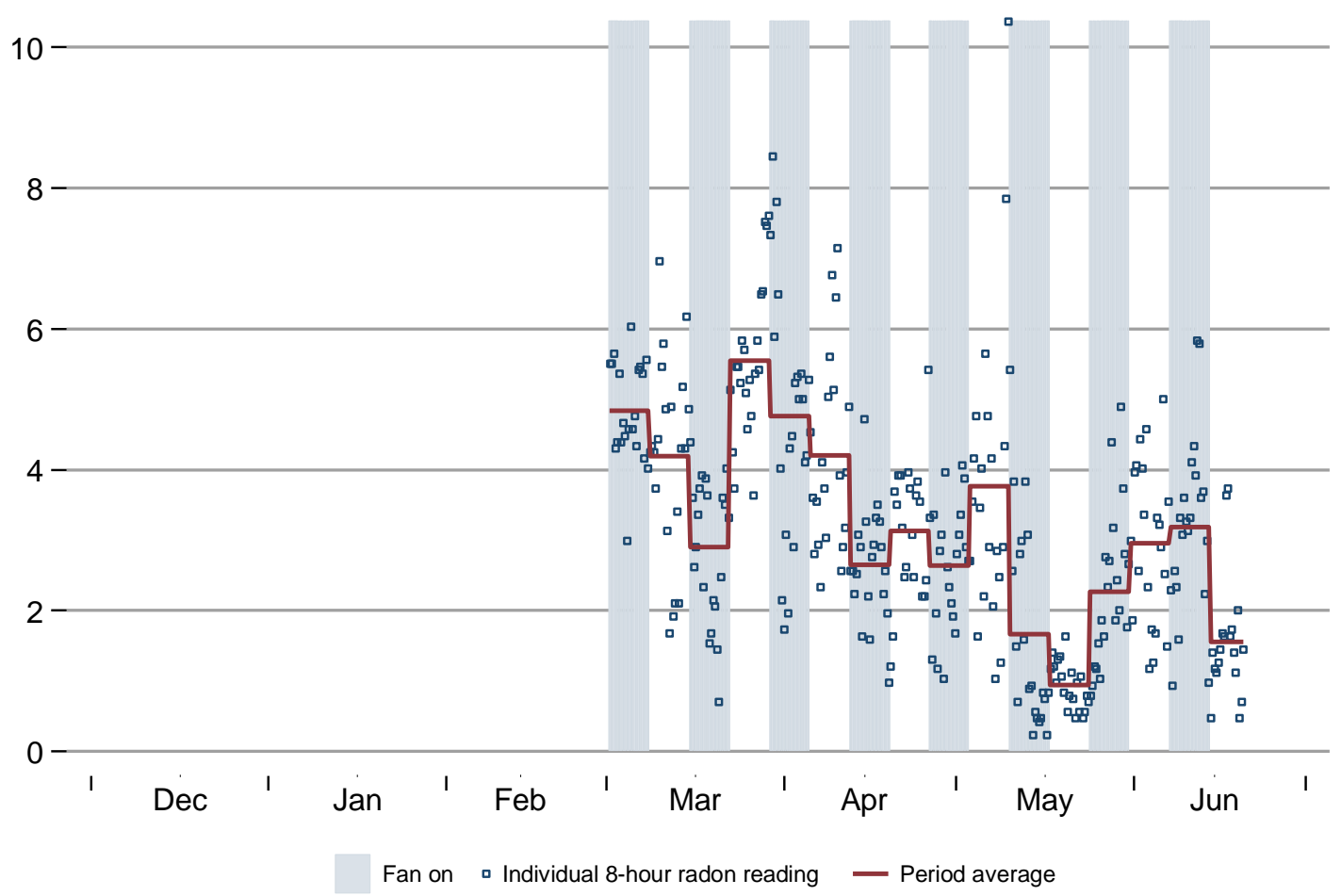


Site 9

Radon level ( $p C i / L)$

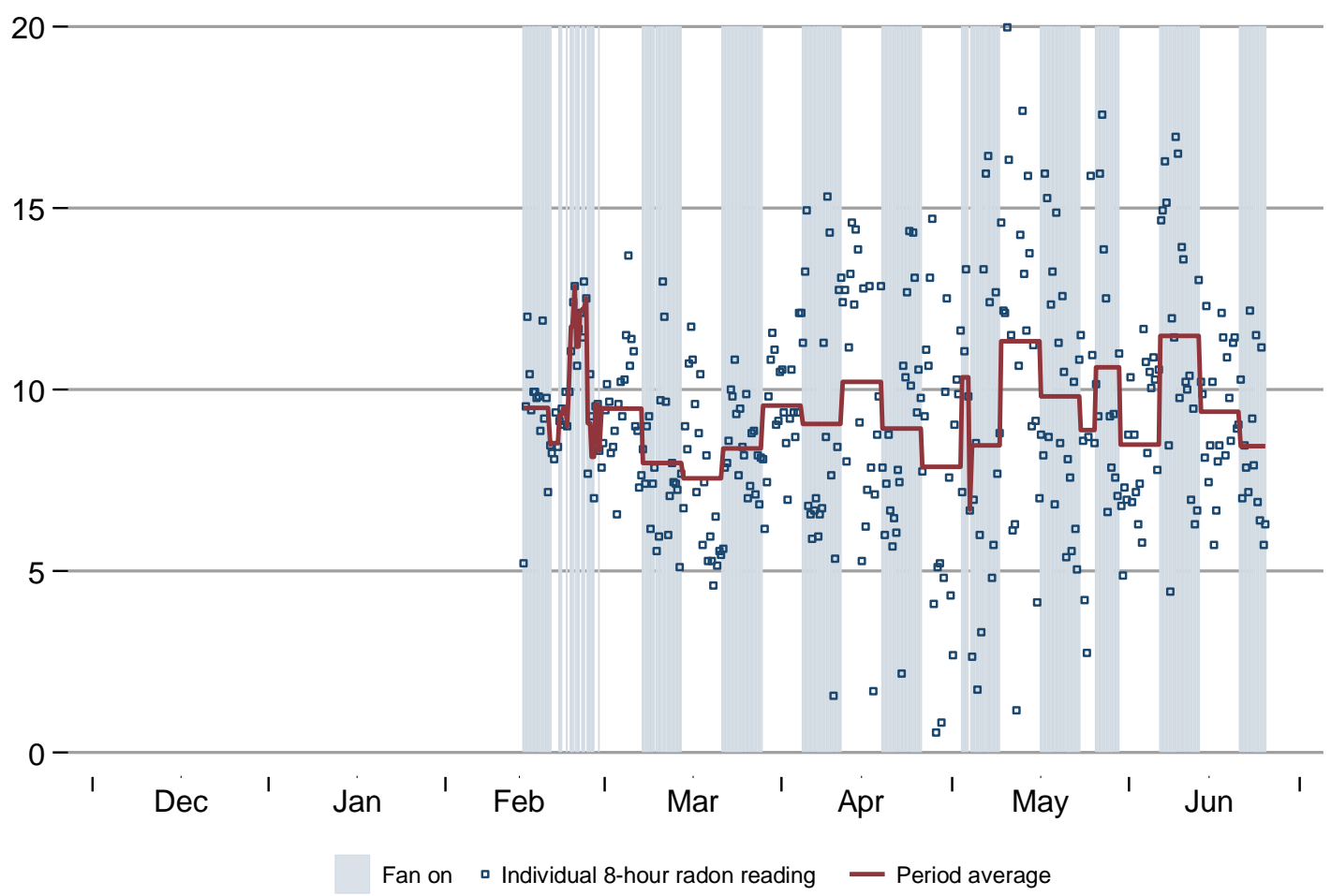

\section{Site 10}

Radon level (pCi/L)

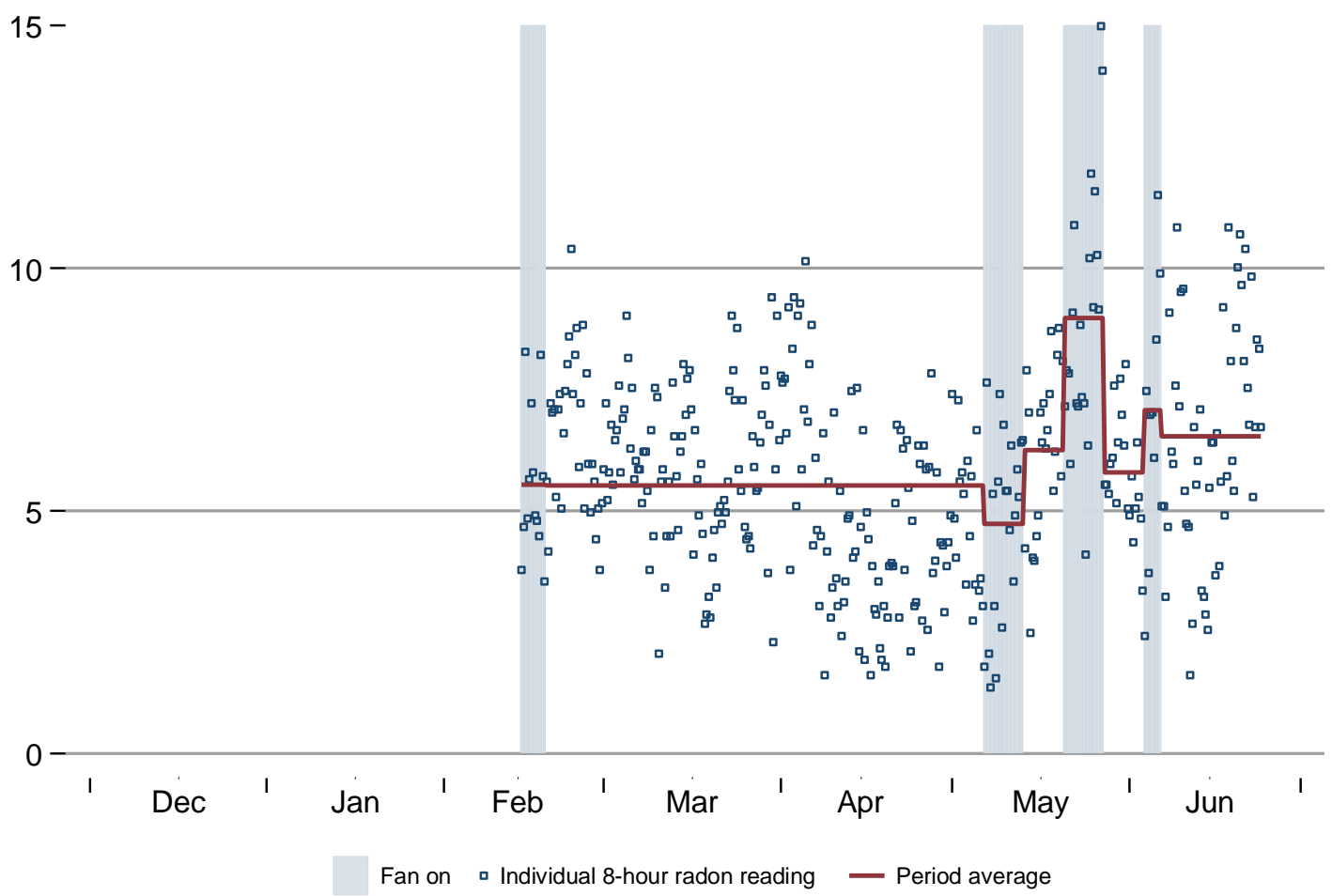


Site 11

Radon level ( $\mathrm{pCi} / \mathrm{L})$

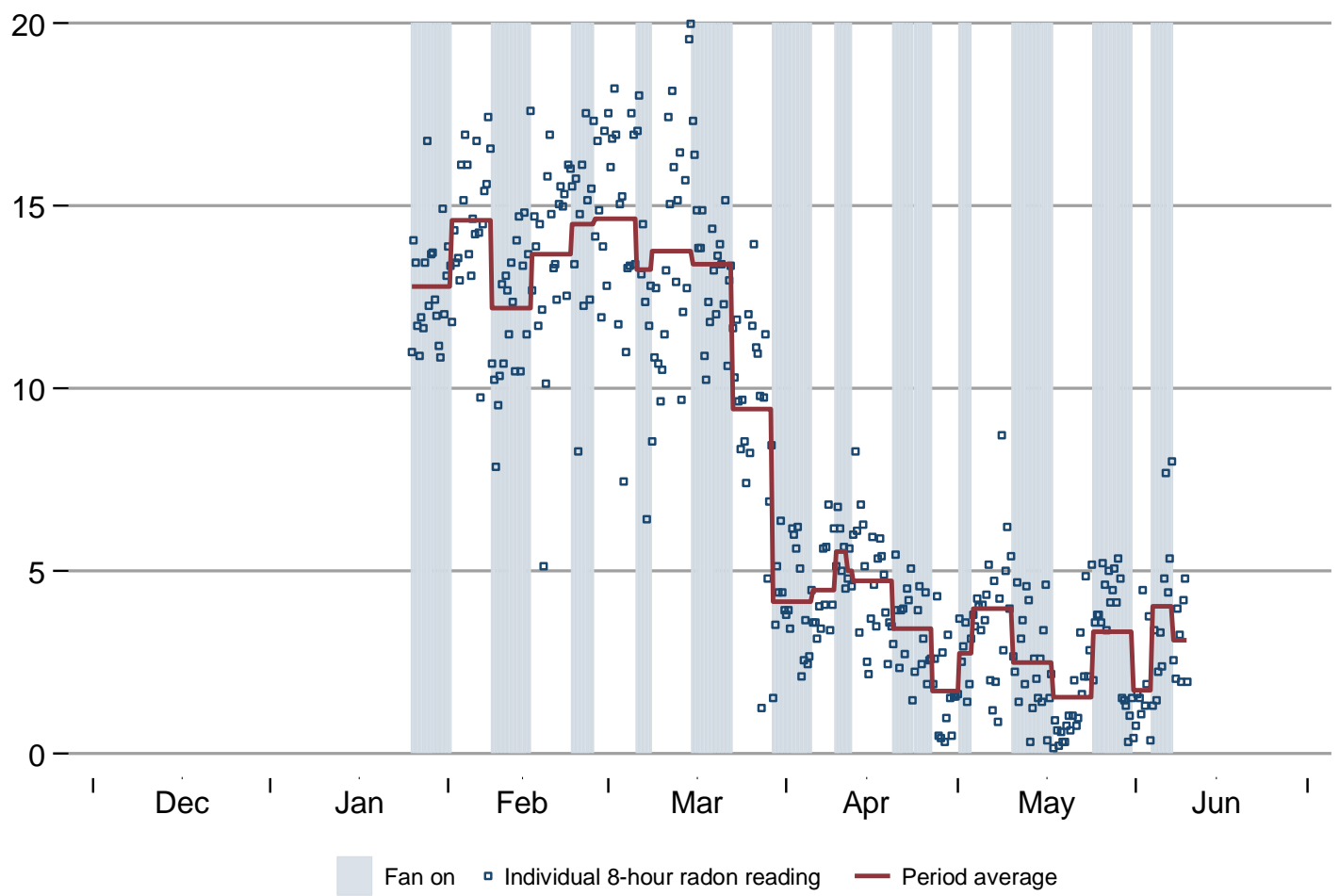

Site 12

Radon level (pCi/L)

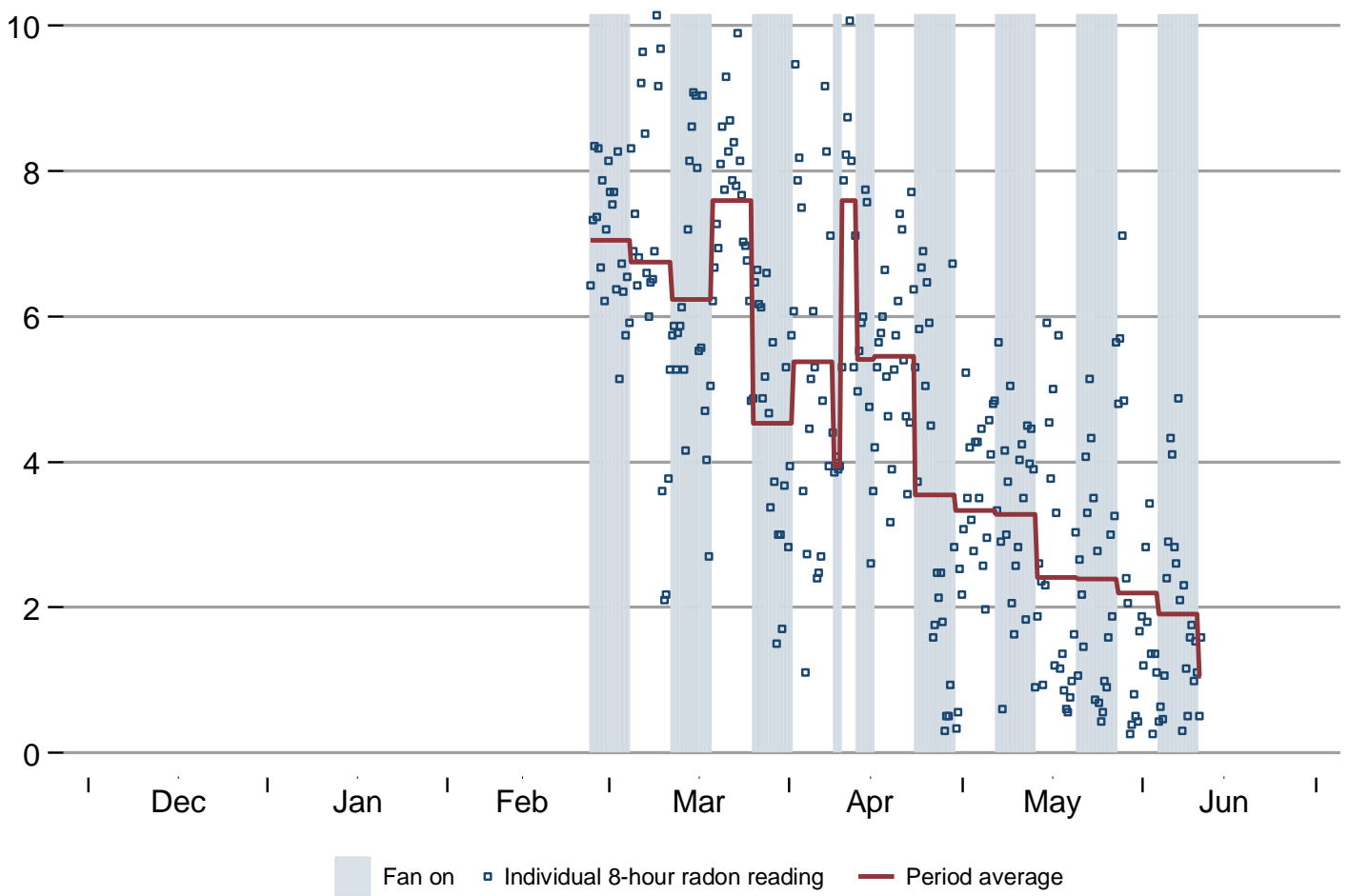


Site 13

Radon level (pCi/L)

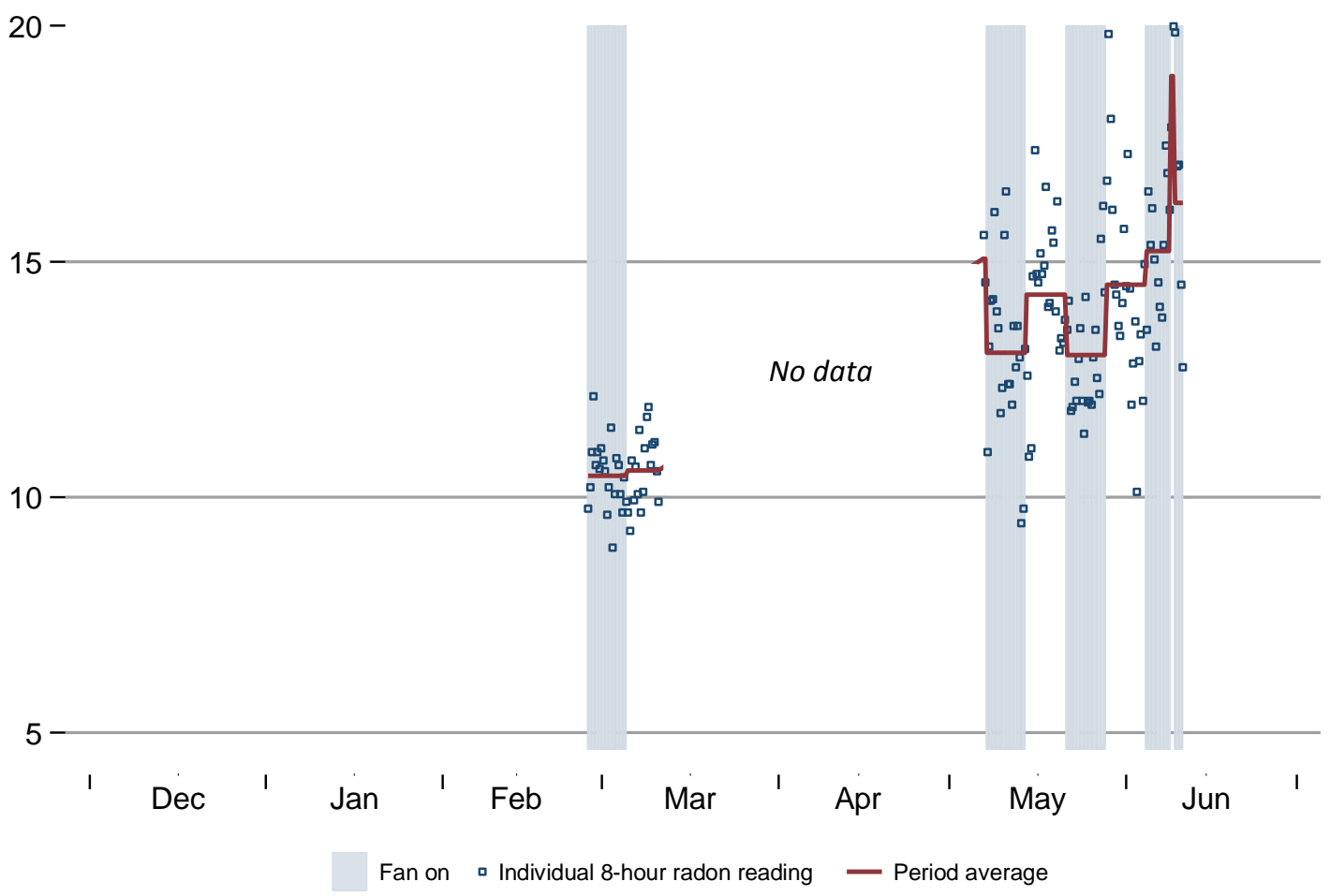

Site 14

Radon level ( $p \mathrm{pi} / \mathrm{L}$ )

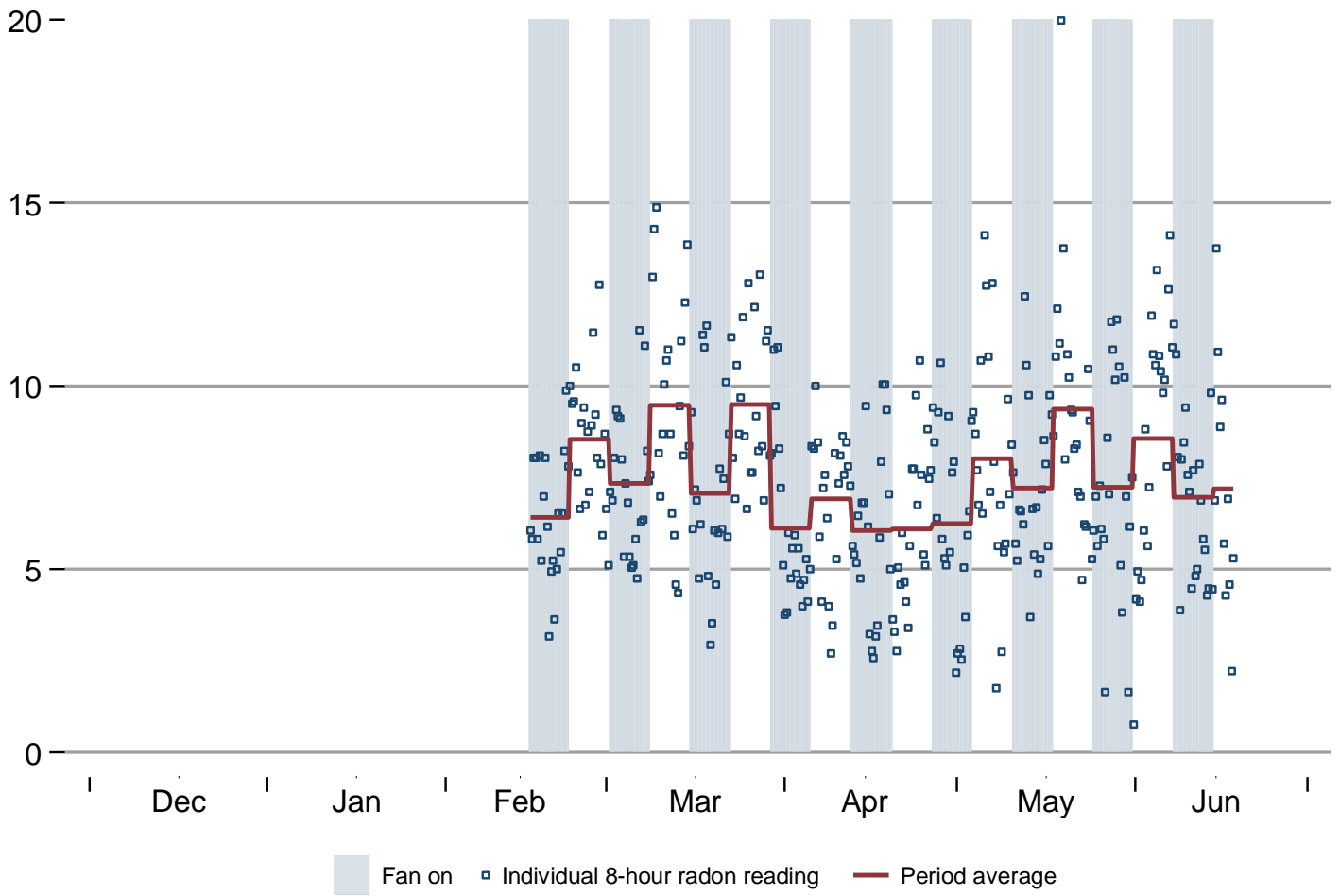




\section{Site 15}

Radon level (pCi/L)

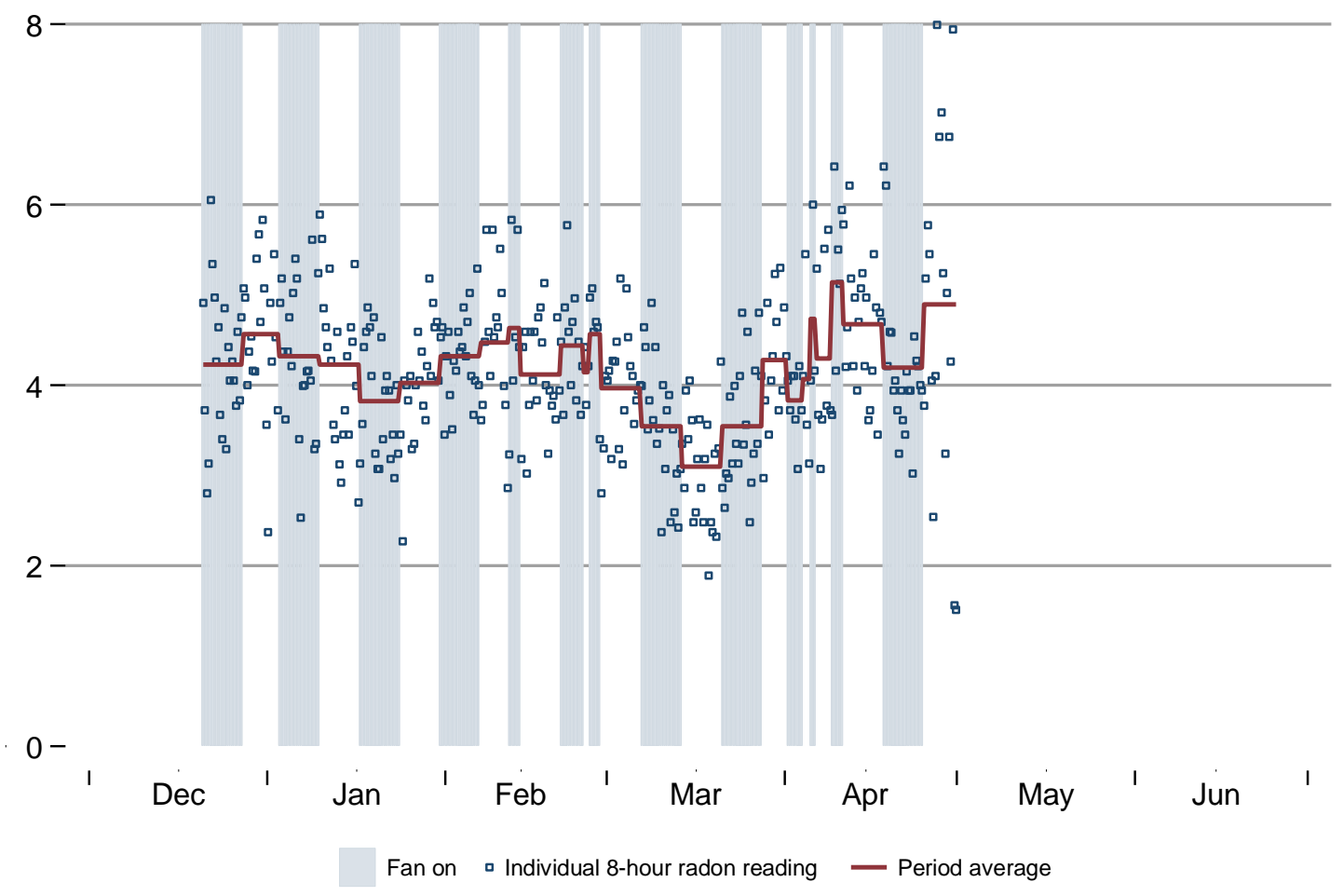

Site 16

Radon level ( $p C i / L)$

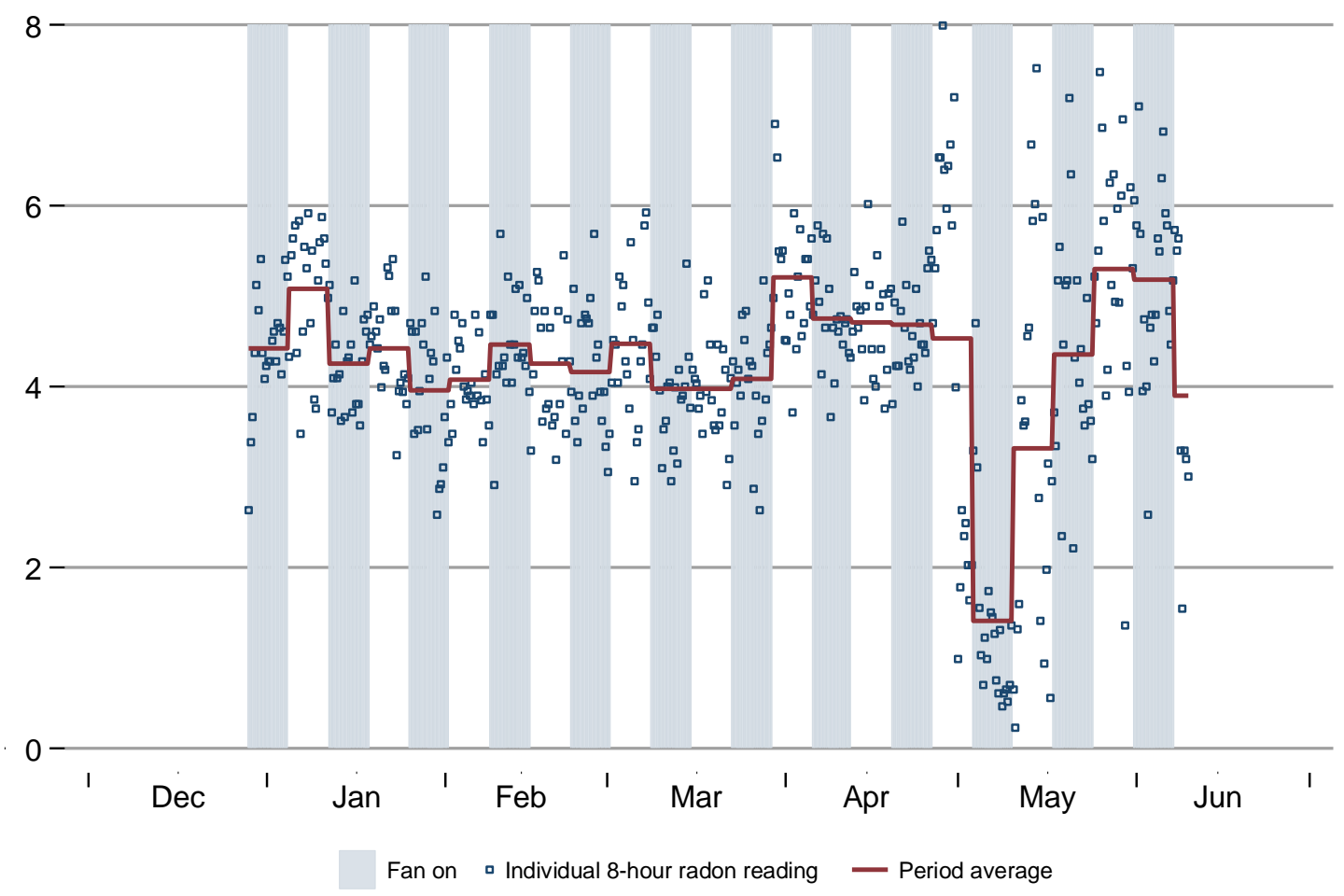


Site 17

Radon level (pCi/L)

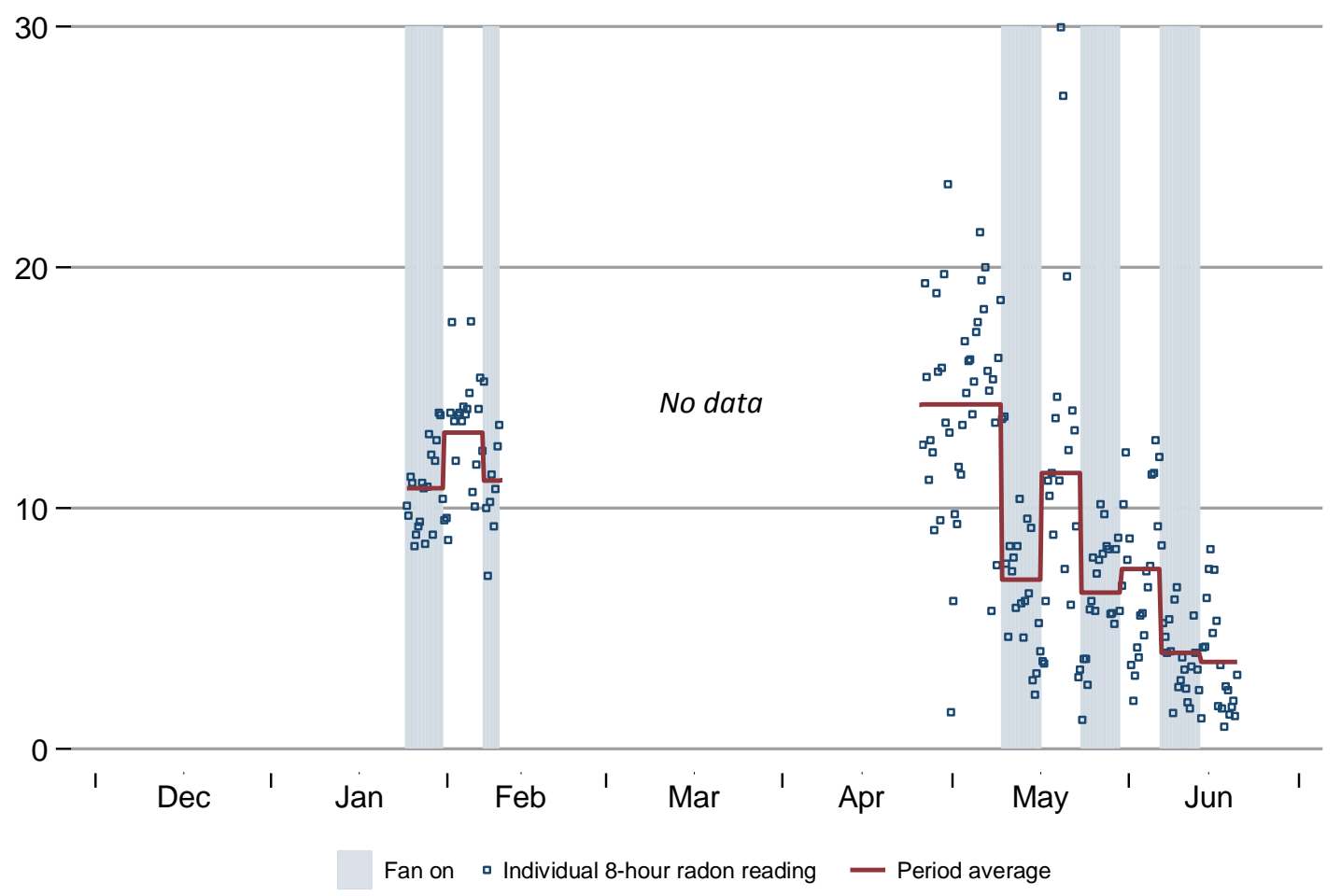

\section{Site 18}

Radon level ( $p \mathrm{Ci} / \mathrm{L}$ )

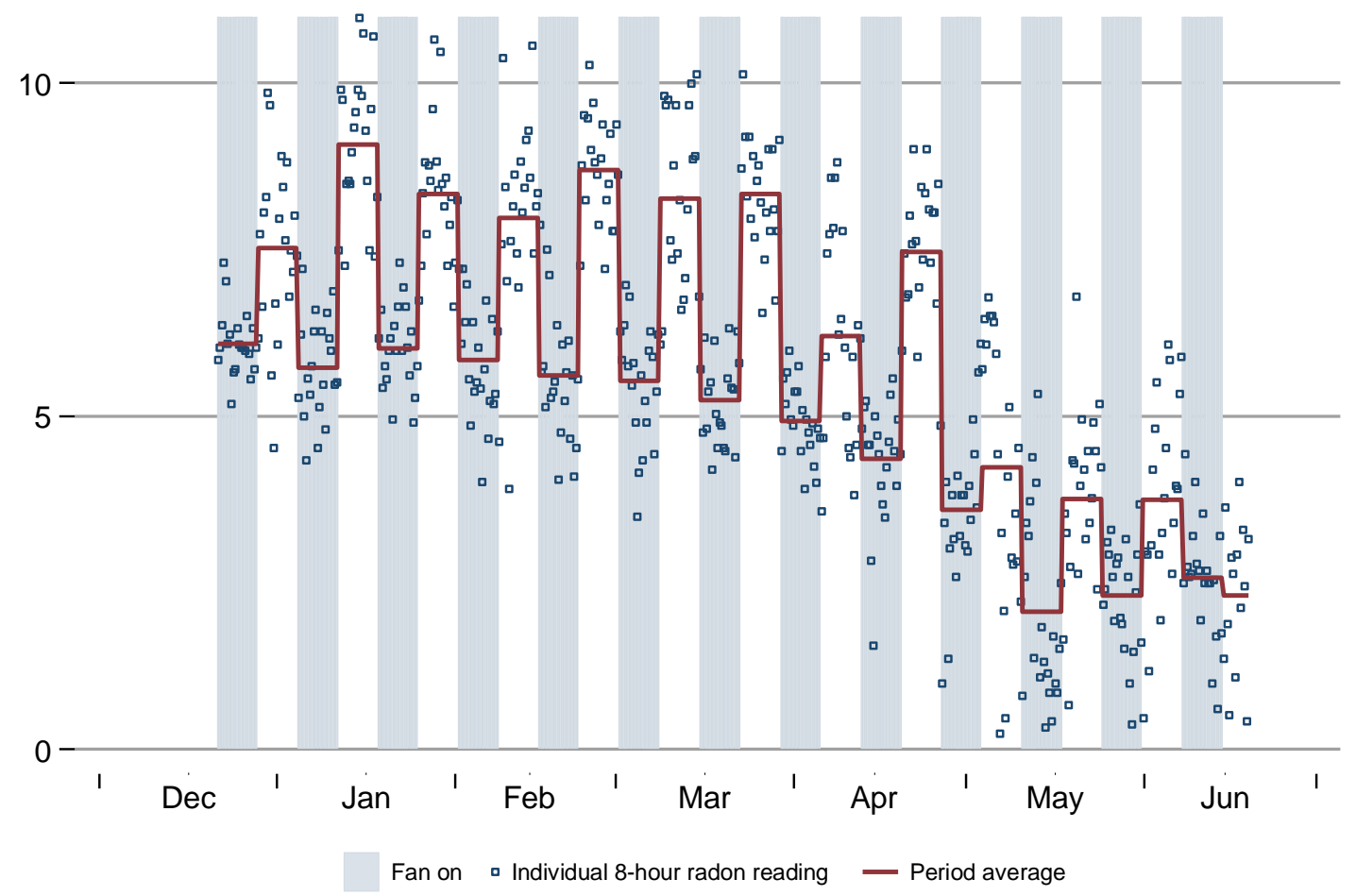

